\title{
AGR-1 IRRADIATION TEST FINAL AS-RUN REPORT
}

Blaise P. Collin

The INL is a

U.S. Department of Energy

National Laboratory

operated by

Battelle Energy Alliance

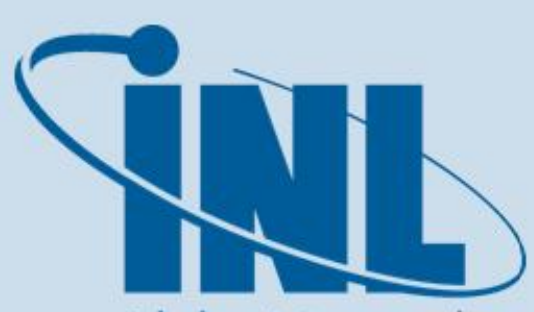

Idaho National Laboratory
January 2015

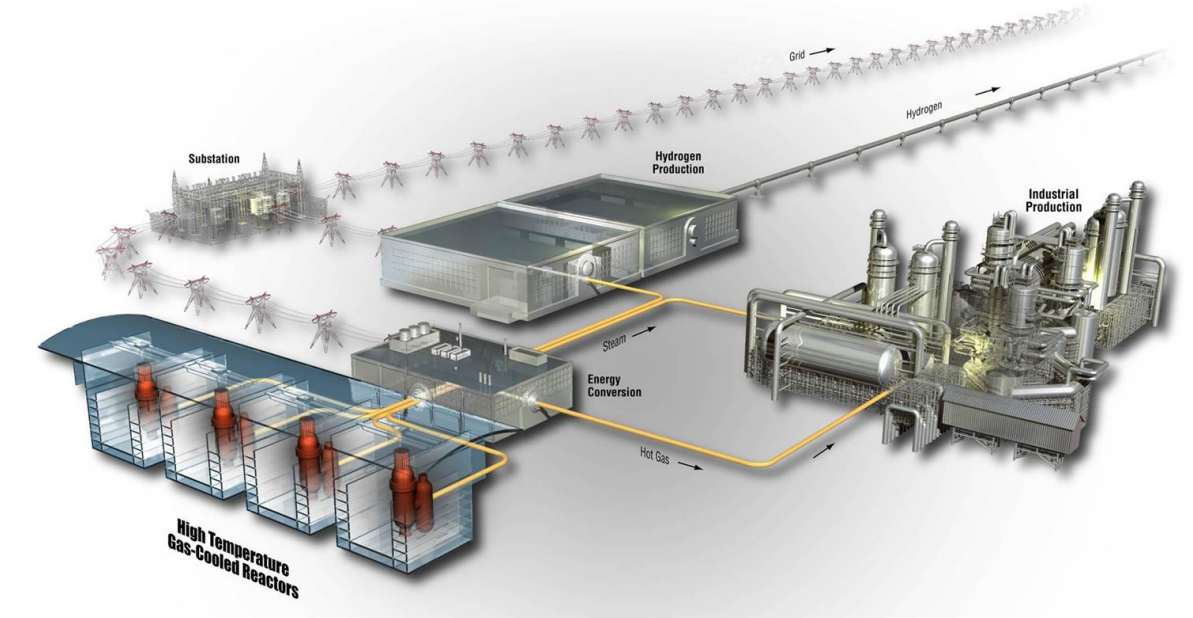




\section{DISCLAIMER}

This information was prepared as an account of work sponsored by an agency of the U.S. Government. Neither the U.S. Government nor any agency thereof, nor any of their employees, makes any warranty, expressed or implied, or assumes any legal liability or responsibility for the accuracy, completeness, or usefulness, of any information, apparatus, product, or process disclosed, or represents that its use would not infringe privately owned rights. References herein to any specific commercial product, process, or service by trade name, trade mark, manufacturer, or otherwise, does not necessarily constitute or imply its endorsement, recommendation, or favoring by the U.S. Government or any agency thereof. The views and opinions of authors expressed herein do not necessarily state or reflect those of the U.S. Government or any agency thereof. 


\title{
AGR-1 IRRADIATION TEST FINAL AS-RUN REPORT
}

\author{
Blaise P. Collin
}

January 2015

\begin{abstract}
Idaho National Laboratory
ART Program

Idaho Falls, Idaho 83415
\end{abstract}

http://www.inl.gov

Prepared for the

U.S. Department of Energy

Assistant Secretary for the Office of Nuclear Energy

Under DOE Idaho Operations Office

Contract DE-AC07-05ID14517 
INL ART Program

\title{
AGR-1 IRRADIATION TEST FINAL AS-RUN REPORT
}

\author{
INL/EXT-10-18097 \\ Revision 3 \\ January 2015
}

Prepared by:

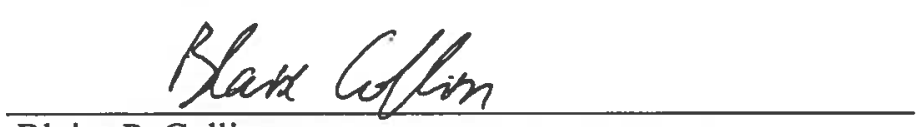

Blaise P. Collin

Approved by:

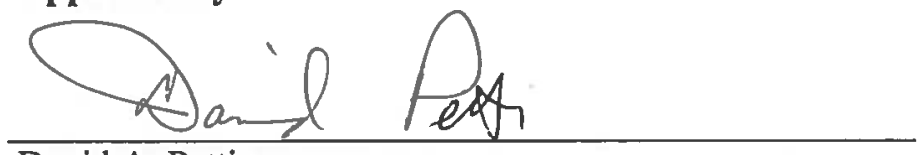

David A. Petti

ART Co-National Technical Director

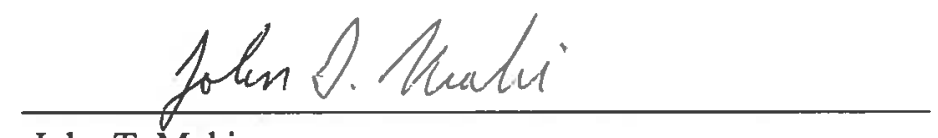

John T. Maki

Fuel Pefformance Lead

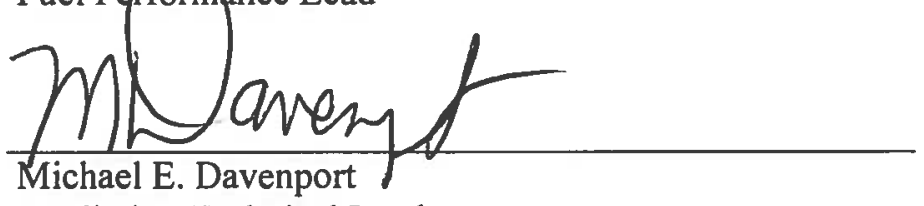

Irradiation Technical Lead

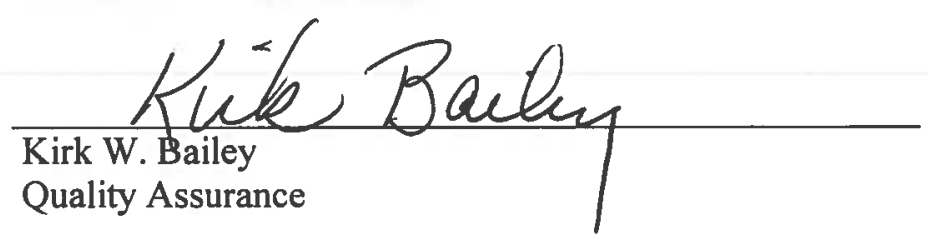

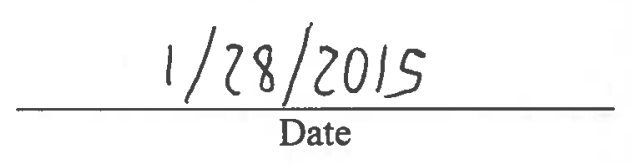

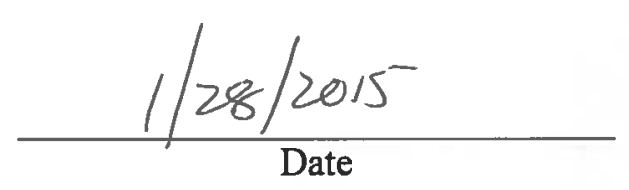

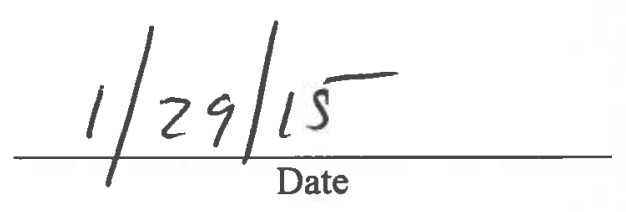

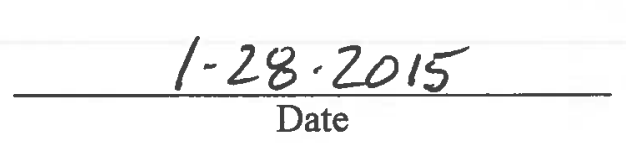




\section{REVISION LOG}

\begin{tabular}{|c|c|c|l|}
\hline Rev. & Date & Affected Pages & \multicolumn{1}{c|}{ Revision Description } \\
\hline 0 & $4 / 12 / 2010$ & All & $\begin{array}{l}\text { Initial issue of the AGR-1 Irradiation Test Final } \\
\text { As-Run Report }\end{array}$ \\
\hline 1 & $06 / 08 / 2012$ & All & $\begin{array}{l}\text { New results from Neutronics (Sterbentz 2011), } \\
\text { Thermal (Hawkes 2012), and R/B (Scates 2012) } \\
\text { calculations. } \\
\text { Temperature uncertainty quantification (Pham et al. } \\
\text { 2012) } \\
\text { Results on Palladium penetration. } \\
\text { Minor corrections. }\end{array}$ \\
\hline 2 & $8 / 27 / 2014$ & All & $\begin{array}{l}\text { New results from Neutronics (Sterbentz 2013) } \\
\text { Updated results in Tables 3.1 and 3.2. Made changes } \\
\text { to Summary, Section 2.3, Section 3.1, Section 6 and } \\
\text { Appendix D }\end{array}$ \\
\hline 3 & & & \\
\hline
\end{tabular}




\section{SUMMARY}

This document presents the as-run analysis of the AGR-1 irradiation experiment. AGR-1 is the first of eight planned irradiations for the Advanced Gas Reactor (AGR) Fuel Development and Qualification Program. Funding for this program is provided by the U.S. Department of Energy as part of the Next Generation Nuclear Plant Project. The objectives of the AGR-1 experiment are to:

a. Gain experience with multi-capsule test train design, fabrication, and operation with the intent to reduce the probability of capsule or test train failure in subsequent irradiation tests.

b. Irradiate fuel produced in conjunction with the AGR fuel process development effort.

c. Provide data that will support the development of an understanding of the relationship between fuel fabrication processes, fuel product properties, and irradiation performance.

To achieve the test objectives, the AGR-1 experiment was irradiated in the B-10 position of the Advanced Test Reactor (ATR) at Idaho National Laboratory for a total duration of 620 effective full power days of irradiation. Irradiation began on December 24, 2006, and ended on November 6, 2009, spanning 13 ATR cycles and approximately three calendar years. The test contained six independently controlled and monitored capsules. Each capsule contained 12 compacts of a single type, or variant, of the AGR coated fuel.

No fuel particles failed during the AGR-1 irradiation. Final burnup values on a per compact basis ranged from 11.3 to $19.6 \%$ fissions per initial heavy-metal atom, while fast fluence values ranged from 2.17 to $4.30 \times 10^{25} \mathrm{n} / \mathrm{m}^{2}$ $(\mathrm{E}>0.18 \mathrm{MeV})$. Time-averaged volume-averaged temperatures on a capsule basis at the end of irradiation ranged from $1002^{\circ} \mathrm{C}$ in Capsule 2 to $1087^{\circ} \mathrm{C}$ in Capsule 6. Thermocouples performed well, failing at a lower rate than expected. At the end of the irradiation, nine of the originally planned 19 thermocouples were considered functional. Fission product release-to-birth $(\mathrm{R} / \mathrm{B})$ ratios were quite low. In most capsules, $\mathrm{R} / \mathrm{B}$ values at the end of the irradiation were well below $10^{-7}$ with the exception of two capsules, one of which reached $10^{-7}$ and another reached $2 \times 10^{-7}$ near the end of the irradiation.

Several shakedown issues were encountered and resolved during the first three cycles, including the repair of minor gas line leaks and faulty gas line valves, the need to position moisture monitors in regions of low radiation fields for proper functioning, the enforcement of proper online data storage and backup, the need to monitor thermocouple performance, correcting for detector spectral gain shift, and changing the mass flow rate range of the neon flow controllers. 


\section{CONTENTS}

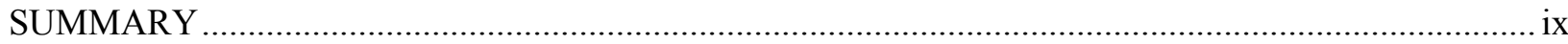

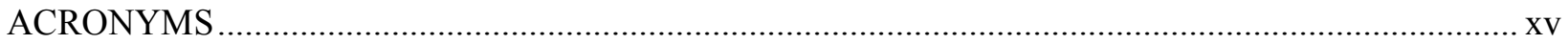

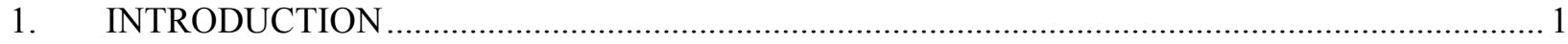

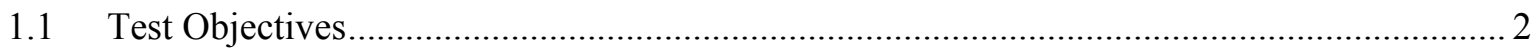

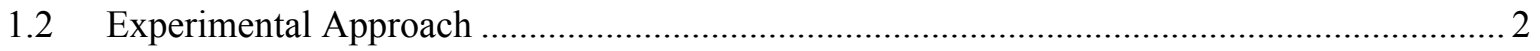

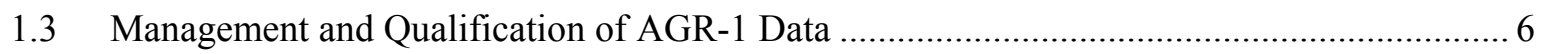

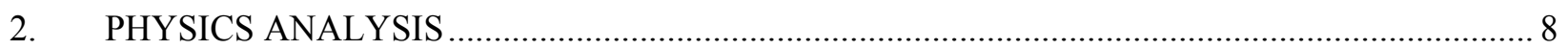

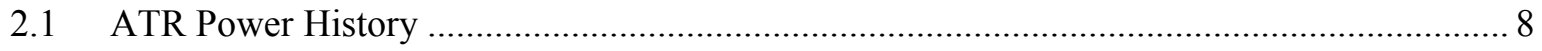

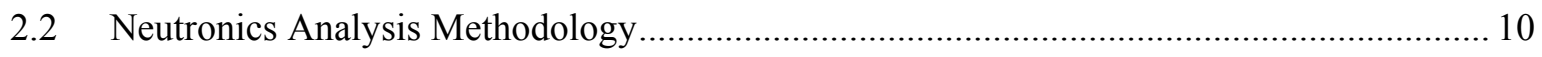

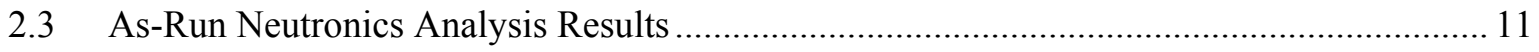

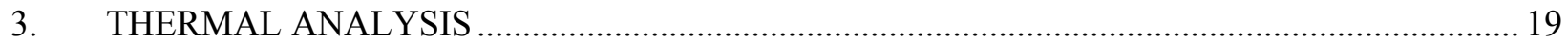

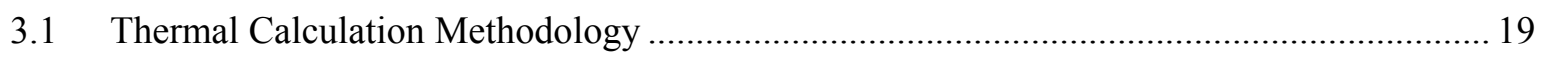

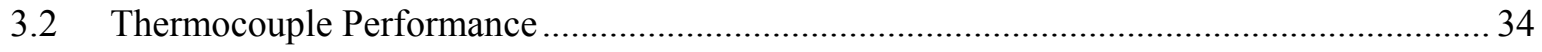

3.3 Uncertainty Quantification of Calculated Temperatures ................................................. 40

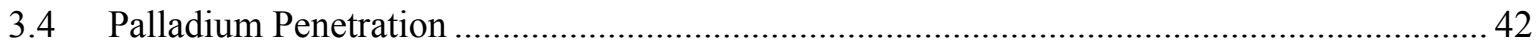

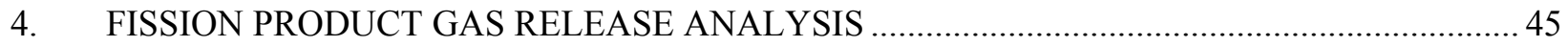

4.1 Birth Rate Calculations Methodology ................................................................................ 45

4.2 Release Rate Calculations Methodology .................................................................... 45

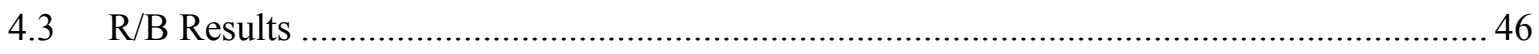

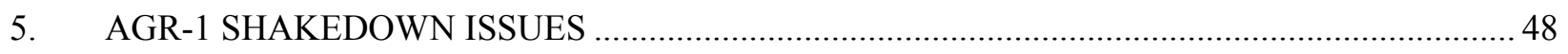

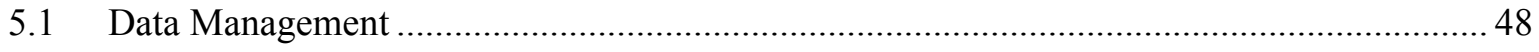

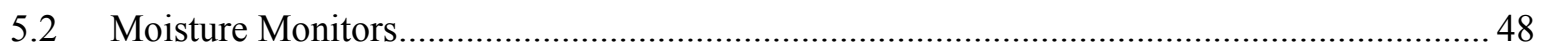

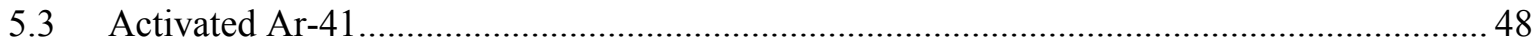

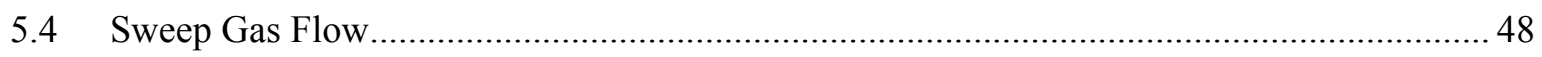

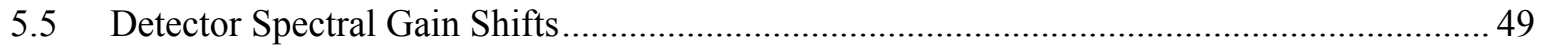

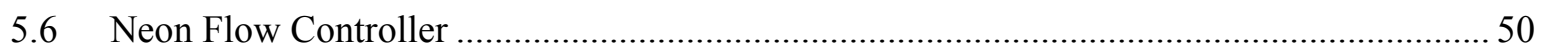

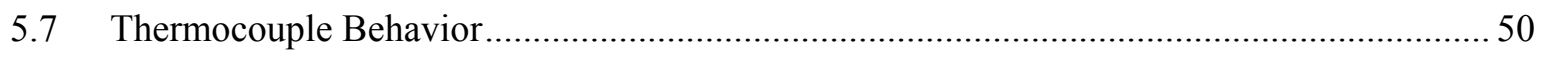

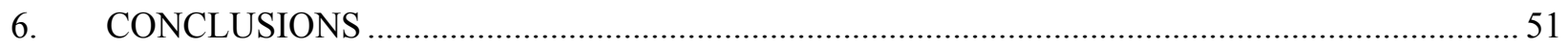

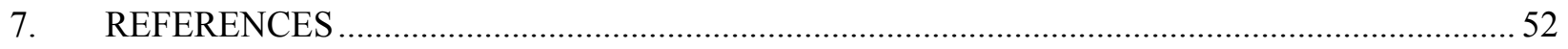

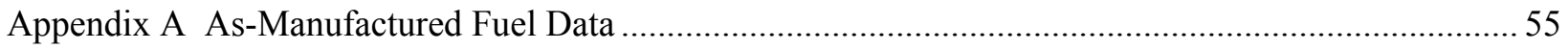

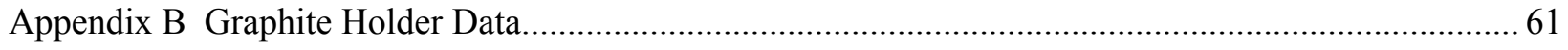

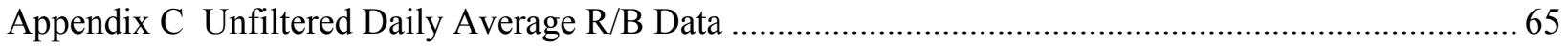


Appendix D Compact Burnup and Fast Fluence by Cycle

Appendix E Palladium Penetration.

\section{FIGURES}

Figure 1. ATR core cross section displaying the B-10 position. ......................................................... 2

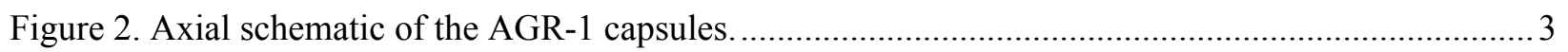

Figure 3. Schematic of a radial cut of an AGR-1 capsule....................................................................... 4

Figure 4. Three-dimensional cutaway rendering of single AGR-1 capsule ............................................... 4

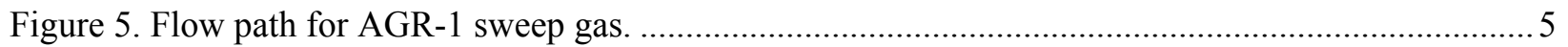

Figure 6. Capsule average power density versus irradiation time in EFPD............................................... 12

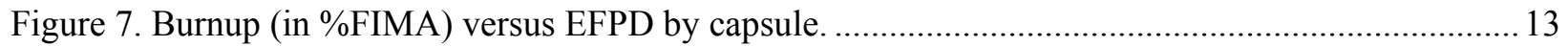

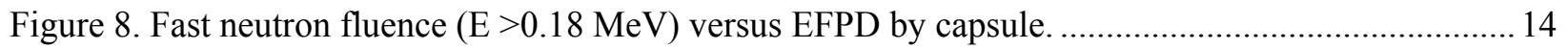

Figure 9. Fast neutron fluence $(\mathrm{E}>0.18 \mathrm{MeV})$ vs. Burnup (\%FIMA) for AGR-1 compacts.................... 15

Figure 10. Fast neutron fluence $(\mathrm{E}>0.18 \mathrm{MeV})$ vs. Burnup (\%FIMA) for AGR-1 capsules.................... 15

Figure 11. Rendering of ABAQUS finite element mesh of a single AGR-1 capsule.............................. 19

Figure 12. Thermal conductivity of unirradiated, boronated graphite holders (Thompson 2006).............20

Figure 13. Sweep gas thermal conductivity versus temperature and mole fraction helium.......................21

Figure 14. Sample temperature profile in Capsule 4 from Cycle 141A..................................................22

Figure 15. Calculated daily minimum, maximum, and volume average temperatures for Capsules 4-6.

Figure 16. Calculated daily minimum, maximum, and volume average temperatures for Capsules $1-3$.

Figure 17. Calculated time-average minimum, time-average maximum, and time-average volume-average temperatures for Capsules 4-6. .25

Figure 18. Calculated time-average minimum, time-average maximum, and time-average

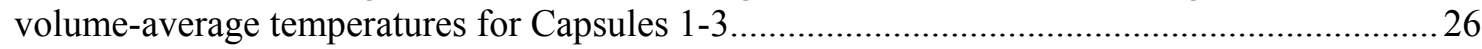

Figure 19. Time-average fuel temperature distribution for AGR-1 and GA SC-MHR ........................... 30

Figure 20. Time-average fuel temperature distribution for AGR-1 and GA SC-MHR (close-up).............31

Figure 21. 3-D scatter plot of the irradiation characteristics of the 72 AGR-1 compacts......................... 32

Figure 22. Time-average volume-average temperature $\left({ }^{\circ} \mathrm{C}\right)$ vs. Burnup (\%FIMA) for AGR-1 compacts. .33

Figure 23. Time-average volume-average temperature $\left({ }^{\circ} \mathrm{C}\right)$ vs. Fast neutron fluence $(\mathrm{E}>0.18$

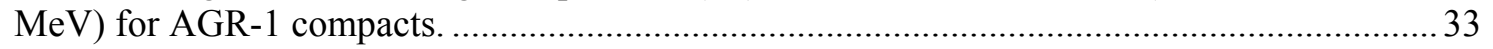

Figure 24. Cutaway view of each capsule showing type and position of TCs......................................... 35

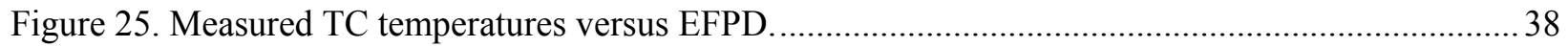

Figure 26. Difference between measured and calculated TC temperatures versus EFPD........................39 
Figure 27. Instantaneous peak and average fuel temperature and associated uncertainty for

Capsule 4. 41

Figure 28. Time-average peak and time-average volume-average temperatures for Capsule 4 ............... 42

Figure 29. R/B ratios for $\mathrm{Kr}-85 \mathrm{~m}, \mathrm{Kr}-88$, and $\mathrm{Xe}-135$ versus time in EFPD. ..........................................46

\section{TABLES}

Table 1. AGR-1 capsule contents. 6

Table 2. ATR power history during AGR-1 irradiation................................................................... 8

Table 3. Burnup and fast neutron fluence by compact and capsule averages for Capsules 6-4................. 16

Table 4. Burnup and fast neutron fluence by compact and capsule averages for Capsules 3-1................ 17

Table 5. Minimum, average, and peak compact burnup and fast fluence at the end of irradiation. ............ 18

Table 6. Compact temperature data for Capsules 6-4 at end of irradiation. ............................................22

Table 7. Compact temperature data for Capsules 3-1 at end of irradiation. .............................................29

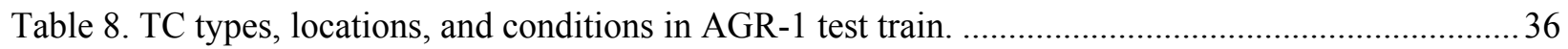

Table 9. Uncertainty information of the most significant parameters of the AGR-1 thermal model. ........ 40

Table 10. Temperatures and uncertainty for time-average fuel temperatures at the end of AGR-1 ..........41

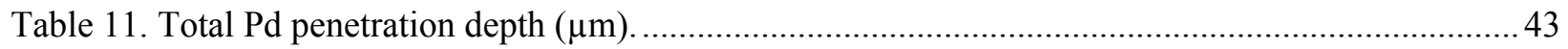

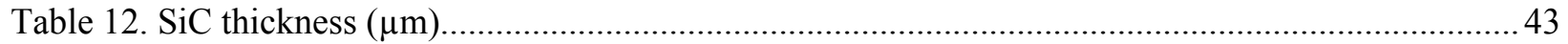

Table 13. Temperature sensitivity of the total Pd penetration depth $(\mu \mathrm{m})$. and relative increase over base calculation (\%). 


\section{ACRONYMS}

AG against grain

AGR Advanced Gas Reactor

ATR Advanced Test Reactor

DNE DIDO Nickel Equivalent

EFPD effective full-power days

FIMA fissions per initial heavy-metal atom

FPMS Fission Product Monitoring System

GA General Atomics

HPGe High-Purity Germanium

INL Idaho National Laboratory

IPyC inner pyrolytic carbon

LEU low-enriched uranium

MCNP Monte Carlo N-Particle transport code

NDMAS NGNP Data Management and Analysis System

NGNP next generation nuclear plant

OPyC outer pyrolytic carbon

PIE post-irradiation examination

$\mathrm{R} / \mathrm{B} \quad$ release rate to birth rate ratio

SC-MHR steam cycle - modular helium reactor

TAVA time-average volume-average

TC ThermoCouple

TRISO tristructural isotropic

UCO uranium oxycarbide

VHTR very high temperature gas-cooled reactor

WG with grain 


\section{AGR-1 IRRADIATION TEST FINAL AS-RUN REPORT}

\section{INTRODUCTION}

Several fuel and material irradiation experiments are planned for the Advanced Gas Reactor (AGR) Fuel Development and Qualification Program, which supports development of the very high temperature gas-cooled reactor (VHTR) under the VHTR Program. The goals of these experiments are to provide irradiation performance data to support fuel process development, qualify fuel for normal operating conditions, support development and validation of fuel performance and fission product transport models and codes, and provide irradiated fuel and materials for post-irradiation examination (PIE) and safety testing (Simonds 2010). AGR-1 is the first in this series of planned experiments to test tristructural isotropic (TRISO)-coated fuel particles containing, low-enriched uranium (LEU) fuel in a uranium oxycarbide (UCO) form.

The primary objective of the AGR-1 test was to shakedown of test train. If substantial failures had occurred during irradiation, such as leakage or malfunctions with temperature control, gas monitoring, or instrumentation, the test train could have been removed from the reactor before the planned completion of irradiation. Test components would have then been examined to determine what modifications would be required for subsequent test trains.

In conjunction with the fuel process development effort, AGR-1 irradiated early fuel, which was produced in a laboratory scale small coater. Subsequent tests in the AGR program will irradiate fuel produced in an industrial scale coater. Also, as the VHTR design matures, the fuel design may change. A most likely design change will be an increase in fuel kernel diameter.

The AGR-1 fuel test was successful in irradiating the fuel compacts to a substantial burnup (peak burnup of $19.6 \%$ fissions per initial heavy-metal atom [FIMA]) and fast neutron fluence (peak fast fluence ${ }^{\mathrm{a}}$ of $4.30 \times 10^{25} \mathrm{n} / \mathrm{m}^{2}$ ) with no particle failures. The results of this test will provide irradiation performance data for baseline fuel and for variants of this fuel fabricated with predetermined, yet slight changes in selected fabrication processes. Once the PIE is completed, this test will provide the first in a series of data that will improve the understanding between fabrication processes, fuel product properties, and irradiation performance.

This document presents the AGR-1 data collected and the analysis results of the as-run fuel irradiation conditions. This includes a summary of the experimental approach, as-run reactor physics and thermal analysis, uncertainty quantification of calculated temperatures, palladium penetration calculations, fission product release-to-birthrate ratio (R/B) calculations and measurements, shakedown issues encountered, and a summary of SAS data qualification work. The present document is Revision 1 of the initial AGR-1 irradiation experiment as-run report. It is based on updated neutronics, thermal, and $\mathrm{R} / \mathrm{B}$ calculations, and it includes uncertainty quantification of calculated temperatures and calculation of palladium penetration in the silicon carbide layer of TRISO particles. The updated neutronics calculations (Sterbentz 2013) were motivated by the need to increase the number of fission products tracked in the Monte Carlo N-Particle (MCNP) input model in order to support PIE tests. It also provided the opportunity to make corrections and modifications in the input model: corrected boron-10 weight in the bottom axial segment of Capsule 6, re-calculated ATR lobe power split, and addition of decay time between power cycles. The heat rates produced by the updated neutronics calculations were used to compute updated R/B ratios (Scates 2012) as well as updated thermal calculations (Hawkes 2012). The updated thermal calculations also include modeling improvements: linearly time-dependent control gas gaps and compact-graphite holder gas gaps, and the use of individual component heat rates for graphite.

a. Fast neutron fluence is defined as $\mathrm{E}>0.18 \mathrm{MeV}$. 
When this report was released, the AGR-1 test train had been unloaded from the reactor and some post-irradiation observations had been made, but the full PIE had not occurred, so it will be documented in a later report.

\section{$1.1 \quad$ Test Objectives}

As defined in the AGR Technical Program Plan for the Next Generation Nuclear Plant/Advanced Gas Reactor Fuel Development and Qualification Plan (Simonds 2010), the objectives of the AGR-1 experiment are to:

1. Gain experience with multi-capsule test train design, fabrication, and operation with the intent of reducing the probability of capsule or test train failure in subsequent irradiation tests.

2. Provide data on irradiated fuel performance to support specification of the fuel to be qualified in later irradiation test trains, early Next Generation Nuclear Plant (NGNP) licensing interactions, and produced in conjunction with the AGR fuel process development effort.

3. Provide data that will support the development of an understanding of the relationship between fuel fabrication processes, fuel product properties, and irradiation performance.

\subsection{Experimental Approach}

To achieve the test objectives outlined above, in accordance with requirements from the Technical Program Plan (Simonds 2010) and the Irradiation Test Specification (Maki 2004), AGR-1 was irradiated in the B-10 position of the Advanced Test Reactor (ATR) at Idaho National Laboratory (INL). A cross-sectional view of the ATR core indicating this location is displayed in Figure 1. A priori physics calculations (Chang 2002, Chang and Lilo 2007) showed that anticipated VHTR end-of-irradiation conditions (burnup to about 20\% FIMA and maximum fast neutron fluence of $5 \times 10^{25} \mathrm{n} / \mathrm{m}^{2}$, $\mathrm{E}>0.18 \mathrm{MeV}$ ) were best matched by the conditions obtained from irradiation in these Large $\mathrm{B}$ positions.

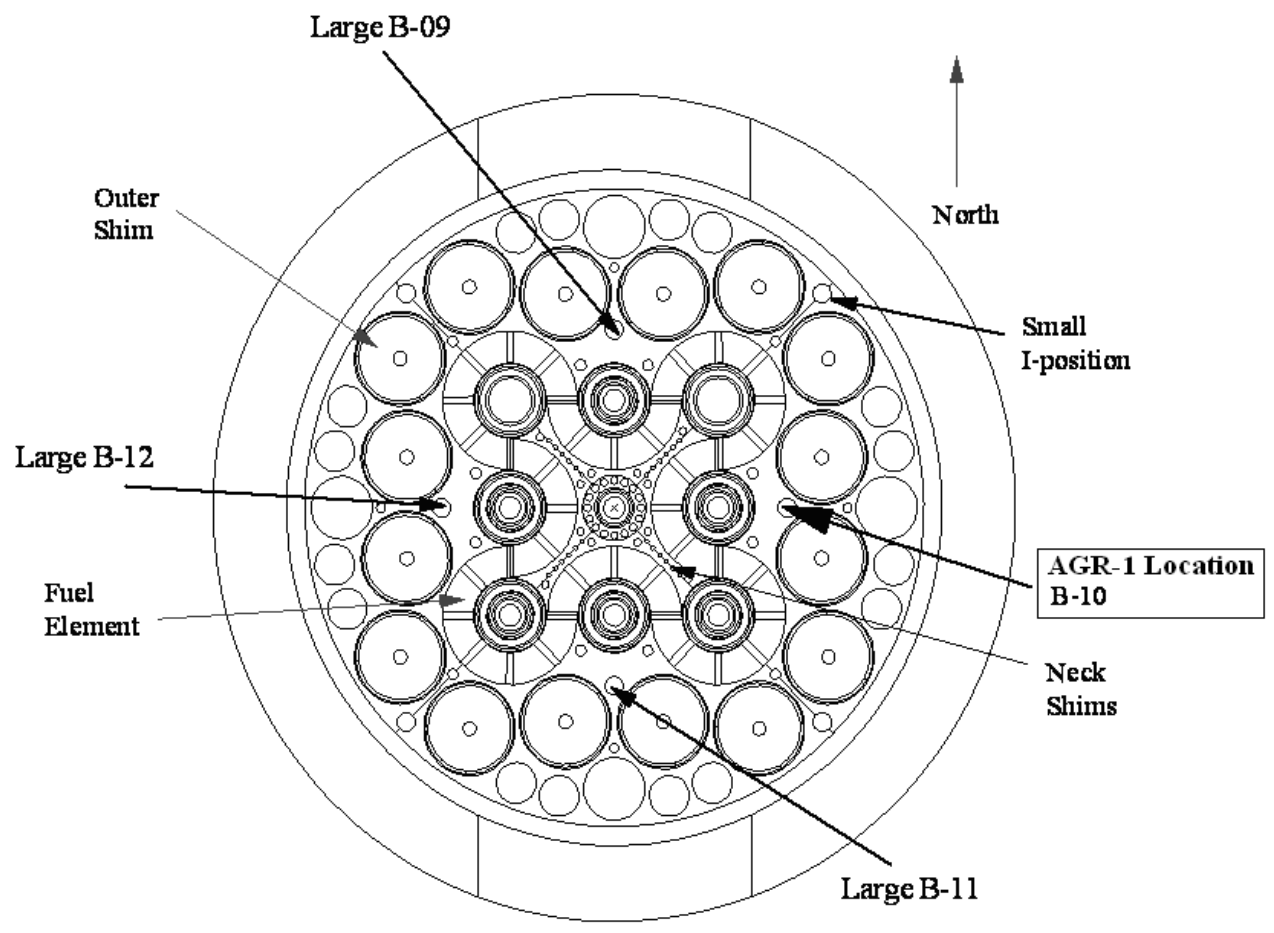

Figure 1. ATR core cross section displaying the B-10 position. 
The AGR-1 test train is a multi-capsule, instrumented lead experiment, designed for irradiation in the $38.1 \mathrm{~mm}$ (1.5 in.) diameter B-10 position of the ATR. The test train contains six capsules, each independently controlled for temperature and independently monitored for fission product gas release. An axial view of the test train is illustrated in Figure 2. Each AGR-1 capsule is $152.4 \mathrm{~mm}$ (6 in.) long and contains 12 fuel compacts arranged in three vertical stacks with each stack containing four compacts. Figure 3 shows a radial cutaway view of a capsule illustrating the arrangement of the three compact stacks and showing the hafnium shroud used to suppress flux on the West side of the capsule.

Independent gas lines route a mixture of helium and neon gases through each of the six capsules to provide temperature control and to sweep released fission product gases to the fission product monitoring system (FPMS). Temperature control is based upon temperature feedback from the thermocouples (TCs) in each capsule and is performed by varying the sweep gas composition (between 100\% helium for high conductivity and $100 \%$ neon for low conductivity). This blending of sweep gases is accomplished by a computerized mass flow controller before the gas enters the test train. The arrangement of the gas lines can be seen in the three-dimensional (3-D) rendering of a test capsule shown in Figure 4. Figure 5 shows a schematic diagram of the FPMS.

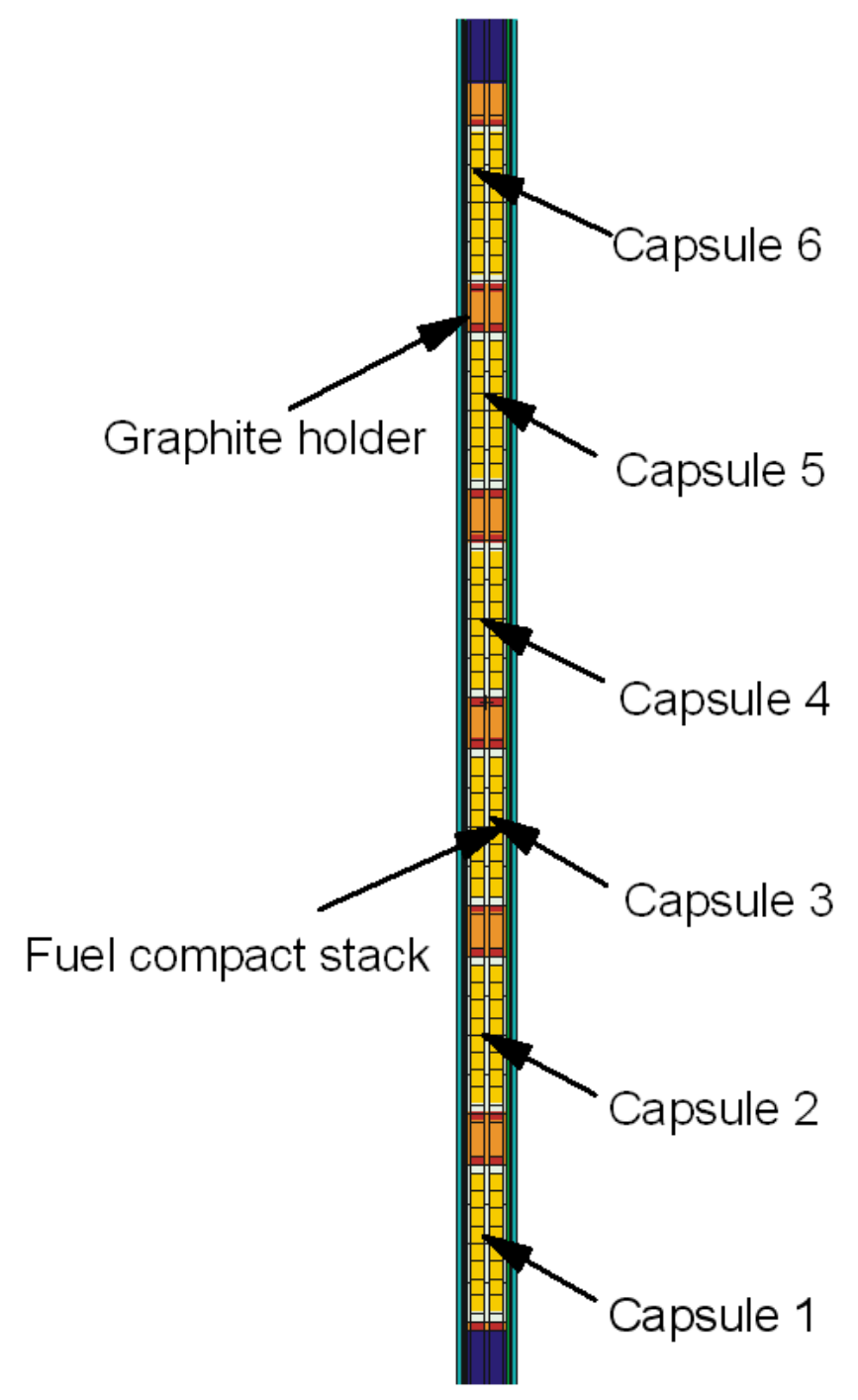

Figure 2. Axial schematic of the AGR-1 capsules. 


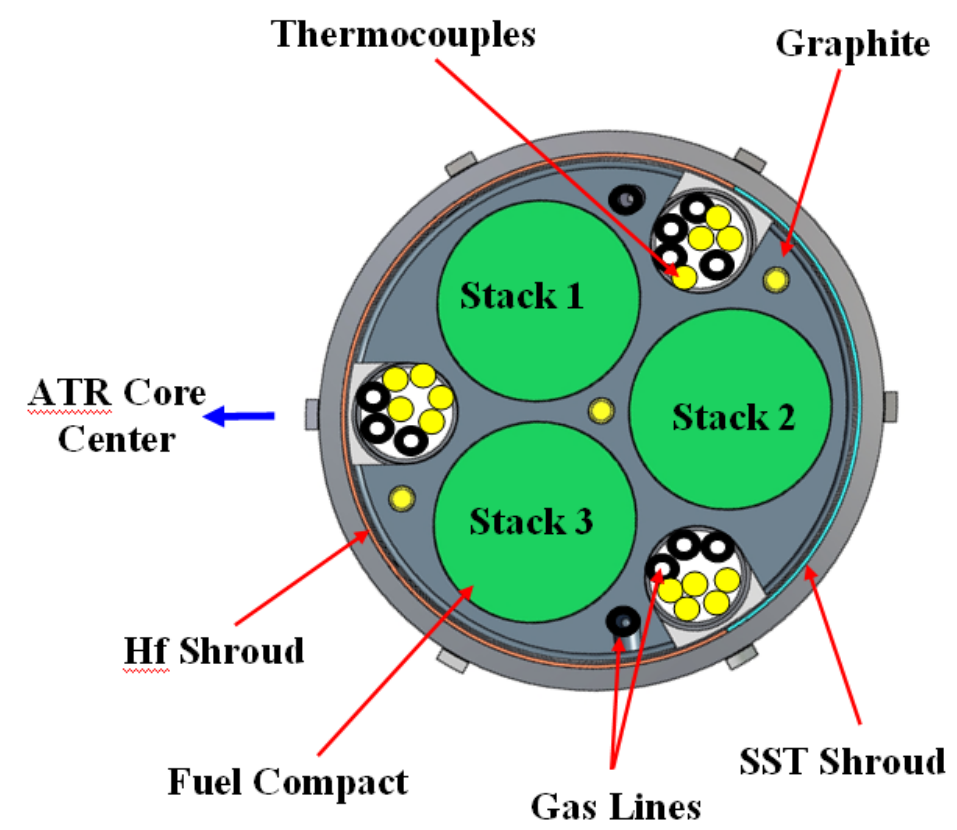

Figure 3. Schematic of a radial cut of an AGR-1 capsule.

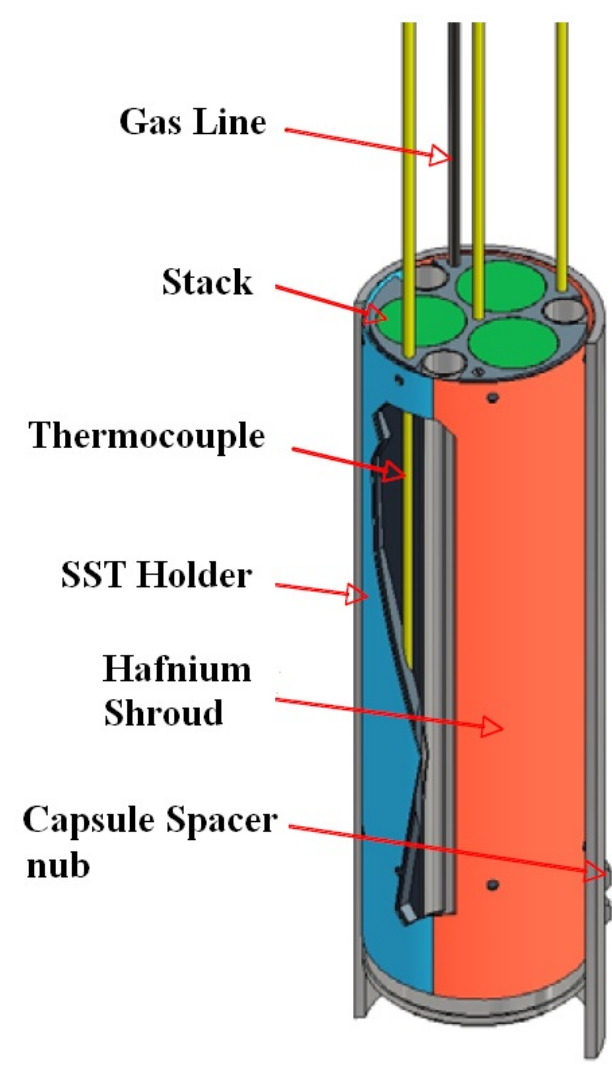

Figure 4. Three-dimensional cutaway rendering of single AGR-1 capsule.
A detailed description of the FPMS can be found in Hartwell et al. (2005). This system continuously measures the sweep gas from each AGR-1 capsule to provide an indicator of fuel irradiation performance. Spectrometer detector systems measure the concentrations of various krypton and xenon isotopes in the sweep gas from each capsule. Eight-hour counting intervals were used to measure the concentrations of $\mathrm{Kr}-85 \mathrm{~m}, \mathrm{Kr}-87, \mathrm{Kr}-88, \mathrm{Kr}-89$, $\mathrm{Kr}-90$, Xe-131m, Xe-133, Xe-135, Xe-135m, Xe-137, Xe-138, and Xe-139.

The FPMS incorporates seven individual monitoring systems: one for each of the individual capsule effluent lines, and one unit that can monitor any individual effluent line or any combination of the six lines. The seventh monitor is primarily provided as a backup unit capable of providing effluent line monitoring should any of the primary monitoring systems fail. Each monitor consists of a high purity germanium (HPGe), detector-based, gamma-ray spectrometer and a sodium iodide $[\mathrm{NaI}(\mathrm{Tl})]$ scintillation detector-based total radiation detector (often termed the "Gross" radiation detector). The gross detectors are able to detect the failure of individual TRISO particles, while the gamma-ray spectroscopy is used for isotopic quantification of the noble gas release. These detector units are located in the ATR 2C Secondary cubicle. 


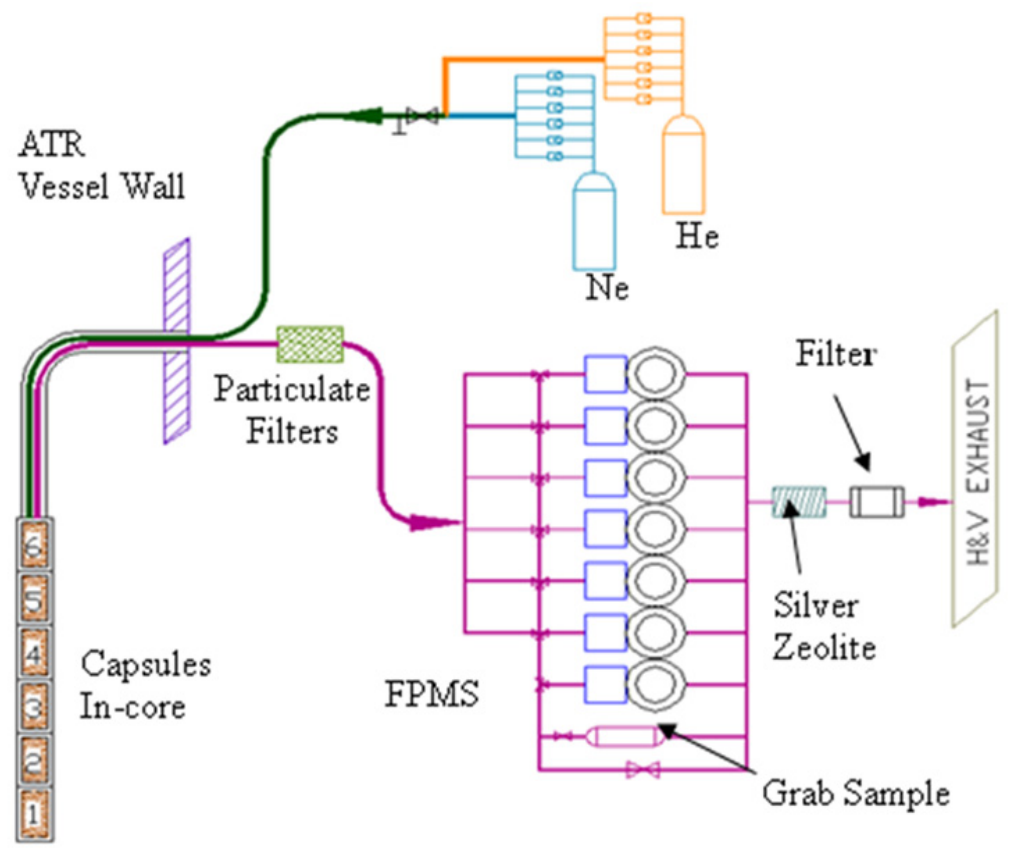

Figure 5. Flow path for AGR-1 sweep gas.

The sweep gas from each test capsule is routed via sampling lines to the monitoring station associated with that capsule. The sample lines, valves, and filters are predominately contained in the 2C Primary cubicle. The sample lines have only two short, shielded segments in the $2 \mathrm{C}$ secondary cubicle. These short segments run through the gross detector monitoring station and into the HPGe spectrometer shield.

Each gross detector monitoring station (seven stations implemented) incorporates a Ø25 $\times 25 \mathrm{~mm}$ thallium-activated $\mathrm{NaI}(\mathrm{Tl})$ scintillation detector viewing a $25 \mathrm{~mm}$ long segment of the capsule effluent line just before its entry into the HPGe spectrometer shield. The scintillation detector counting rate is monitored using a computer-controlled multi-channel scaler.

Fuel for AGR-1 consisted of TRISO particles - coated particles slightly less than $1 \mathrm{~mm}$ in diameter. Each particle has a central kernel containing LEU UCO fuel, which is nominally $350 \mu \mathrm{m}$ in diameter and is coated with a porous carbon buffer, inner pyrolytic carbon (IPyC), $\mathrm{SiC}$ (silicon carbide), and an outer pyrolytic carbon (OPyC) layer. The UCO kernels were fabricated by Babcock and Wilcox (B\&W) in accordance with the AGR-1 Fuel Product Specification (Barnes 2006). The UCO kernels were coated by Oak Ridge National Laboratory (ORNL), which also provided characterization data (Hunn and Lowden 2006a through 2006d). This fuel is based on the gas-turbine modular helium reactor fissile particle design and was fabricated, to the extent possible, according to German process practices. This fuel form was used as a starting point in defining a baseline fuel, which was considered to possess the best attributes for successful irradiation in AGR-1. Three variant fuels were also irradiated in AGR-1. These variants were fabricated according to predetermined variations in the baseline process and, may provide new information concerning the linkage between fabrication processes, product properties, and irradiation performance. Briefly, these fuels are described as follows:

- Baseline. Because of its excellent irradiation performance, coating process conditions used to fabricate historic German fuel were chosen as the starting point for the baseline fuel. Parametric studies refined these conditions for the specific coater used to coat AGR-1 fuel. This fuel was expected to perform successfully during irradiation. 
- Variant 1. The IPyC coating temperature was increased relative to the baseline process for this variant. This change is expected to enhance the irradiation dimensional stability of the pyrocarbon but with increased uranium dispersion. Also, the IPyC layer density was slightly lower than the baseline density.

- Variant 2. The IPyC coating gas fraction was increased relative to the baseline process for this variant. This change is also expected to enhance the irradiation dimensional stability of the pyrocarbon without significantly increasing uranium dispersion. Also, the IPyC layer density was slightly higher than the baseline density.

- Variant 3. The carrier gas composition for the $\mathrm{SiC}$ layer deposition was changed from hydrogen to an argon-hydrogen mixture, and deposition temperature was lowered. This change is expected to reduce $\mathrm{SiC}$ defects resulting from uranium dispersion.

After coating, AGR-1 fuel was formed into right cylindrical compacts at ORNL. The compact matrix material is composed of a thermosetting carbonaceous material. Prior to compacting, the fuel particles were overcoated with approximately $165 \mu \mathrm{m}$ thick layers of the compact matrix material. This overcoat was intended to prevent particle-to-particle contact and to help achieve the desired packing fraction of fuel particles. AGR-1 compacts were nominally $25 \mathrm{~mm}$ in length and $12.3 \mathrm{~mm}$ in diameter with fuel free end caps of matrix material approximately $1.5 \mathrm{~mm}$ thick. These end caps ensure smooth, protected surfaces that help to prevent fuel particle damage during handling. The same compacting process was used for the baseline fuel and each fuel variant.

Each AGR-1 capsule contained only one fuel type or variant. Baseline fuel was irradiated in Capsules 6 and 3, Variant 1 in Capsule 5, Variant 2 in Capsule 2, and Variant 3 in Capsules 1 and 4. These assignments are listed in Table 1 where the capsules are numbered consecutively from the top, Capsule 6, to the bottom, Capsule 1. Appendix A gives as-manufactured data for the fuel compacts. Characterization data for the fuel particles and compacts is detailed in the AGR-1 Test Plan (Maki 2009).

Table 1. AGR-1 capsule contents.

\begin{tabular}{|c|c|c|}
\hline Location & Coated Particle Composite & Fuel Designation \\
\hline Capsule 6 & LEU01-46T & Baseline \\
\hline Capsule 5 & LEU01-47T & Variant 1 \\
\hline Capsule 4 & LEU01-49T & Variant 3 \\
\hline Capsule 3 & LEU01-46T & Baseline \\
\hline Capsule 2 & LEU01-48T & Variant 2 \\
\hline Capsule 1 & LEU01-49T & Variant 3 \\
\hline
\end{tabular}

\subsection{Management and Qualification of AGR-1 Data}

The AGR-1 test spanned 13 cycles of ATR operation and generated five major streams of data. At the outset, detailed data provided a description of the fuel fabrication process and the contents of each compact. Data streams resulting from neutronic and thermal modeling of the experiment as run in the ATR were created both during the experiment and more recently during the post-experiment evaluation. Particularly, the most accurate post-experiment calculations, summarized in the remainder of this document, are important for future reference. Finally, during the entire course of the irradiation, the following three trains of data were generated on an ongoing basis:

- Fuel irradiation data, which include TC readings, sweep gas compositions, flow rates and pressures, and moisture monitor readings 
- FPMS data, which include both isotopic release data and gross gamma counts

- ATR operating conditions data, which include lobe powers, control cylinder positions, neck shim positions, and control rod positions.

AGR-1 data also include calculated quantities during the experiment such as fission isotope birth rates and effective full-power days (EFPDs) at the start of each ATR cycle.

The preservation and management of these data is a critical contribution to the experiment's ability to meet its objectives. The VHTR program established the NGNP Data Management and Analysis System (NDMAS) to ensure that VHTR data are qualified for use, stored in a readily accessible electronic form, and analyzed to extract useful results. The system is described in the Very High Temperature Gas Reactor Program Data Management and Analysis Plan (INL 2009a).

The NDMAS provides a single controlled repository for all of the AGR-1 data and makes the data available to users on an easily accessible website. During the experiment, the website showed the progress of the irradiation within a short period after the data were generated. The gross gamma data were displayed almost daily, and other irradiation, FPMS, and ATR operational data were displayed within a week or so of real time.

In addition to displays of the data as it accrues in time, summaries of the data are provided by the NDMAS. Many of the plots in this document are examples of the displays that this system provides.

Another important function of the NDMAS is that it facilitates data qualification and stores the associated documentation. Specific data qualification activities within NDMAS depend on the data qualification category for each data entity as assigned by the data generator. Activities include:

(1) capture testing to confirm that the data stored within NDMAS are identical to the raw data supplied, (2) accuracy testing to confirm that the data are an accurate representation of the system or object being measured, and (3) documentation that the data were collected under a Nuclear Quality Assurance NQA-1 or equivalent quality assurance program. Within the VHTR program, the NQA-1 requirements are implemented through the Very-High-Temperature Gas-Cooled Reactor Technology Development Office Quality Assurance Program Plan (INL 2009b).

The status of these data streams is summarized below (Abbott et al. 2010):

1. Fuel fabrication data - All data have been processed into the NDMAS database and qualified (1,819 records).

2. Fuel irradiation data - Data from all 13 AGR-1 reactor cycles have been processed into the NDMAS database and tested. Of these, $85 \%$ have been qualified and $15 \%$ have failed NDMAS accuracy testing.

3. FPMS data - Reprocessed (January 2010) data from all 13 AGR-1 reactor cycles have been processed into the database and capture tested. Qualification of these data (Scates 2012) has been recorded in NDMAS.

4. ATR Operating Conditions Data - Data for all AGR-1 cycles have been stored and capture tested. These data, which come from outside the VHTR program, are assumed to be qualified by ATR quality control procedures.

5. Neutronics and Thermal Modeling Data - All data have been stored in NDMAS and capture passed. Qualification of these data (Sterbentz 2013, Hawkes 2012) has been recorded in NDMAS. 


\section{PHYSICS ANALYSIS}

This section summarizes the physics analyses used to characterize the neutron flux environment and burnup of the fuel compacts. It gives the operational history of ATR during the AGR-1 irradiation, followed by a description of the methodology used to analyze the test train. Key parameters, such as burnup and fast fluence of the fuel compacts, are included.

\subsection{ATR Power History}

The AGR-1 test train was irradiated in the B-10 location of the ATR for 13 cycles, from December 2006 until November 2009.

Table 2 shows the irradiation history, including start and stop times and dates for each cycle, unplanned outages, and other relevant operational details such as the $100 \%$ helium flow in Cycles 1 and 2. Times of reactor events are given to the nearest hour and the cumulative burnup in EFPD is based on ATR core-wide fuel burnup and not AGR-1 fuel burnup. The burnup achieved with the AGR-1 test train in the B-10 location was 620.2 EFPD.

During the first irradiation cycle, the moisture monitors connected to the gas lines were producing excessively high readings (which were shown later to be caused by small gas line leaks and that the readings indicated moisture trends and not exact values). Consequently, all capsules were swept with $100 \%$ helium, resulting in the low fuel temperatures for the first cycle. The capsules for the second and third cycles were swept mostly with neon as the control gas (plus a small amount of helium into the leadout cavity to prevent cross capsule flow), resulting in the higher fuel temperatures.

Table 2. ATR power history during AGR-1 irradiation.

\begin{tabular}{|c|c|c|c|c|c|c|}
\hline $\begin{array}{c}\text { AGR-1 } \\
\text { Cycle }\end{array}$ & $\begin{array}{l}\text { ATR } \\
\text { Cycle }\end{array}$ & $\begin{array}{l}\text { Cycle } \\
\text { EFPD }\end{array}$ & $\begin{array}{c}\text { Cumulative } \\
\text { EFPD }\end{array}$ & $\begin{array}{c}\text { Date } \\
\text { M-D-Y }\end{array}$ & Time $^{(a)}$ & Reactor Event \\
\hline \multirow[t]{3}{*}{1} & \multirow[t]{3}{*}{$138 \mathrm{~B}$} & \multirow[t]{3}{*}{46.6} & 0.0 & $12-24-06$ & 1600 & Reactor start-up $(100 \% \mathrm{He})$ \\
\hline & & & 0.4 & $12-26-06$ & 0500 & Full power reached \\
\hline & & & 46.6 & $02-10-07$ & 1000 & Reactor down \\
\hline \multirow[t]{8}{*}{2} & \multirow[t]{8}{*}{$139 \mathrm{~A}$} & \multirow[t]{8}{*}{51.6} & 46.6 & $02-25-07$ & 1700 & Reactor start-up \\
\hline & & & 46.8 & 02-26-07 & 0300 & Full power reached \\
\hline & & & 54.3 & 03-05-07 & 1800 & End $100 \%$ helium flow \\
\hline & & & 54.6 & 03-06-07 & 0000 & Start $100 \%$ neon flow \\
\hline & & & 67.9 & 03-19-07 & 0900 & Unplanned reactor scram \\
\hline & & & 67.9 & $03-22-07$ & 0200 & Reactor restart \\
\hline & & & 68.0 & $03-22-07$ & 0600 & Full power reached \\
\hline & & & 98.2 & 04-21-07 & 1000 & Reactor down \\
\hline \multirow[t]{6}{*}{3} & \multirow[t]{6}{*}{ 139B } & \multirow[t]{6}{*}{51.1} & 98.2 & $06-24-07$ & 1900 & Reactor start-up \\
\hline & & & 98.3 & $06-25-07$ & 0400 & Full power reached \\
\hline & & & 129.5 & $07-26-07$ & 1000 & Unplanned reactor scram \\
\hline & & & 129.5 & 09-08-07 & 2300 & Reactor restart \\
\hline & & & 129.7 & 09-09-07 & 1800 & Full power reached \\
\hline & & & 149.3 & 09-29-07 & 0900 & Reactor down \\
\hline \multirow[t]{3}{*}{4} & \multirow[t]{3}{*}{$140 \mathrm{~A}$} & \multirow[t]{3}{*}{46.5} & 149.3 & $10-15-07$ & 1700 & Reactor start-up \\
\hline & & & 150.1 & $10-16-07$ & 1600 & Full power reached \\
\hline & & & 195.8 & $12-01-07$ & 0800 & Reactor down \\
\hline
\end{tabular}


Table 2 (continued)

\begin{tabular}{|c|c|c|c|c|c|c|}
\hline $\begin{array}{l}\text { AGR-1 } \\
\text { Cycle }\end{array}$ & $\begin{array}{l}\text { ATR } \\
\text { Cycle }\end{array}$ & $\begin{array}{l}\text { Cycle } \\
\text { EFPD }\end{array}$ & $\begin{array}{c}\text { Cumulative } \\
\text { EFPD }\end{array}$ & $\begin{array}{c}\text { Date } \\
\text { M-D-Y }\end{array}$ & Time $^{(a)}$ & Reactor Event \\
\hline \multirow[t]{6}{*}{5} & \multirow[t]{6}{*}{ 140B } & \multirow[t]{6}{*}{35.7} & 195.8 & $12-15-07$ & 1600 & Reactor start-up \\
\hline & & & 196.2 & $12-16-07$ & 1200 & Full power reached \\
\hline & & & 220.5 & 01-09-08 & 1800 & Unplanned reactor scram \\
\hline & & & 220.5 & $01-15-08$ & 0300 & Reactor restart \\
\hline & & & 220.7 & $01-15-08$ & 1400 & Full power reached \\
\hline & & & 231.5 & 01-26-08 & 1000 & Reactor down \\
\hline \multirow[t]{3}{*}{6} & \multirow[t]{3}{*}{$141 \mathrm{~A}$} & \multirow[t]{3}{*}{32.4} & 231.5 & 02-04-08 & 2000 & Reactor start-up \\
\hline & & & 231.6 & $02-05-08$ & 0400 & Full power reached \\
\hline & & & 263.9 & 03-08-08 & 1100 & Reactor down \\
\hline \multirow[t]{6}{*}{7} & \multirow[t]{6}{*}{$142 \mathrm{~A}$} & \multirow[t]{6}{*}{48.0} & 263.9 & $05-02-08$ & 0300 & Reactor start-up \\
\hline & & & 264.1 & $05-02-08$ & 1100 & Full power reached \\
\hline & & & 295.9 & 06-03-08 & 0700 & Unplanned reactor scram \\
\hline & & & 295.9 & $06-05-08$ & 1000 & Reactor restart \\
\hline & & & 296.0 & 06-05-08 & 1400 & Full power reached \\
\hline & & & 311.9 & $06-21-08$ & 1100 & Reactor down \\
\hline \multirow[t]{9}{*}{8} & \multirow[t]{9}{*}{ 142B } & \multirow[t]{9}{*}{52.0} & 311.9 & 07-04-08 & 1400 & Reactor start-up \\
\hline & & & 312.0 & 07-05-08 & 0000 & Full power reached \\
\hline & & & 313.0 & 07-06-08 & 0100 & Unplanned reactor scram \\
\hline & & & 313.0 & 07-08-08 & 2000 & Reactor restart \\
\hline & & & 313.1 & 07-09-08 & 0300 & Full power reached \\
\hline & & & 340.6 & 08-05-08 & 1500 & Unplanned reactor scram \\
\hline & & & 340.6 & 08-07-08 & 1200 & Reactor restart \\
\hline & & & 340.7 & 08-07-08 & 1800 & Full power reached \\
\hline & & & 363.9 & 08-30-08 & 2200 & Reactor down \\
\hline \multirow[t]{9}{*}{9} & \multirow[t]{9}{*}{$143 \mathrm{~A}$} & \multirow[t]{9}{*}{48.9} & 363.9 & 09-23-08 & 1400 & Reactor start-up \\
\hline & & & 364.3 & 09-24-08 & 0300 & Full power reached \\
\hline & & & 386.7 & $10-16-08$ & 1300 & Unplanned reactor scram \\
\hline & & & 386.7 & $11-05-08$ & 0700 & Reactor restart \\
\hline & & & 386.8 & $11-05-08$ & 1200 & Full power reached \\
\hline & & & 402.7 & $11-21-08$ & 1000 & Unplanned reactor scram \\
\hline & & & 402.7 & $11-26-08$ & 0400 & Reactor restart \\
\hline & & & 402.8 & $11-26-08$ & 0900 & Full power reached \\
\hline & & & 412.8 & $12-06-08$ & 1000 & Reactor down \\
\hline \multirow[t]{7}{*}{10} & \multirow[t]{7}{*}{ 143B } & \multirow[t]{7}{*}{57.3} & 412.8 & $12-22-08$ & 1400 & Reactor start-up \\
\hline & & & 413.1 & $12-23-08$ & 1600 & Full power reached \\
\hline & & & 439.7 & 01-19-09 & 0800 & Begin gradual shutdown \\
\hline & & & 439.8 & 01-19-09 & 1000 & Zero power reached \\
\hline & & & 439.8 & 01-21-09 & 0200 & Reactor restart \\
\hline & & & 439.9 & 01-21-09 & 0500 & Full power reached \\
\hline & & & 470.1 & 02-20-09 & 1100 & Reactor down \\
\hline
\end{tabular}


Table 2 (continued)

\begin{tabular}{|c|c|c|c|c|c|c|}
\hline $\begin{array}{c}\text { AGR-1 } \\
\text { Cycle }\end{array}$ & $\begin{array}{l}\text { ATR } \\
\text { Cycle } \\
\end{array}$ & $\begin{array}{l}\text { Cycle } \\
\text { EFPD } \\
\end{array}$ & $\begin{array}{c}\text { Cumulative } \\
\text { EFPD }\end{array}$ & $\begin{array}{c}\text { Date } \\
\text { M-D-Y }\end{array}$ & Time $^{(a)}$ & Reactor Event \\
\hline \multirow[t]{3}{*}{11} & \multirow[t]{3}{*}{$144 \mathrm{~A}$} & \multirow[t]{3}{*}{43.7} & 470.1 & 03-12-09 & 0900 & Reactor start-up \\
\hline & & & 470.2 & 03-12-09 & 1900 & Full power reached \\
\hline & & & 513.8 & 04-25-09 & 1000 & Reactor down \\
\hline \multirow[t]{6}{*}{12} & \multirow[t]{6}{*}{ 144B } & \multirow[t]{6}{*}{51.7} & 513.8 & 05-10-09 & 1600 & Reactor start-up \\
\hline & & & 514.0 & 05-10-09 & 2400 & Full power reached \\
\hline & & & 534.8 & 05-31-09 & 1800 & Unplanned reactor scram \\
\hline & & & 534.8 & 06-03-09 & 1400 & Reactor restart \\
\hline & & & 534.9 & 06-03-09 & 1900 & Full power reached \\
\hline & & & 565.5 & 07-04-09 & 1000 & Reactor down \\
\hline \multirow[t]{12}{*}{13} & \multirow[t]{12}{*}{$145 \mathrm{~A}$} & \multirow[t]{12}{*}{54.7} & 565.5 & 09-05-09 & 0300 & Reactor start-up \\
\hline & & & 565.7 & 09-05-09 & 1200 & Full power reached \\
\hline & & & 589.5 & 09-29-09 & 0900 & Unplanned reactor scram \\
\hline & & & 589.5 & 10-01-09 & 0300 & Reactor restart \\
\hline & & & 589.6 & 10-01-09 & 0900 & Full power reached \\
\hline & & & 596.3 & 10-08-09 & 0200 & Unplanned reactor scram \\
\hline & & & 596.3 & $10-10-09$ & 1400 & Reactor restart \\
\hline & & & 596.5 & 10-10-09 & 2200 & Full power reached \\
\hline & & & 598.4 & $10-12-09$ & 1900 & Unplanned reactor scram \\
\hline & & & 598.4 & 10-15-09 & 0500 & Reactor restart \\
\hline & & & 598.5 & $10-15-09$ & 1300 & Full power reached \\
\hline & & & 620.2 & $11-06-09$ & 0600 & Reactor down \\
\hline
\end{tabular}

a. Reactor event time was obtained from hourly ATR Surveillance Data Reports. Events are observed at the nearest full hour increment.

\subsection{Neutronics Analysis Methodology}

Neutronics analysis of the AGR-1 test train was performed using JMOCUP, a coupling developed at INL combining the continuous energy Monte Carlo N-Particle (MCNP) transport code (LANL 2004) and the depletion code ORIGEN (Croff 1983). The JMOCUP depletion methodology was used to model and deplete the AGR-1 TRISO fuel compacts in the B-10 test position of ATR. Application of the JMOCUP code system to an experiment in ATR is new and this calculation represents the first application to date. Validation of the JMOCUP calculation will eventually come with the comparison of calculated results to PIE measurement data; for example, comparison of end-of-life U-235 burnup, actinide concentrations, fission product concentrations, etc. Verification that the calculation executed properly was done through both technical checkers and post-processing of calculated data. A detailed description of the JMOCUP system, along with the Verification and Validation of the JMOCUP depletion calculation is documented in (Sterbentz 2013). 
The AGR-1 JMOCUP depletion calculation involves multiple depletion zones: ATR driver core, AGR-1 TRISO compacts, AGR-1 hafnium capsule shroud, and AGR-1 borated graphite holder. The ATR driver core consists of 840 depletion cells in the MCNP model, or three radial and seven axial cells per each of the 40 driver elements in the serpentine ATR core. The 72 fuel compacts of the AGR-1 experiment are split in half for a total of 144 depletion cells - the hafnium shroud has 24 depletion cells, and the borated graphite holder has 23 depletion cells. There are therefore a total of 1,031 depletion cells that JMOCUP operates on and keeps track of during each time step of each cycle.

The ATR driver fuel depletion cells each contain nine actinides and 24 fission product isotopes that are tracked along with their fission and radiative capture cross sections, which must be updated at each time step. Similarly, the compacts have 19 tracked actinides and 71 fission products. In the hafnium shroud cells, the seven naturally occurring hafnium isotopes are tracked, as is the Boron-10 in the 23 borated graphite cells that compose the AGR-1 graphite compact holder. The MCNP code in each case calculates the cell flux and specified reaction rate(s) for each isotope in each depletion cell at each time step and calculates an updated one-group cross section. These updated cross sections are then part of the next ORIGEN depletion calculation.

The neutron transport problem in the JMOCUP method is solved using the KCODE option in the MCNP code. For the KCODE option to be effective, the reactor core, in this case the ATR driver fuel must be simultaneously depleted along with the AGR-1 experiment. Modeling the depletion of the entire ATR core provides a realistic neutron and gamma source for analyzing the AGR-1 experiment's radiation environment. Effects of important operational details can be taken into account on a daily-averaged basis using this methodology, such as the positions of the outer shim cylinders.

\subsection{As-Run Neutronics Analysis Results}

Figure 6 shows the capsule-average heat generation in the fuel compacts of the AGR-1 test train versus time in EFPD plotted using NDMAS. The general trend shared by each capsule is an increase over the first several cycles as the boron in the graphite is depleted, followed by a leveling-off over the remaining cycles. In many of the individual irradiation cycles, an increase in power density can be observed toward the end. This is because late in the cycle, the northeast outer shim cylinders (shown in Figure 1) are often rotated such that the hafnium absorbers are oriented further away from the core. This is done to balance lobe powers in the ATR and tends to substantially increase the thermal flux in the region of the $\mathrm{B}-10$ position. 


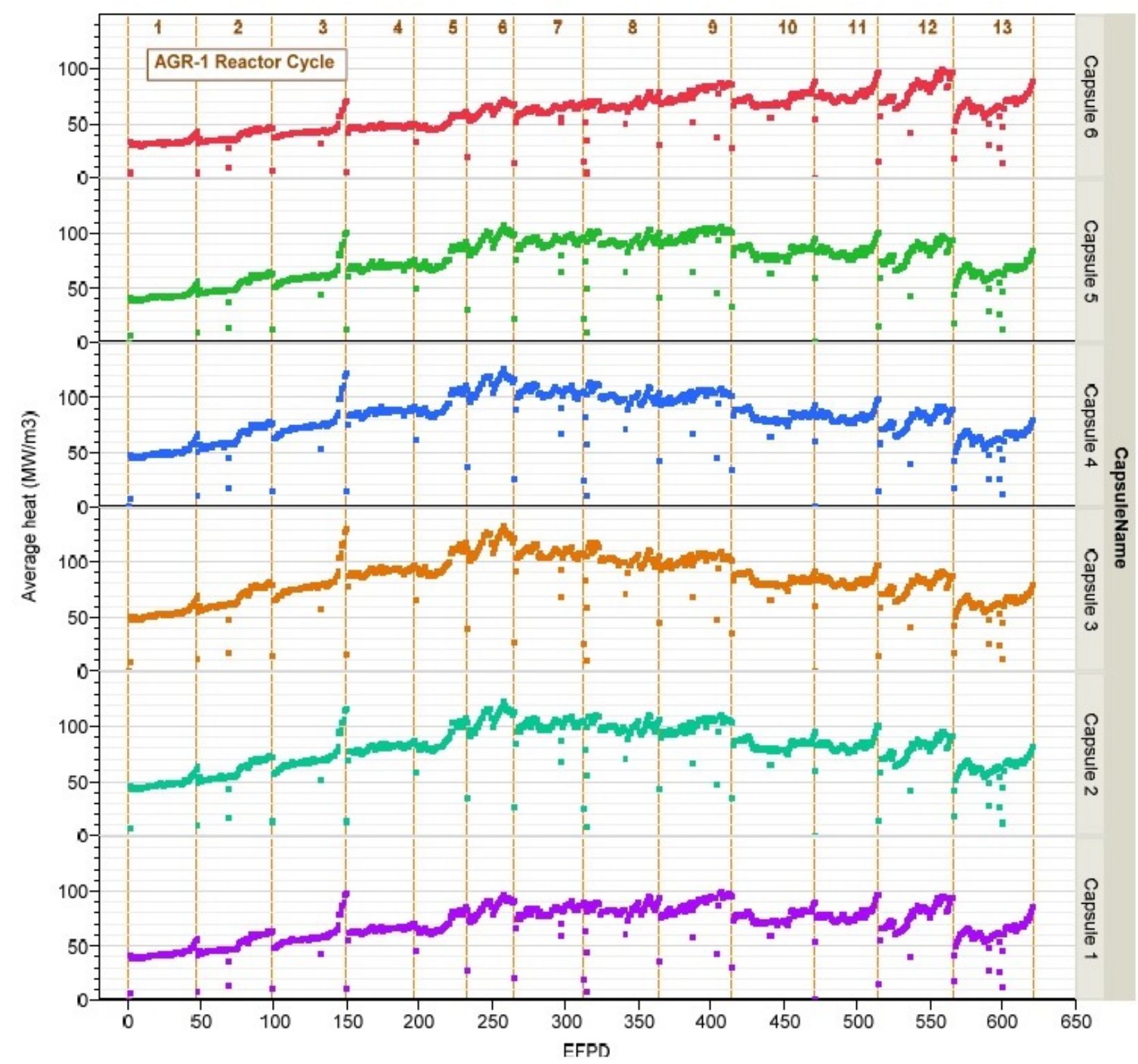

Figure 6. Capsule average power density versus irradiation time in EFPD.

Burnups of the AGR-1 fuel compacts versus EFPDs are shown in Figure 7. These are in units of $\%$ FIMA, and AGR-1 irradiation intervals are numbered across the top. Capsule average burnup is shown for each capsule, along with the values for the peak and minimum compact in each capsule. The capsules at the top and bottom of the reactor (Capsules 6 and 1, respectively) have the lowest burnup, with higher values found toward the center. Capsule-average burnups ranged from 13.4\% FIMA in Capsule 6 to $18.6 \%$ FIMA in Capsule 3. Figure 8 shows fast neutron fluence $(\mathrm{E}>0.18 \mathrm{MeV})$ versus time in EFPD, again with AGR-1 irradiation intervals shown across the top. As would be expected, the trends of fast fluence follow quite closely those of FIMA. The capsule with the lowest average fluence at the end of the irradiation was Capsule 6 with a value of $2.65 \times 10^{25} \mathrm{n} / \mathrm{m}^{2}(\mathrm{E}>0.18 \mathrm{MeV})$, and the capsule with the highest was Capsule 3 at $4.07 \times 10^{25} \mathrm{n} / \mathrm{m}^{2}(\mathrm{E}>0.18 \mathrm{MeV})$. 


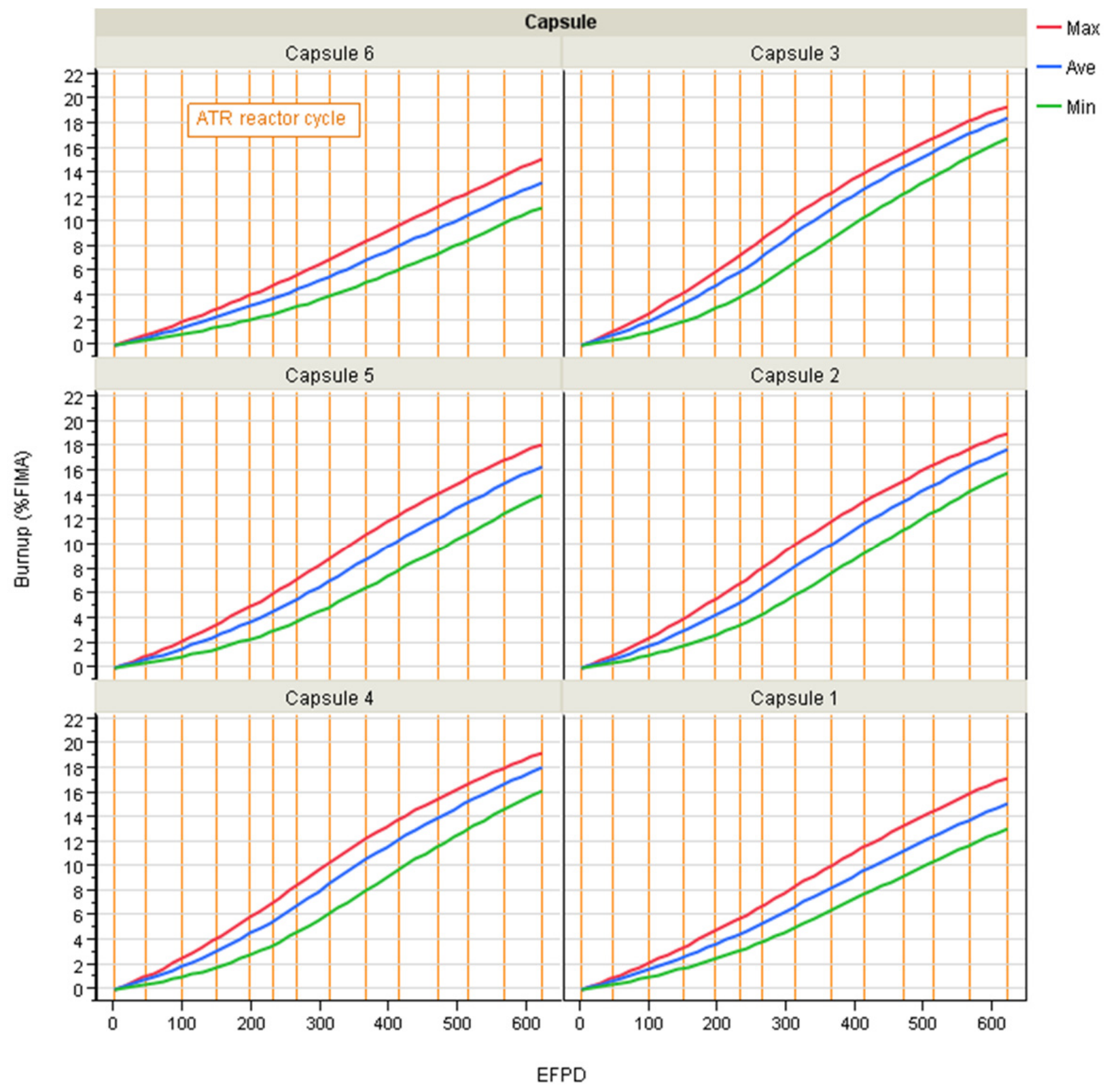

Figure 7. Burnup (in \%FIMA) versus EFPD by capsule. 


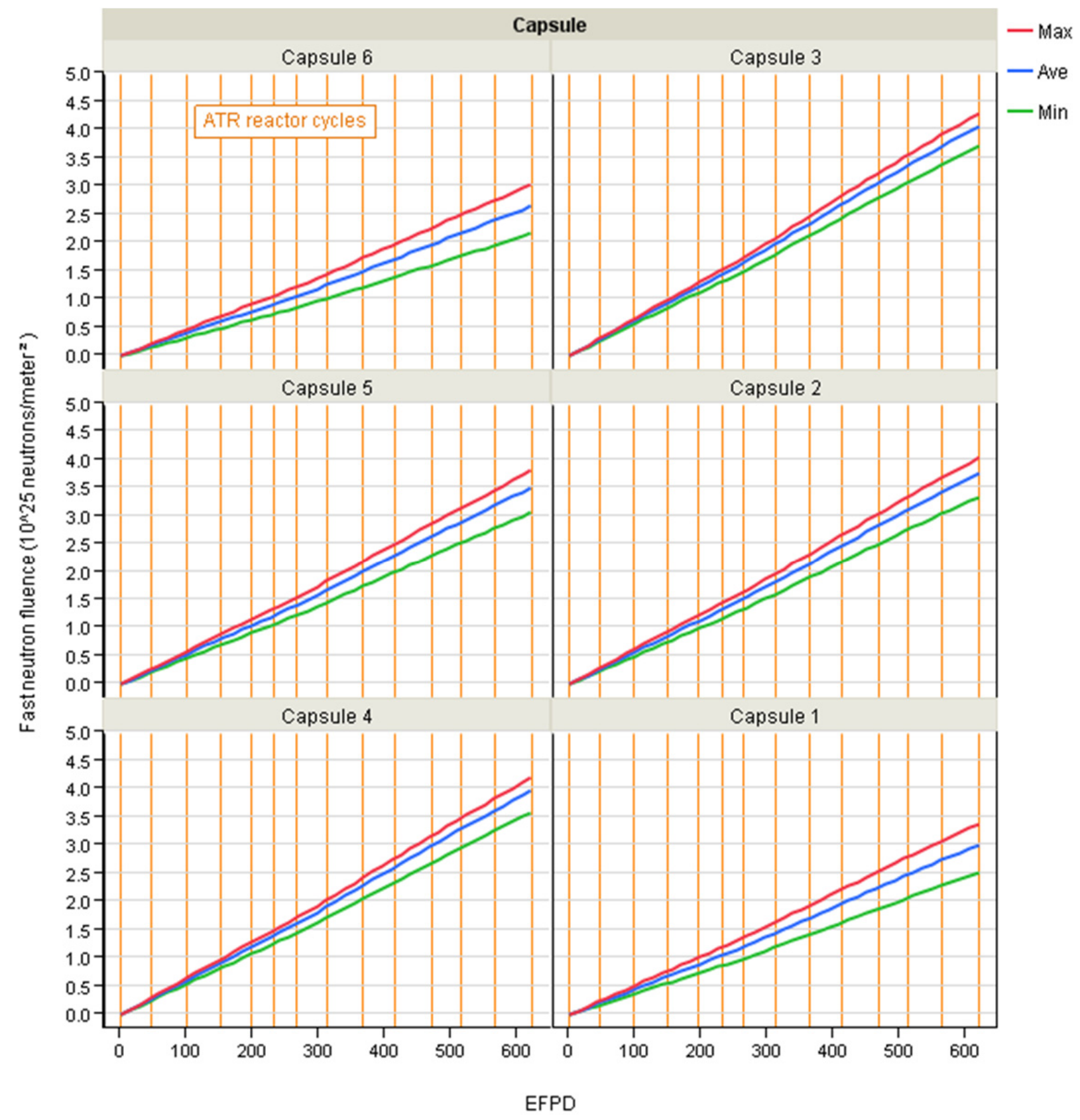

Figure 8 . Fast neutron fluence $(\mathrm{E}>0.18 \mathrm{MeV})$ versus EFPD by capsule.

In addition, Figure 9 and Figure 10 show the correlation between burnup and fast fluence for the 72 AGR-1 compacts (Figure 9) and 6 AGR-1 capsules (Figure 10). A 3-D scatter plot of the irradiation characteristics of the 72 AGR-1 compacts is presented in Figure 21 (Section 3.1). 


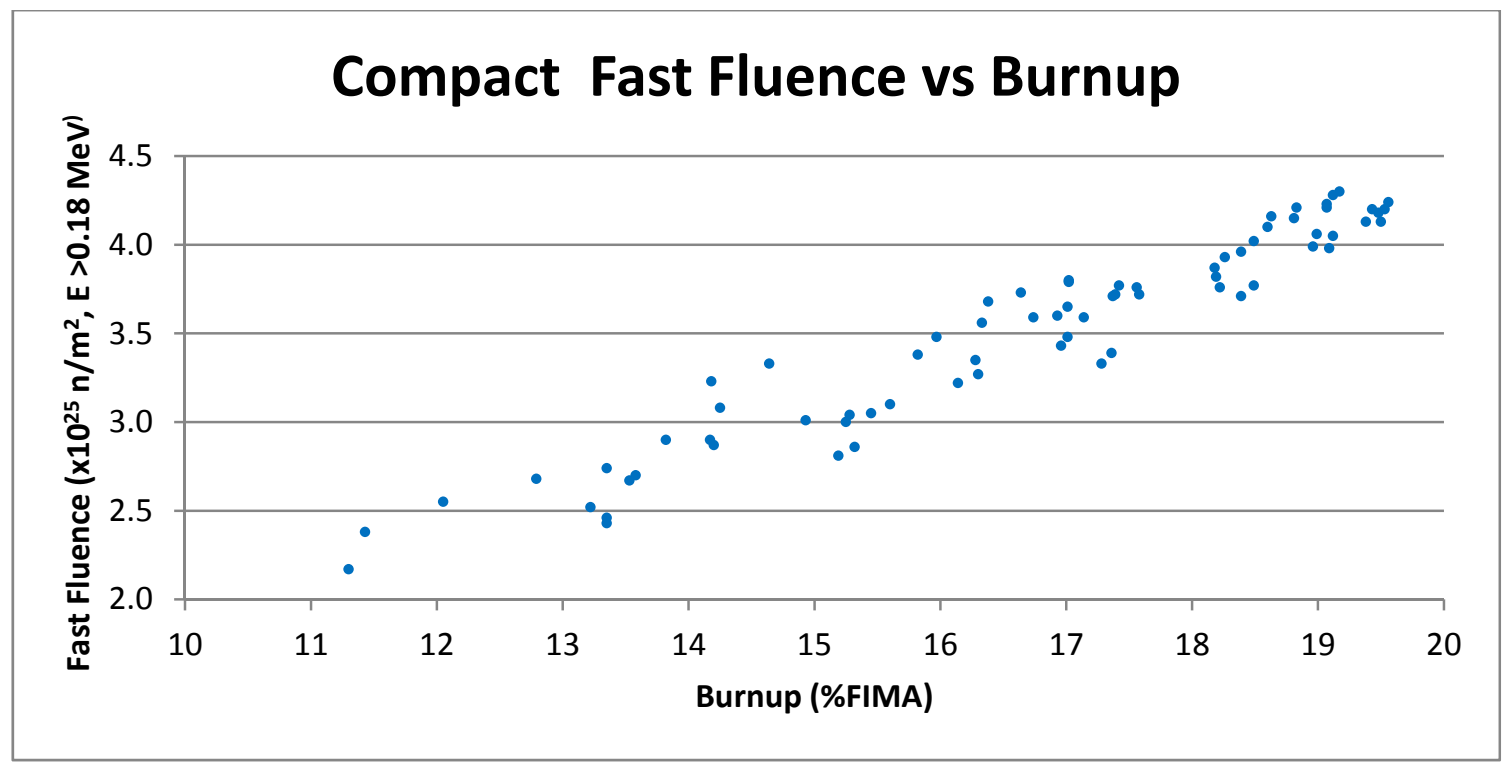

Figure 9. Fast neutron fluence $(\mathrm{E}>0.18 \mathrm{MeV}$ ) vs. Burnup (\%FIMA) for AGR-1 compacts.

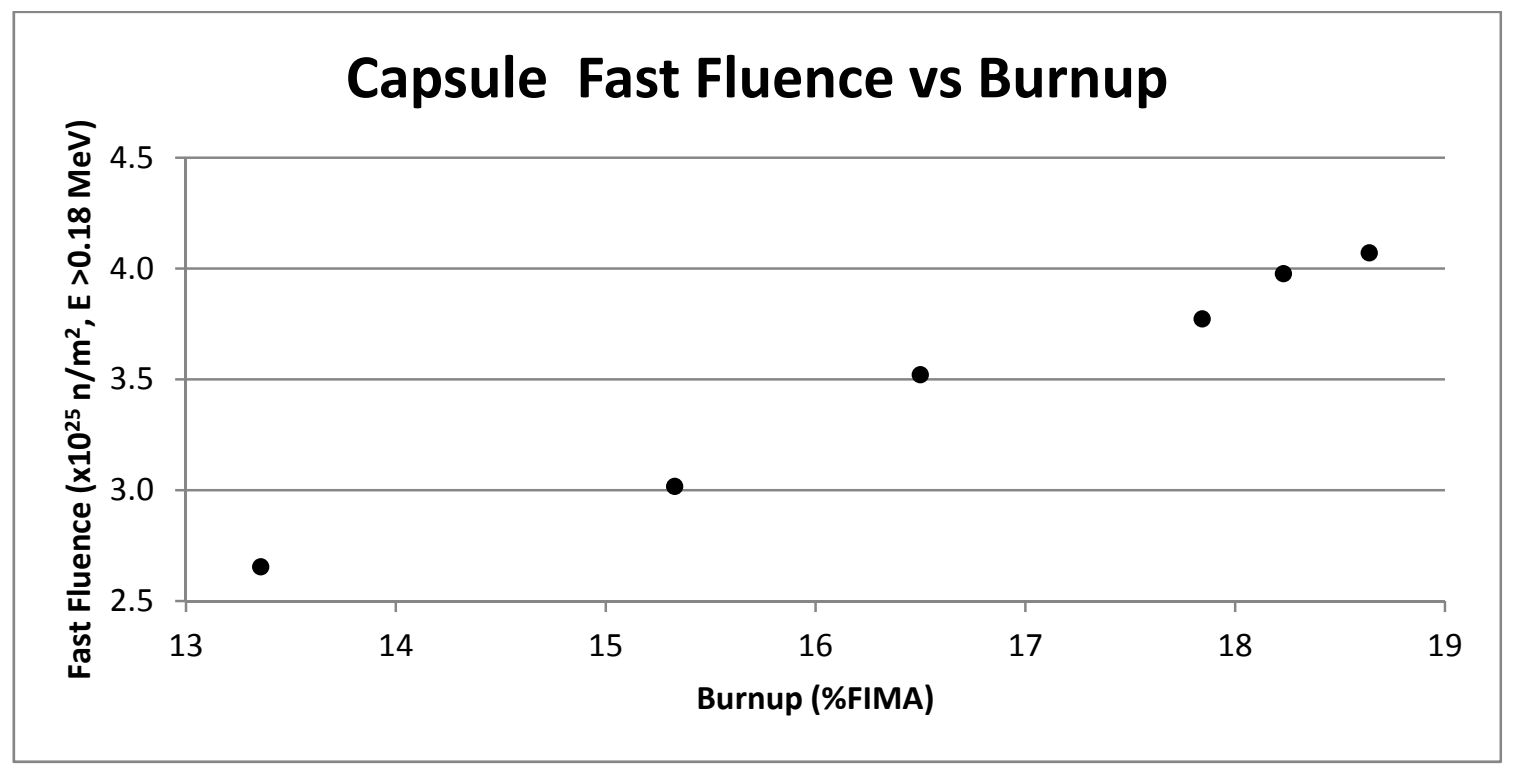

Figure 10. Fast neutron fluence $(\mathrm{E}>0.18 \mathrm{MeV})$ vs. Burnup (\%FIMA) for AGR-1 capsules.

Table 3 and Table 4 show burnup and fast fluence at the end of irradiation for all of the compacts in the test train - capsule averages are also included. From these tables, one can see that burnup on a compact basis ranged from 11.3 to $19.6 \%$ FIMA and the compact fast fluence ranged from $2.17 \times 10^{25}$ to $4.30 \times 10^{25} \mathrm{n} / \mathrm{m}^{2}(\mathrm{E}>0.18 \mathrm{MeV})$. According to these results, a total of nine compacts reached a burnup of greater than 19\% FIMA. Separation by stack also shows that Stacks 1 and 3 consistently receive more neutron flux than Stack 2 as a result of their orientation towards the core as shown in Figure 3. These data are also summarized in Table 5 with only peak, minimum, and capsule average values given for fast fluence and burnup. Burnup and fast fluence data at the end of each cycle for all of the compacts are shown in Appendix D and stored in NDMAS. 
Table 3. Burnup and fast neutron fluence by compact and capsule averages for Capsules 6-4.

\begin{tabular}{|c|c|c|c|c|}
\hline Capsule & Stack & Compact & $\begin{array}{l}\text { Burnup }^{(a)} \\
(\% \text { FIMA) } \\
\end{array}$ & $\begin{array}{c}\text { Fast Neutron Fluence } \\
\left(10^{25} \mathrm{n} / \mathrm{m}^{2} \mathrm{E}>0.18 \mathrm{MeV}\right)\end{array}$ \\
\hline \multirow{12}{*}{$\begin{array}{c}6 \\
\text { (top) }\end{array}$} & \multirow{4}{*}{1} & 4 & 13.35 & 2.43 \\
\hline & & 3 & 13.53 & 2.67 \\
\hline & & 2 & 14.20 & 2.87 \\
\hline & & 1 & 15.25 & 3.00 \\
\hline & \multirow{4}{*}{2} & 4 & 11.30 & 2.17 \\
\hline & & 3 & 11.43 & 2.38 \\
\hline & & 2 & 12.05 & 2.55 \\
\hline & & 1 & 12.79 & 2.68 \\
\hline & \multirow{4}{*}{3} & 4 & 13.35 & 2.46 \\
\hline & & 3 & 13.58 & 2.70 \\
\hline & & 2 & 14.17 & 2.90 \\
\hline & & 1 & 15.28 & 3.04 \\
\hline \multicolumn{3}{|c|}{ Capsule 6 Average } & 13.36 & 2.65 \\
\hline \multirow{12}{*}{5} & \multirow{4}{*}{1} & 4 & 16.96 & 3.43 \\
\hline & & 3 & 16.93 & 3.60 \\
\hline & & 2 & 17.37 & 3.71 \\
\hline & & 1 & 18.22 & 3.76 \\
\hline & \multirow{4}{*}{2} & 4 & 14.25 & 3.08 \\
\hline & & 3 & 14.18 & 3.23 \\
\hline & & 2 & 14.64 & 3.33 \\
\hline & & 1 & 15.82 & 3.38 \\
\hline & \multirow{4}{*}{3} & 4 & 17.01 & 3.48 \\
\hline & & 3 & 17.01 & 3.65 \\
\hline & & 2 & 17.42 & 3.77 \\
\hline & & 1 & 18.19 & 3.82 \\
\hline \multicolumn{3}{|c|}{ Capsule 5 Average } & 16.50 & 3.52 \\
\hline \multirow{12}{*}{4} & \multirow{4}{*}{1} & 4 & 18.96 & 3.99 \\
\hline & & 3 & 18.60 & 4.10 \\
\hline & & 2 & 18.81 & 4.15 \\
\hline & & 1 & 19.38 & 4.13 \\
\hline & \multirow{4}{*}{2} & 4 & 16.74 & 3.59 \\
\hline & & 3 & 16.38 & 3.68 \\
\hline & & 2 & 16.64 & 3.73 \\
\hline & & 1 & 17.39 & 3.72 \\
\hline & \multirow{4}{*}{3} & 4 & 18.99 & 4.06 \\
\hline & & 3 & 18.63 & 4.16 \\
\hline & & 2 & 18.83 & 4.21 \\
\hline & & 1 & 19.43 & 4.20 \\
\hline \multicolumn{3}{|c|}{ Capsule 4 Average } & 18.23 & 3.98 \\
\hline
\end{tabular}


Table 4. Burnup and fast neutron fluence by compact and capsule averages for Capsules 3-1.

\begin{tabular}{|c|c|c|c|c|}
\hline Capsule & Stack & Compact & $\begin{array}{l}\text { Burnup }^{(a)} \\
\text { (\% FIMA) }\end{array}$ & $\begin{array}{l}\text { Fast Neutron Fluence } \\
\left(10^{25} \mathrm{n} / \mathrm{m}^{2} \mathrm{E}>0.18 \mathrm{MeV}\right)\end{array}$ \\
\hline \multirow{12}{*}{3} & \multirow{4}{*}{1} & 4 & 19.48 & 4.18 \\
\hline & & 3 & 19.07 & 4.23 \\
\hline & & 2 & 19.07 & 4.21 \\
\hline & & 1 & 19.50 & 4.13 \\
\hline & \multirow{4}{*}{2} & 4 & 17.56 & 3.76 \\
\hline & & 3 & 17.02 & 3.80 \\
\hline & & 2 & 17.02 & 3.79 \\
\hline & & 1 & 17.58 & 3.72 \\
\hline & \multirow{4}{*}{3} & 4 & 19.56 & 4.24 \\
\hline & & 3 & 19.17 & 4.30 \\
\hline & & 2 & 19.12 & 4.28 \\
\hline & & 1 & 19.53 & 4.20 \\
\hline \multicolumn{3}{|c|}{ Capsule 3 Average } & 18.64 & 4.07 \\
\hline \multirow{12}{*}{2} & \multirow{4}{*}{1} & 4 & 19.09 & 3.98 \\
\hline & & 3 & 18.39 & 3.96 \\
\hline & & 2 & 18.18 & 3.87 \\
\hline & & 1 & 18.39 & 3.71 \\
\hline & \multirow{4}{*}{2} & 4 & 17.14 & 3.59 \\
\hline & & 3 & 16.33 & 3.56 \\
\hline & & 2 & 15.97 & 3.48 \\
\hline & & 1 & 16.28 & 3.35 \\
\hline & \multirow{4}{*}{3} & 4 & 19.12 & 4.05 \\
\hline & & 3 & 18.49 & 4.02 \\
\hline & & 2 & 18.26 & 3.93 \\
\hline & & 1 & 18.49 & 3.77 \\
\hline \multicolumn{3}{|c|}{ Capsule 2 Average } & 17.84 & 3.77 \\
\hline \multirow{12}{*}{$\begin{array}{c}1 \\
\text { (bottom) }\end{array}$} & \multirow{4}{*}{1} & 4 & 17.28 & 3.33 \\
\hline & & 3 & 16.14 & 3.22 \\
\hline & & 2 & 15.45 & 3.05 \\
\hline & & 1 & 15.19 & 2.81 \\
\hline & \multirow{4}{*}{2} & 4 & 14.93 & 3.01 \\
\hline & & 3 & 13.82 & 2.90 \\
\hline & & 2 & 13.35 & 2.74 \\
\hline & & 1 & 13.22 & 2.52 \\
\hline & \multirow{4}{*}{3} & 4 & 17.36 & 3.39 \\
\hline & & 3 & 16.30 & 3.27 \\
\hline & & 2 & 15.60 & 3.10 \\
\hline & & 1 & 15.32 & 2.86 \\
\hline \multicolumn{3}{|c|}{ Capsule 1 Average } & 15.33 & 3.02 \\
\hline
\end{tabular}


Table 5. Minimum, average, and peak compact burnup and fast fluence at the end of irradiation.

\begin{tabular}{|c|c|c|c|c|c|c|}
\hline \multirow{2}{*}{} & \multicolumn{3}{|c|}{$\begin{array}{c}\text { Compact Burnup } \\
\text { (\% FIMA) }\end{array}$} & \multicolumn{3}{c|}{$\begin{array}{c}\text { Compact Fast Neutron Fluence } \\
\left(10^{25} \mathrm{n} / \mathrm{m}^{2} \mathrm{E}>0.18 \mathrm{MeV}\right)\end{array}$} \\
\cline { 2 - 7 } Capsule & $\begin{array}{c}\text { Minimum } \\
\text { Compact }\end{array}$ & $\begin{array}{c}\text { Capsule } \\
\text { Average }\end{array}$ & $\begin{array}{c}\text { Peak } \\
\text { Compact }\end{array}$ & $\begin{array}{c}\text { Minimum } \\
\text { Compact }\end{array}$ & $\begin{array}{c}\text { Capsule } \\
\text { Average }\end{array}$ & $\begin{array}{c}\text { Peak } \\
\text { Compact }\end{array}$ \\
\hline 1 & 13.2 & 15.3 & 17.4 & 2.52 & 3.02 & 3.39 \\
\hline 2 & 16.0 & 17.8 & 19.1 & 3.35 & 3.77 & 4.05 \\
\hline 3 & 17.0 & 18.6 & 19.6 & 3.72 & 4.07 & 4.30 \\
\hline 4 & 16.4 & 18.2 & 19.4 & 3.59 & 3.98 & 4.21 \\
\hline 5 & 14.2 & 16.5 & 18.2 & 3.08 & 3.52 & 3.82 \\
\hline 6 & 11.3 & 13.4 & 15.3 & 2.17 & 2.65 & 3.04 \\
\hline
\end{tabular}

The neutronic specifications of the irradiation as enumerated in the AGR-1 Irradiation Test Specification (Maki 2004) are listed below with comments on the performance of the experiment with respect to each:

- $\quad$ The minimum compact average burnup for each fuel compact shall be $>14 \%$ FIMA.

On a compact basis, 61 of the 72 compacts exceeded an average burnup of 14\% FIMA.

- The compact average burnup goal for the majority of the fuel compacts should be $>18 \%$ FIMA.

On a compact basis, 26 of the 72 compacts reached a burnup of $18 \%$ FIMA. Compact burnups ranged from 11.30 to $19.56 \%$ FIMA.

- The maximum peak fast neutron fluence for each fuel compact shall be $<5 \times 10^{25} \mathrm{n} / \mathrm{m}^{2}, E>0.18 \mathrm{MeV}$.

This criterion was satisfied both on a capsule average and a per compact basis.

- The minimum peak fast neutron fluence for each fuel compact shall be $>1.5 \times 10^{25} \mathrm{n} / \mathrm{m}^{2}$, $E>0.18 \mathrm{MeV}$.

This criterion was satisfied both on a capsule average and a per compact basis.

- The instantaneous peak power per particle shall be $<400 \mathrm{~mW} /$ particle.

This criterion was satisfied for all compacts. 


\section{THERMAL ANALYSIS}

The temperature at which the fuel compacts were irradiated is an essential component of assessing the performance of the fuel. This section describes the methodology and the results of the finite element thermal analysis used to provide fuel temperatures and to generate predicted TC temperatures for use in calibration of the gas flow control system.

\subsection{Thermal Calculation Methodology}

Three-dimensional (3-D) finite element thermal calculations were performed on a daily basis using ABAQUS. The methods used in the thermal analysis summarized here are described in more detail in a separate report (Hawkes 2012). These calculations were performed using compact heat generation rates provided by the as-run neutronics analysis described in Sections 2.2 and 2.3 and with additional operational input for sweep gas composition versus time. Figure 11 shows a 3-D rendering of the finite element mesh formed from $100 \%$ eight-node hexahedral bricks, which contains approximately 350,000 nodes per AGR-1 capsule.

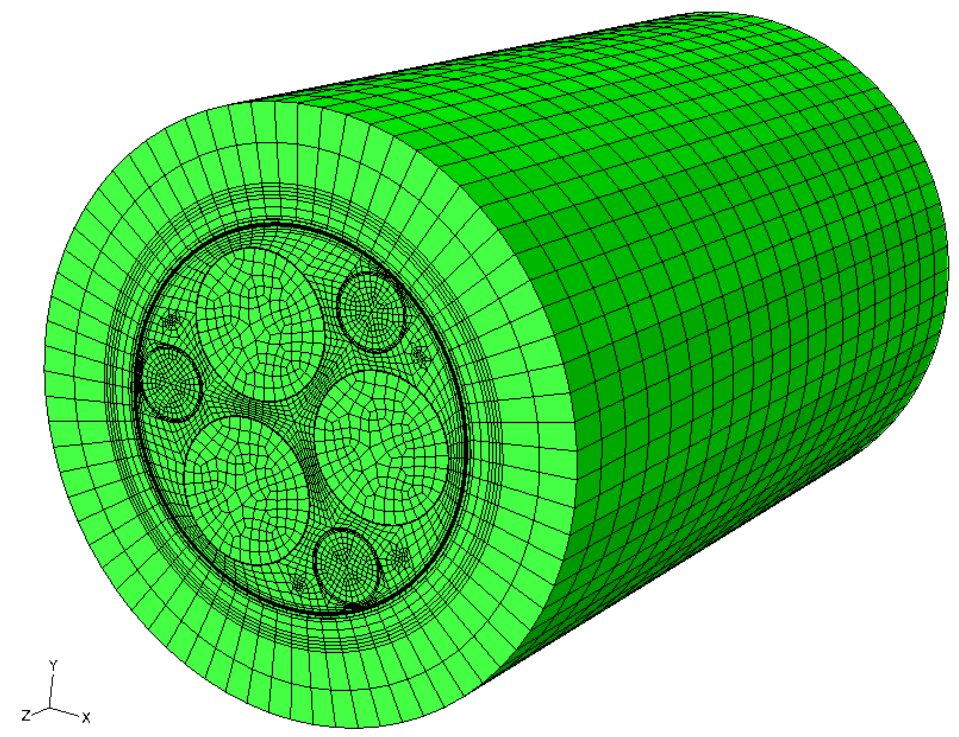

Figure 11. Rendering of ABAQUS finite element mesh of a single AGR-1 capsule.

Fuel compact thermal conductivity was taken from correlations presented in (Gontard and Nabielek1990), which gives correlations for conductivity, taking into account temperature, temperature of heat treatment, neutron fluence, and TRISO packing fraction. In this work, the convention used to quantify neutron damage to a material is fast fluence $\mathrm{E}>0.18 \mathrm{MeV}$, yet in the work by Gontard and Nabielek (1990), the unit used was the dido nickel equivalent (DNE). The following conversion was used to convert from the DNE convention to the $>0.18 \mathrm{MeV}$ fast fluence:

$\Gamma_{>0.18 \mathrm{MeV}}=1.52 \Gamma_{\mathrm{DNE}}$

where $\Gamma$ is neutron fluence in either the $>0.18 \mathrm{MeV}$ unit or DNE. The correlations in the report by Gontard and Nabielek (1990) were further adjusted to account for differences in fuel compact density. The correlations were developed for a fuel compact matrix density of $1.75 \mathrm{~g} / \mathrm{cm}^{3}$, whereas the compact matrix used in AGR-1 had a density of approximately $1.3 \mathrm{~g} / \mathrm{cm}^{3}$. The thermal conductivities were scaled according to the ratio of densities $(0.74)$ in order to correct for this difference. 
Unirradiated graphite thermal conductivity data for the holders were provided GrafTech (Thompson 2006). Figure 12 shows unirradiated thermal conductivity of four different types of boronated graphite. The percentages indicate the weight percent (wt\%) boron present in the material. The 5.5\% against grain (AG) was used in the holders for Capsules 1 and 6, while the 7\% AG was used in Capsules $2-5$. The higher boron content was placed in the interior capsules (2-5) because these locations experience a greater neutron flux than the two peripheral capsules (1 and 6). The types of graphite used are indicated with arrows in the legend of Figure 12.

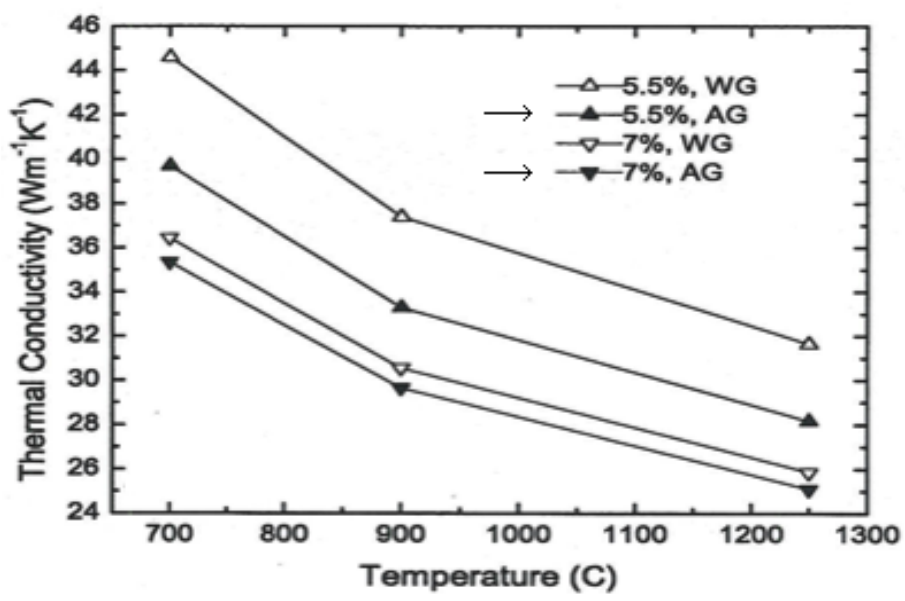

Figure 12. Thermal conductivity of unirradiated, boronated graphite holders (Thompson 2006).

The effect of irradiation on the thermal conductivity of the graphite was accounted for in this analysis using the following correlation by (Snead and Burchell 1995).

$$
\begin{aligned}
& \frac{k_{i r r}}{k_{0}}=\left(0.25-0.00017 * T_{i r r}\right) * A * \log (d p a)+0.000683 * T_{i r r} \\
& A=-1.0
\end{aligned}
$$

where $k_{0}$ and $k_{i r r}$ are thermal conductivity of unirradiated and irradiated graphite, respectively, $T_{i r r}$ is the irradiation temperature and $d p a$ is displacements per atom. The multiplier used to convert fast fluence $(\mathrm{E}>0.18 \mathrm{MeV})$ to dpa is $8.23 \times 10^{-26}$ and has units of $\mathrm{dpa} /\left(\mathrm{n} / \mathrm{m}^{2}\right)$ (Sterbentz 2009$)$.

Heat produced in the fuel compacts is transferred through the gaps surrounding the compacts into the graphite holder via a gap conductance model using the gap width and the conductivity of the sweep gas (discussed below). Heat is transferred across the outer sweep gas flow region between the outside of the graphite holder and the inside of the steel liner via radiation between the two surfaces and conduction through the helium/neon sweep gas. Because the velocity of the sweep gas is very low in this gap, convection is not considered. The thermal conductivity of the sweep gas was determined using the kinetic theory of gases, which gives conductivity $k$ of a gas mixture as a function of the gas constituents $i$ and $j$ according to:

$$
k=\sum_{i} \frac{X_{i} k_{i}}{\sum_{j} X_{j} \phi_{i j}}
$$


Where $X_{i}$ is the mole fraction of gas $i$, and $k_{i}$ is the thermal conductivity of pure gas $i$ (Fluent, Inc., 2006). The parameter $\Phi_{i j}$ in Equation 3 is given by:

$$
\phi_{i j}=\frac{\left[1+\left(\frac{\mu_{i}}{\mu_{j}}\right)^{1 / 2}\left(\frac{M_{w, j}}{M_{w, i}}\right)^{1 / 4}\right]^{2}}{\left[8\left(1+\frac{M_{w, i}}{M_{w, j}}\right)\right]^{1 / 2}}
$$

Where $\mu_{i}$ is the viscosity of pure gas $i$ and $M_{w, i}$ is the molecular weight of pure gas $i$. Figure 13 shows a plot of the resulting helium/neon sweep gas thermal conductivity versus temperature and mole fraction of helium.

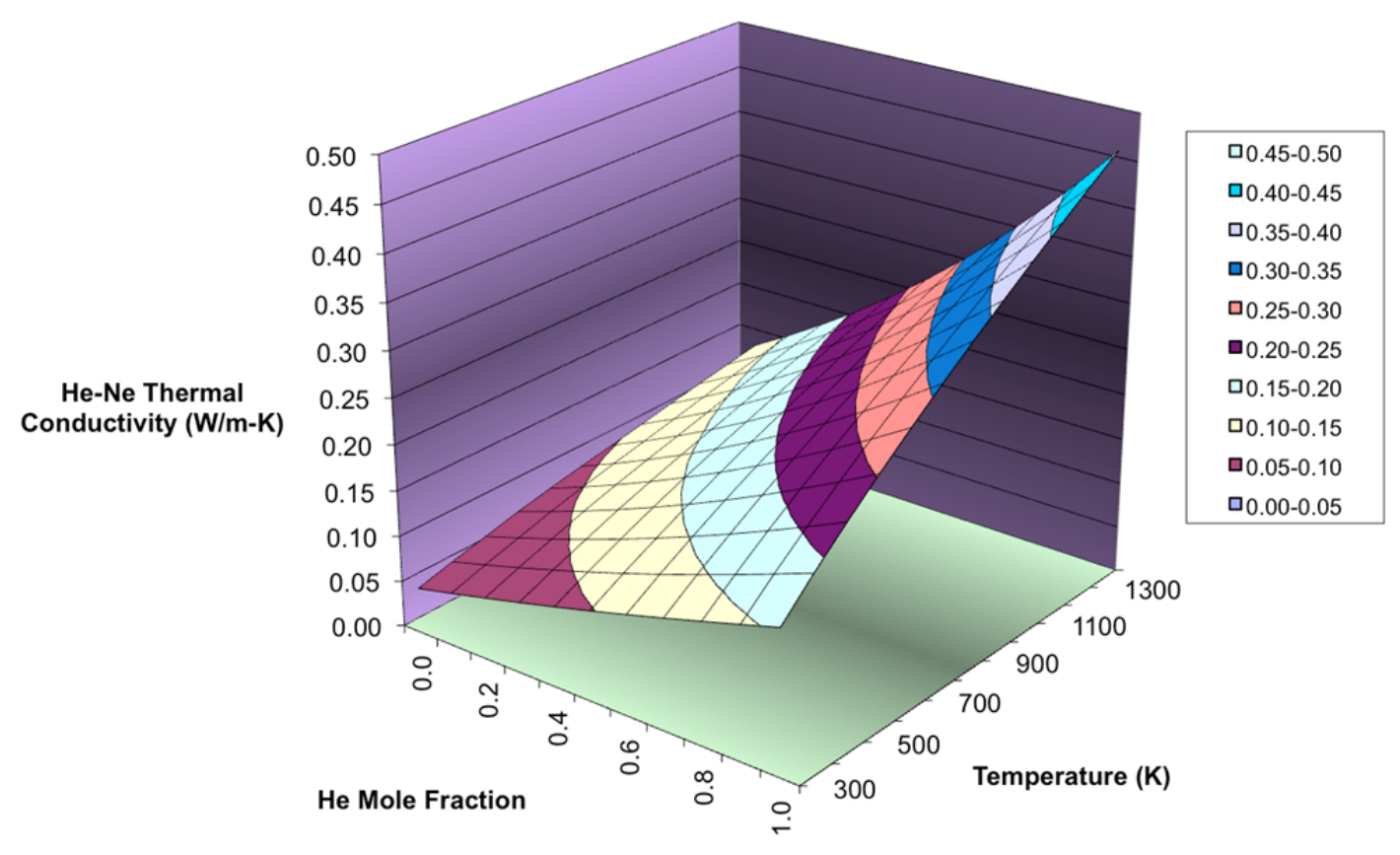

Figure 13. Sweep gas thermal conductivity versus temperature and mole fraction helium.

The radiation heat transfer of the sweep gas gap between the graphite holder and the stainless steel sleeve was modeled assuming radiation and conduction heat transfer. The flow rate of the sweep gas in this gap is low enough that forced convection need not be considered. To calibrate the finite element thermal model, the emissivities of the outer surface of the graphite holder and the inner surface of the stainless steel sleeve were adjusted such that predicted and measured TC temperatures agreed as closely as possible early in the irradiation before TC drift had become important. Emissivity values of 1.0 for these surfaces gave best agreement between calculation and measurements. In fact, during assembly of the test train, the presence of graphite dust was noted on these surfaces, which would serve to raise the emissivities of these surfaces to values closer to their theoretical maximum. Inspection of the test train during PIE may provide more insight into possible physical realization of these high emissivities.

The heat is ultimately transferred to the water flowing up the edge of the test train, which enters at the bottom of Capsule 1 at $125^{\circ} \mathrm{C}$. An insulated boundary condition was used outside the water channel. Gamma heating rates of the non-fuel structural components of the test train were determined with MCNP calculations (Chang and Lilo 2007) and taken into account in the finite element thermal calculations. 
Figure 14 shows a sample temperature profile calculated by ABAQUS from Cycle 141A in Capsule 4. Stacks 1 and 3 are oriented to the left, and higher temperatures can be observed in these as a result of their orientation towards the ATR core center. Figure 15 and Figure 16 show the daily calculated fuel temperatures (capsule-average, capsule maximum, and capsule minimum) for each of the six AGR-1 capsules versus time in EFPD plotted using NDMAS. Figure 17 and Figure 18 show the time averages of these temperatures versus time for the six capsules.

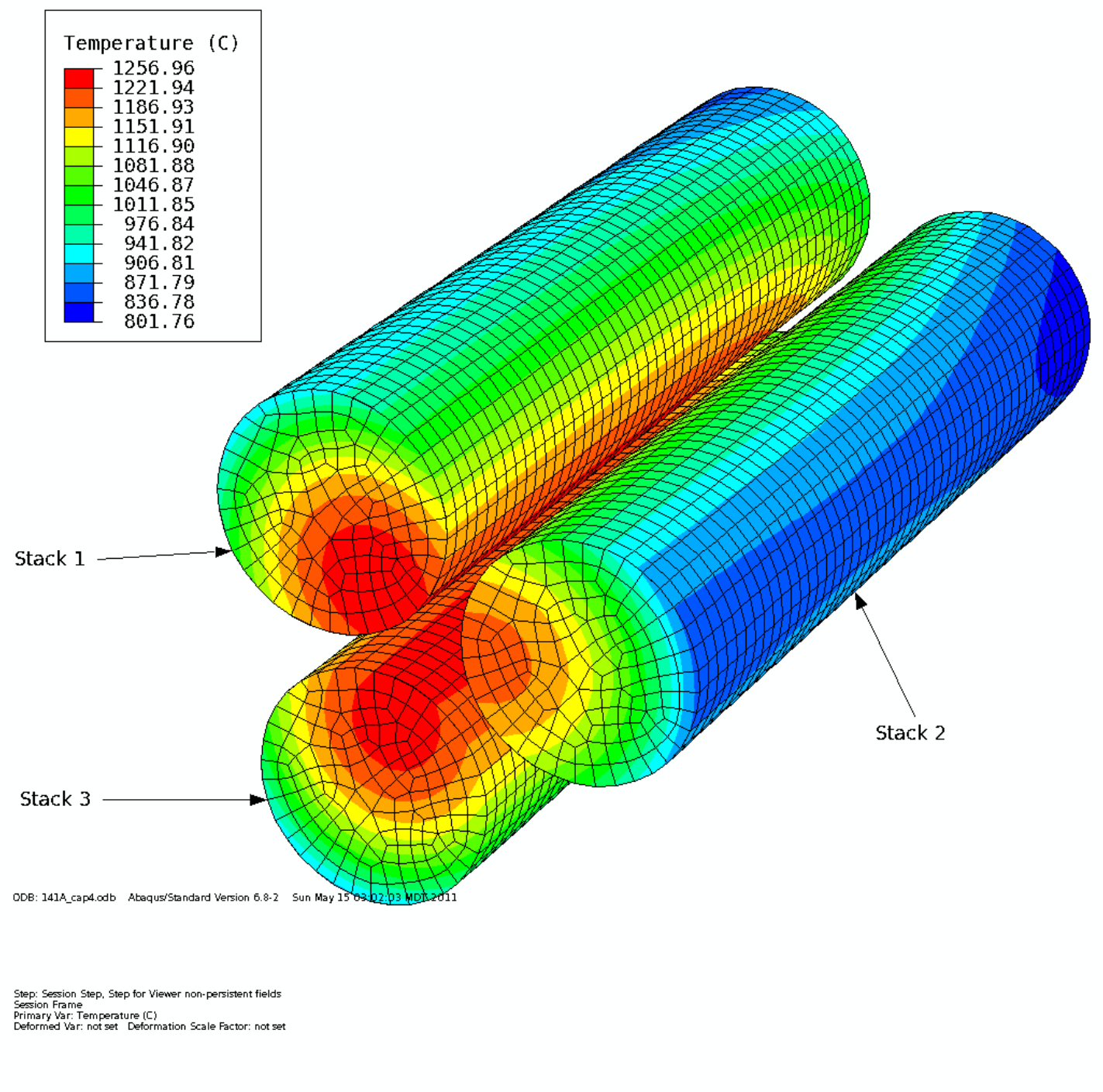

Figure 14. Sample temperature profile in Capsule 4 from Cycle 141A. 


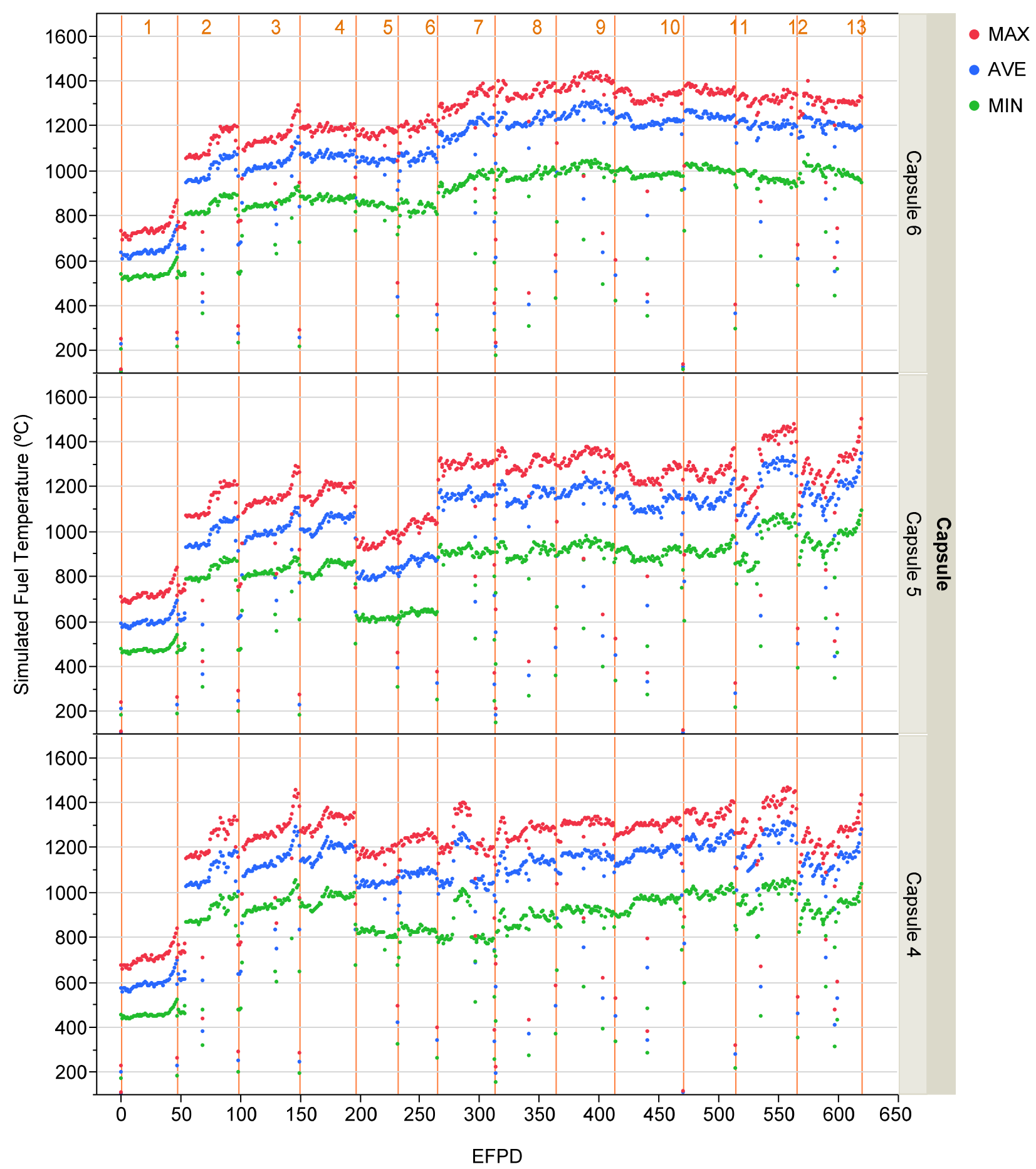

Figure 15. Calculated daily minimum, maximum, and volume average temperatures for Capsules 4-6. 


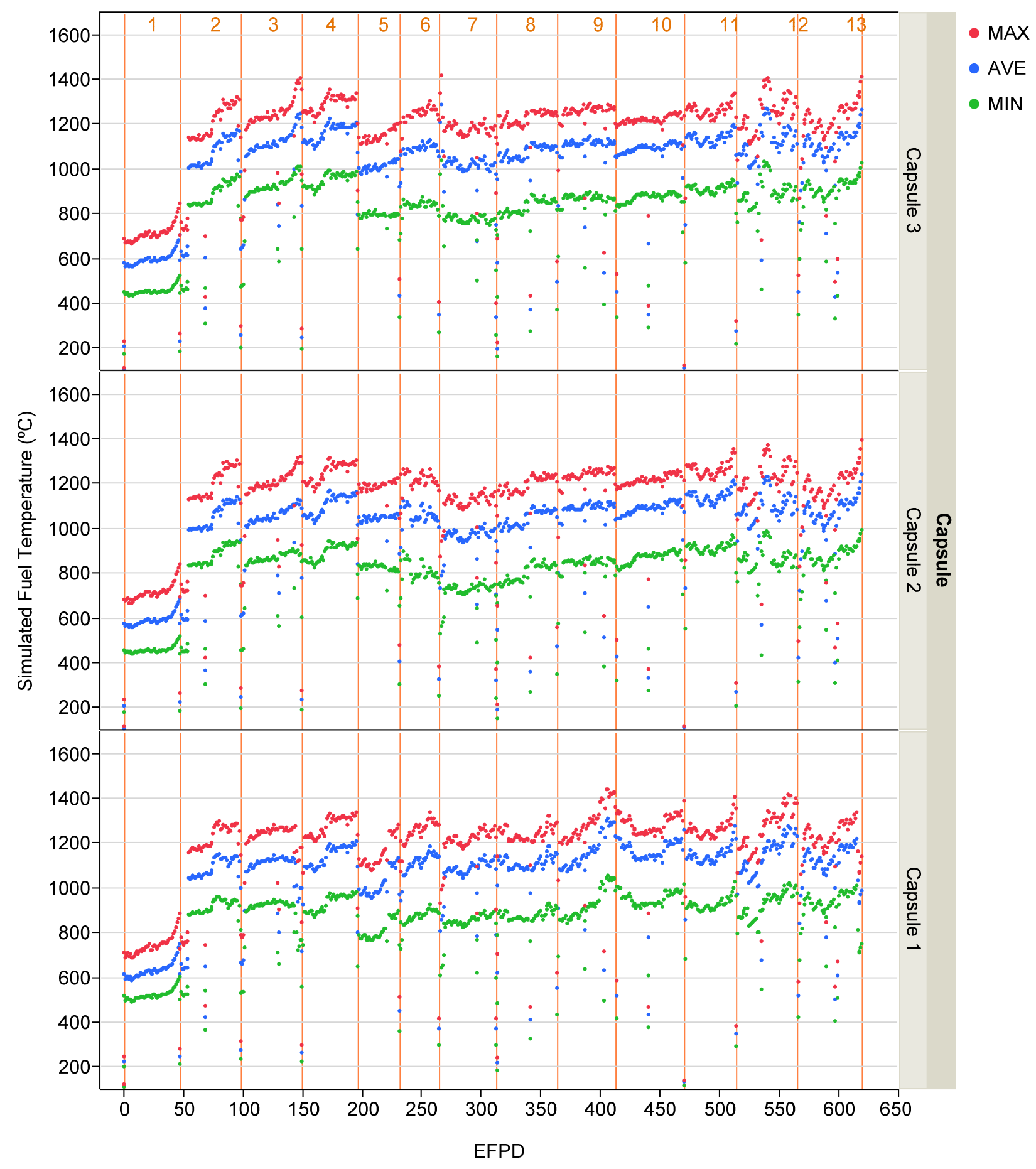

Figure 16. Calculated daily minimum, maximum, and volume average temperatures for Capsules 1-3. 


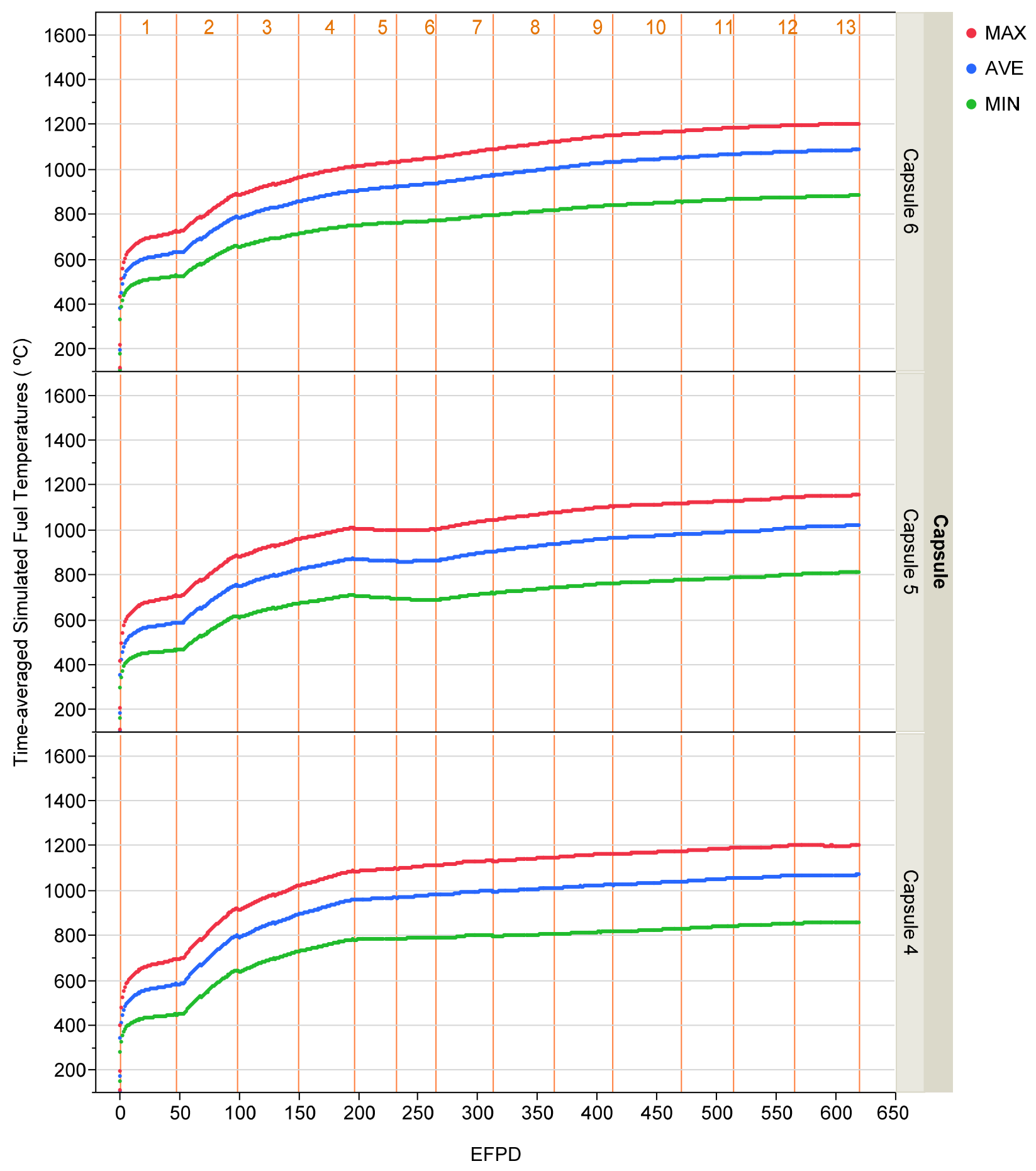

Figure 17. Calculated time-average minimum, time-average maximum, and time-average volume-average temperatures for Capsules 4-6. 


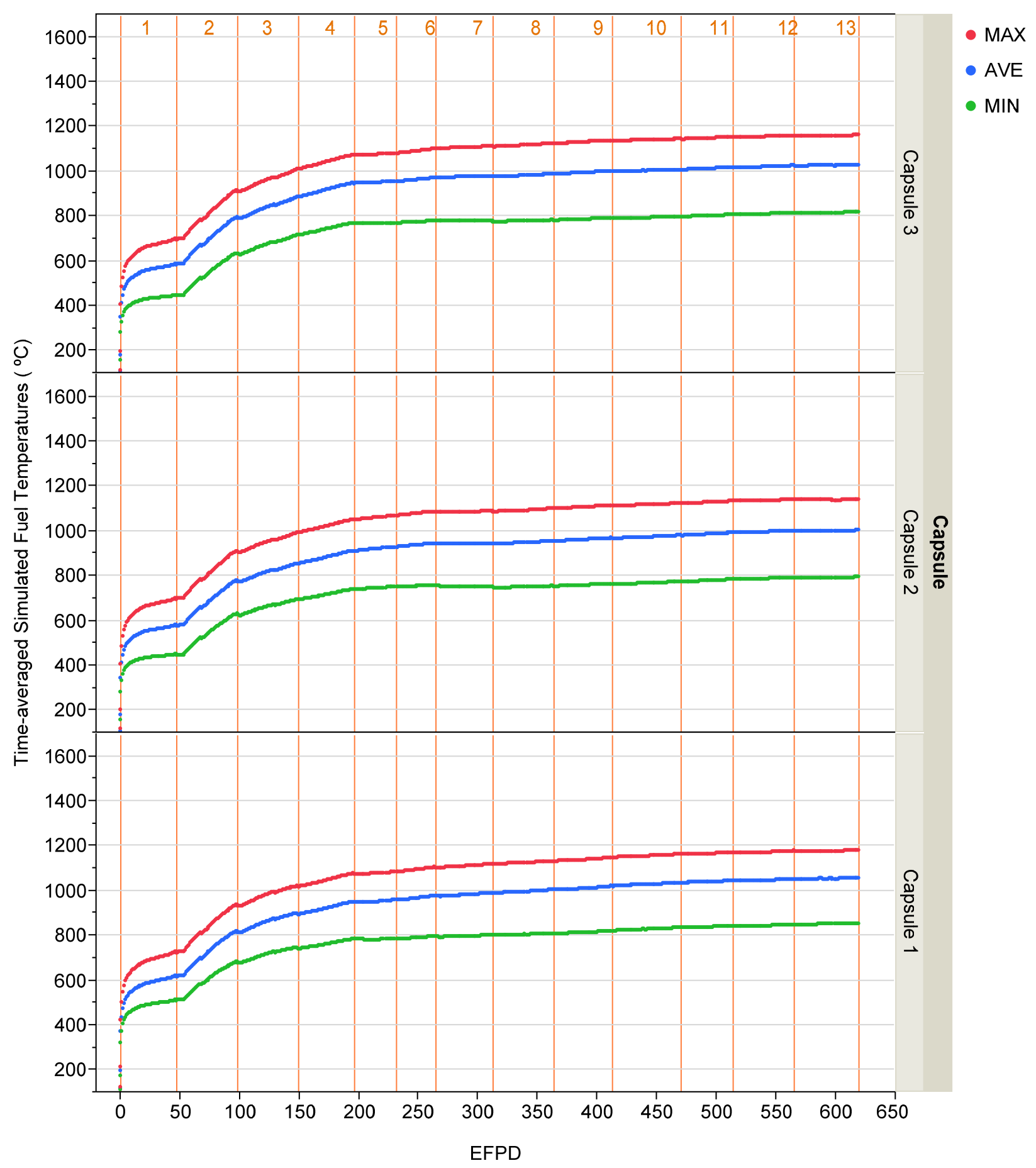

Figure 18. Calculated time-average minimum, time-average maximum, and time-average volume-average temperatures for Capsules 1-3. 
Table 6 and Table 7 show time-averaged minimum, time-averaged volume-averaged, and time-averaged peak temperatures on a compact basis for all 72 compacts in the AGR-1 test.

Time-averaged volume-averaged temperatures on a capsule basis at the end of irradiation ranged from $1002^{\circ} \mathrm{C}$ in Capsule 2 to $1087^{\circ} \mathrm{C}$ in Capsule 6. In the AGR-1 Irradiation Test Specification (Maki 2004), three goals of the experiment were specified related to the thermal conditions of the fuel during irradiation. These are listed below with comments on the performance of the experiment with respect to each:

- The instantaneous peak temperature for each capsule shall be $\leq 1400^{\circ} \mathrm{C}$.

As can be seen in Figure 15 and Figure 16, this temperature was exceeded at some point in time by each capsule, except Capsule 2. The highest instantaneous peak temperature occurred in Capsule 5 at the end of the last irradiation cycle.

- The time-average peak temperature for each capsule shall be $\leq 1250^{\circ} \mathrm{C}$.

This constraint was met by all capsules. The lowest time-average peak temperature was $1104^{\circ} \mathrm{C}$ in Capsule 2 and the highest time-average peak temperature was $1169^{\circ} \mathrm{C}$ in Capsule 4 .

- The time-average volume-average (TAVA) temperature for each capsule shall be $1150+30 /-75{ }^{\circ} \mathrm{C}$.

Time-averaged volume-averaged temperatures on a capsule basis at the end of irradiation ranged from $1002^{\circ} \mathrm{C}$ in Capsule 2 to $1087^{\circ} \mathrm{C}$ in Capsule 6. On a capsule-averaged basis, only Capsule 6 met this criterion.

Table 6. Compact temperature data for Capsules 6-4 at end of irradiation.

\begin{tabular}{|c|c|c|c|c|c|}
\hline Capsule & Stack & Compact & $\begin{array}{c}\text { Time-Average } \\
\text { Minimum Temp. } \\
\left({ }^{\circ} \mathrm{C}\right) \\
\end{array}$ & $\begin{array}{c}\text { Time-Average } \\
\text { Volume-Average Temp. } \\
\left({ }^{\circ} \mathrm{C}\right)\end{array}$ & $\begin{array}{c}\text { Time-Average } \\
\text { Peak Temp. } \\
\left({ }^{\circ} \mathrm{C}\right) \\
\end{array}$ \\
\hline \multirow{12}{*}{$\begin{array}{c}6 \\
\text { (top) }\end{array}$} & \multirow{4}{*}{1} & 4 & 908 & 1041 & 1130 \\
\hline & & 3 & 1007 & 1106 & 1174 \\
\hline & & 2 & 1039 & 1135 & 1197 \\
\hline & & 1 & 969 & 1111 & 1194 \\
\hline & \multirow{4}{*}{2} & 4 & 885 & 1008 & 1100 \\
\hline & & 3 & 974 & 1070 & 1144 \\
\hline & & 2 & 1008 & 1101 & 1167 \\
\hline & & 1 & 948 & 1079 & 1164 \\
\hline & \multirow{4}{*}{3} & 4 & 912 & 1041 & 1130 \\
\hline & & 3 & 1011 & 1106 & 1175 \\
\hline & & 2 & 1044 & 1136 & 1197 \\
\hline & & 1 & 975 & 1112 & 1195 \\
\hline \multicolumn{3}{|c|}{ All Capsule 6 compacts } & 885 & 1087 & 1197 \\
\hline
\end{tabular}


Table 6. (continued)

\begin{tabular}{|c|c|c|c|c|c|}
\hline Capsule & Stack & Compact & $\begin{array}{c}\text { Time-Average } \\
\text { Minimum Temp. } \\
\left({ }^{\circ} \mathrm{C}\right) \\
\end{array}$ & $\begin{array}{c}\text { Time-Average } \\
\text { Volume-Average Temp. } \\
\left({ }^{\circ} \mathrm{C}\right) \\
\end{array}$ & $\begin{array}{c}\text { Time-Average } \\
\text { Peak Temp. } \\
\left({ }^{\circ} \mathrm{C}\right) \\
\end{array}$ \\
\hline \multirow{12}{*}{5} & \multirow{4}{*}{1} & 4 & 843 & 998 & 1100 \\
\hline & & 3 & 908 & 1040 & 1122 \\
\hline & & 2 & 925 & 1057 & 1140 \\
\hline & & 1 & 879 & 1041 & 1143 \\
\hline & \multirow{4}{*}{2} & 4 & 818 & 962 & 1070 \\
\hline & & 3 & 876 & 1002 & 1092 \\
\hline & & 2 & 894 & 1020 & 1111 \\
\hline & & 1 & 856 & 1008 & 1115 \\
\hline & \multirow{4}{*}{3} & 4 & 850 & 1000 & 1102 \\
\hline & & 3 & 917 & 1042 & 1123 \\
\hline & & 2 & 933 & 1059 & 1141 \\
\hline & & 1 & 886 & 1042 & 1144 \\
\hline \multicolumn{3}{|c|}{ All Capsule 5 compacts } & 818 & 1023 & 1144 \\
\hline \multirow{12}{*}{4} & \multirow{4}{*}{1} & 4 & 888 & 1057 & 1166 \\
\hline & & 3 & 950 & 1092 & 1177 \\
\hline & & 2 & 955 & 1098 & 1185 \\
\hline & & 1 & 900 & 1072 & 1182 \\
\hline & \multirow{4}{*}{2} & 4 & 866 & 1024 & 1139 \\
\hline & & 3 & 921 & 1057 & 1150 \\
\hline & & 2 & 929 & 1065 & 1159 \\
\hline & & 1 & 881 & 1042 & 1156 \\
\hline & \multirow{4}{*}{3} & 4 & 896 & 1059 & 1168 \\
\hline & & 3 & 959 & 1094 & 1179 \\
\hline & & 2 & 965 & 1101 & 1187 \\
\hline & & 1 & 909 & 1075 & 1184 \\
\hline \multicolumn{3}{|c|}{ All Capsule 4 compacts } & 866 & 1070 & 1187 \\
\hline
\end{tabular}


Table 7. Compact temperature data for Capsules 3-1 at end of irradiation.

\begin{tabular}{|c|c|c|c|c|c|}
\hline Capsule & Stack & Compact & $\begin{array}{c}\text { Time-Average Minimum } \\
\text { Temp. } \\
\left({ }^{\circ} \mathrm{C}\right) \\
\end{array}$ & $\begin{array}{c}\text { Time-Average } \\
\text { Volume-Average Temp. } \\
\left({ }^{\circ} \mathrm{C}\right)\end{array}$ & $\begin{array}{c}\text { Time-Average Peak } \\
\text { Temp. } \\
\left({ }^{\circ} \mathrm{C}\right) \\
\end{array}$ \\
\hline \multirow{12}{*}{3} & \multirow{4}{*}{1} & 4 & 851 & 1025 & 1140 \\
\hline & & 3 & 897 & 1051 & 1145 \\
\hline & & 2 & 897 & 1051 & 1143 \\
\hline & & 1 & 847 & 1023 & 1137 \\
\hline & \multirow{4}{*}{2} & 4 & 833 & 997 & 1116 \\
\hline & & 3 & 873 & 1020 & 1121 \\
\hline & & 2 & 873 & 1019 & 1119 \\
\hline & & 1 & 828 & 993 & 1113 \\
\hline & \multirow{4}{*}{3} & 4 & 860 & 1028 & 1142 \\
\hline & & 3 & 907 & 1054 & 1147 \\
\hline & & 2 & 908 & 1053 & 1145 \\
\hline & & 1 & 855 & 1025 & 1139 \\
\hline \multicolumn{3}{|c|}{ All Capsule 3 compacts } & 828 & 1028 & 1147 \\
\hline \multirow{12}{*}{2} & \multirow{4}{*}{1} & 4 & 845 & 1013 & 1122 \\
\hline & & 3 & 879 & 1029 & 1122 \\
\hline & & 2 & 872 & 1020 & 1108 \\
\hline & & 1 & 820 & 985 & 1095 \\
\hline & \multirow{4}{*}{2} & 4 & 826 & 984 & 1098 \\
\hline & & 3 & 855 & 998 & 1097 \\
\hline & & 2 & 847 & 987 & 1082 \\
\hline & & 1 & 800 & 955 & 1069 \\
\hline & \multirow{4}{*}{3} & 4 & 854 & 1015 & 1124 \\
\hline & & 3 & 890 & 1032 & 1124 \\
\hline & & 2 & 882 & 1022 & 1110 \\
\hline & & 1 & 828 & 988 & 1097 \\
\hline \multicolumn{3}{|c|}{ All Capsule 2 compacts } & 800 & 1002 & 1124 \\
\hline \multirow{12}{*}{$\begin{array}{c}1 \\
\text { (bottom) }\end{array}$} & \multirow{4}{*}{1} & 4 & 921 & 1071 & 1164 \\
\hline & & 3 & 977 & 1092 & 1166 \\
\hline & & 2 & 957 & 1071 & 1146 \\
\hline & & 1 & 873 & 1017 & 1114 \\
\hline & \multirow{4}{*}{2} & 4 & 905 & 1045 & 1140 \\
\hline & & 3 & 954 & 1064 & 1142 \\
\hline & & 2 & 932 & 1042 & 1122 \\
\hline & & 1 & 854 & 989 & 1089 \\
\hline & \multirow{4}{*}{3} & 4 & 927 & 1072 & 1166 \\
\hline & & 3 & 984 & 1094 & 1167 \\
\hline & & 2 & 964 & 1072 & 1147 \\
\hline & & 1 & 878 & 1018 & 1115 \\
\hline \multicolumn{3}{|c|}{ All Capsule 1 compacts } & 854 & 1054 & 1167 \\
\hline
\end{tabular}


Figure 19 and Figure 20 compare the time-average fuel temperature distributions of AGR-1 capsules with those of the General Atomics (GA) Steam Cycle - Modular Helium Reactor (SC-MHR) demonstration plant conceptual design. The GA SC-MHR is a 350-MWt, high temperature, gas-cooled, graphite-moderated reactor utilizing a prismatic graphite block fuel form selected by $\mathrm{GA}$ for the NGNP project. It operates with an outlet helium temperature of $725^{\circ} \mathrm{C}$ and it is designed to maintain the maximum time-averaged fuel temperature at less than $1250^{\circ} \mathrm{C}$ (GA 2010). Figure 19 shows the volume distribution of fuel temperature averaged over the residence time for two SC-MHR equilibrium cycles. Only a small fraction of the SC-MHR core $(<5 \%)$ is expected to experience time-averaged temperatures above $1000^{\circ} \mathrm{C}$, and its fuel temperature distribution is well bounded by AGR-1, as at least $50 \%$ of all AGR-1 fuel experienced temperatures higher than $1000^{\circ} \mathrm{C}$. Figure 20 provides a close-up of the AGR-1 data.

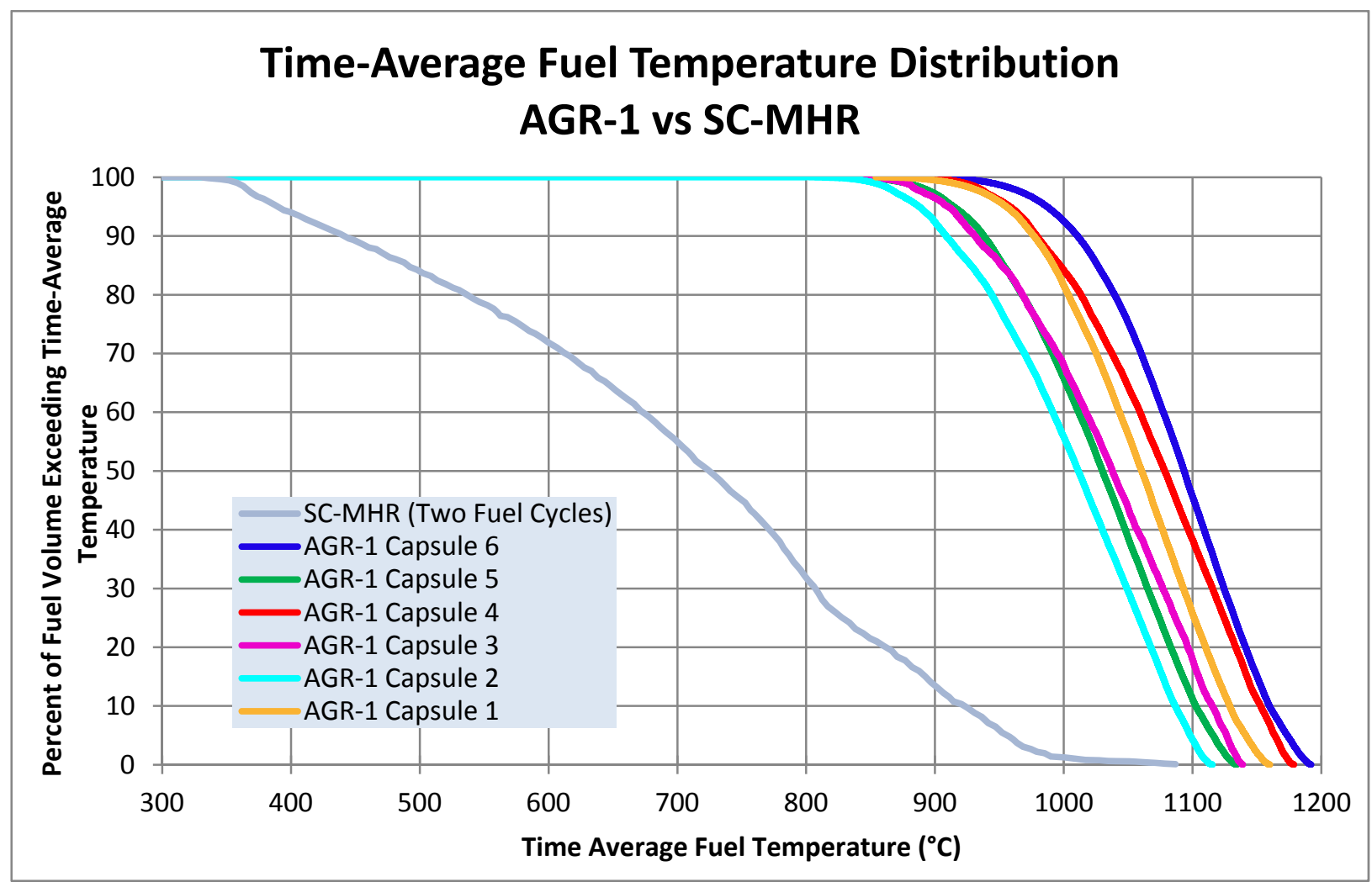

Figure 19. Time-average fuel temperature distribution for AGR-1 and GA SC-MHR. 


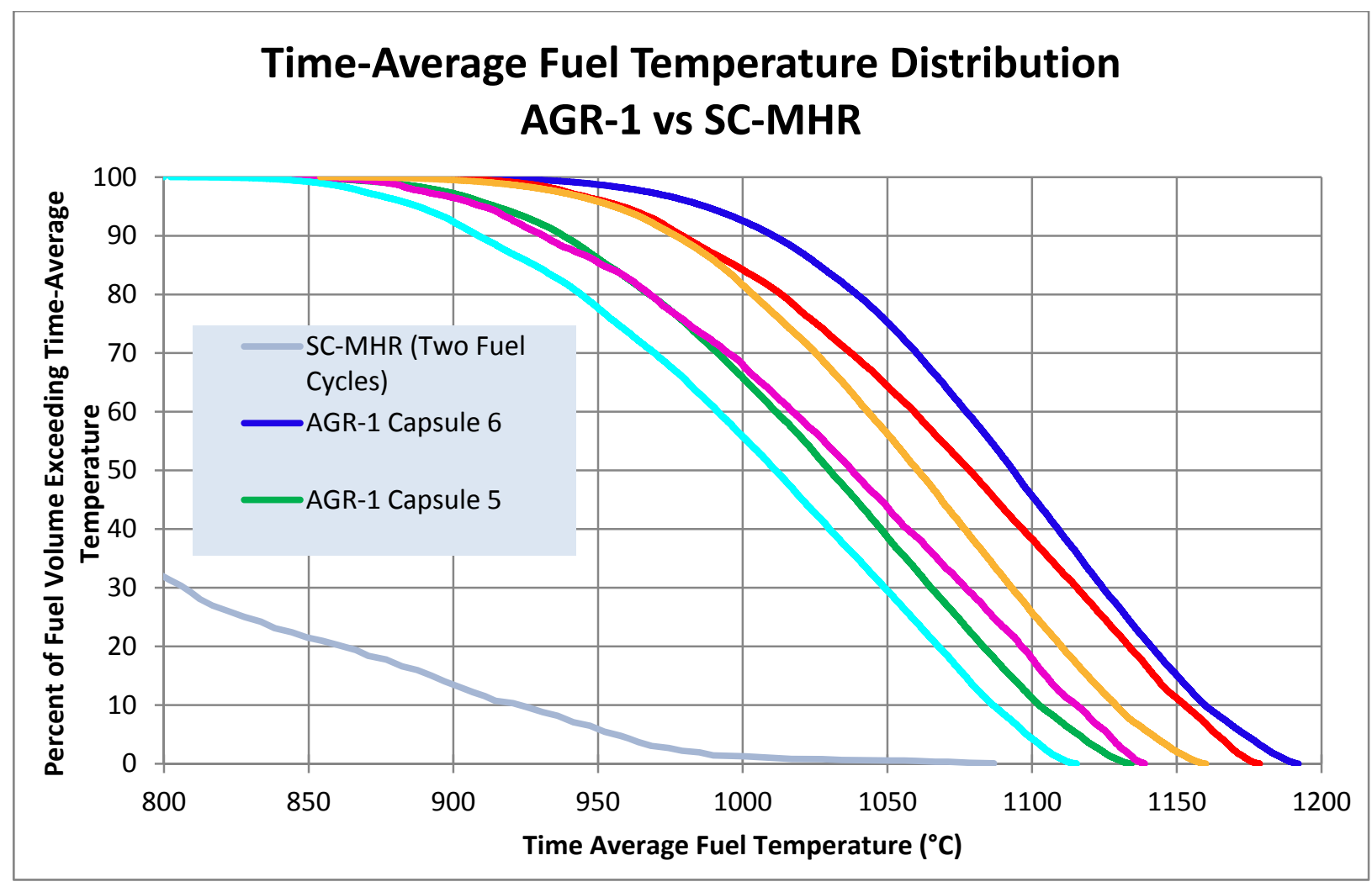

Figure 20. Time-average fuel temperature distribution for AGR-1 and GA SC-MHR (close-up).

In addition, Figure 21 displays a 3-D scatter plot of the irradiation characteristics of the 72 AGR-1 compacts (black dots), along with their 2-D projections on the "Burnup - Fast Fluence" (blue dots), "Burnup - TAVA Temperature" (green dots), and "Fast Fluence - TAVA Temperature" (red dots) plans.

Figure 22 and Figure 23 show the distribution of burnup and TAVA temperature (Figure 22) and the distribution of fast fluence and TAVA temperature (Figure 23) for the 72 AGR-1 compacts. The plots show that AGR-1 covers a broad range of burnup, fast fluence and irradiation temperatures in an effort to bound expected reactor irradiation characteristics. 


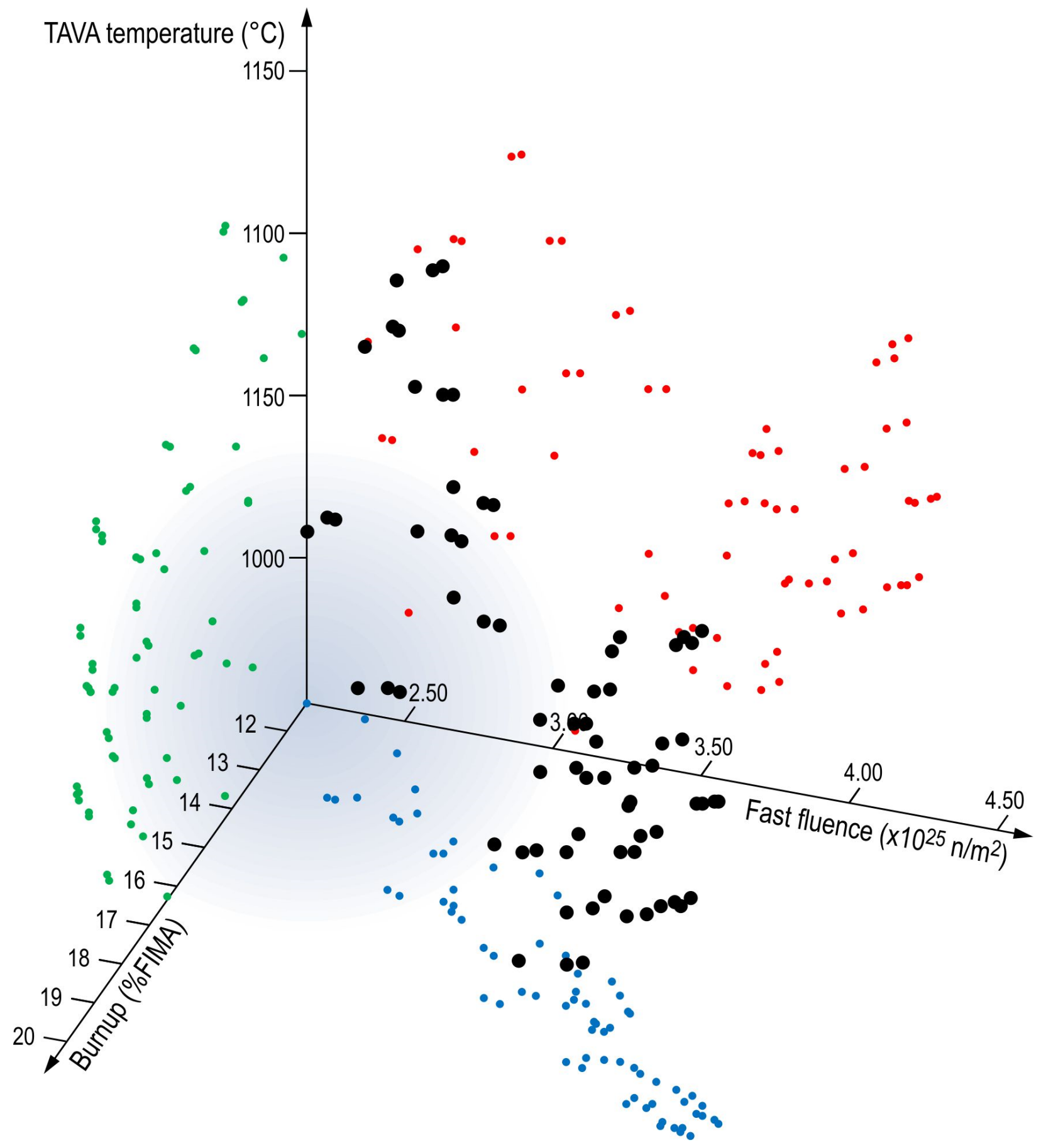

Figure 21. 3-D scatter plot of the irradiation characteristics of the 72 AGR-1 compacts. 


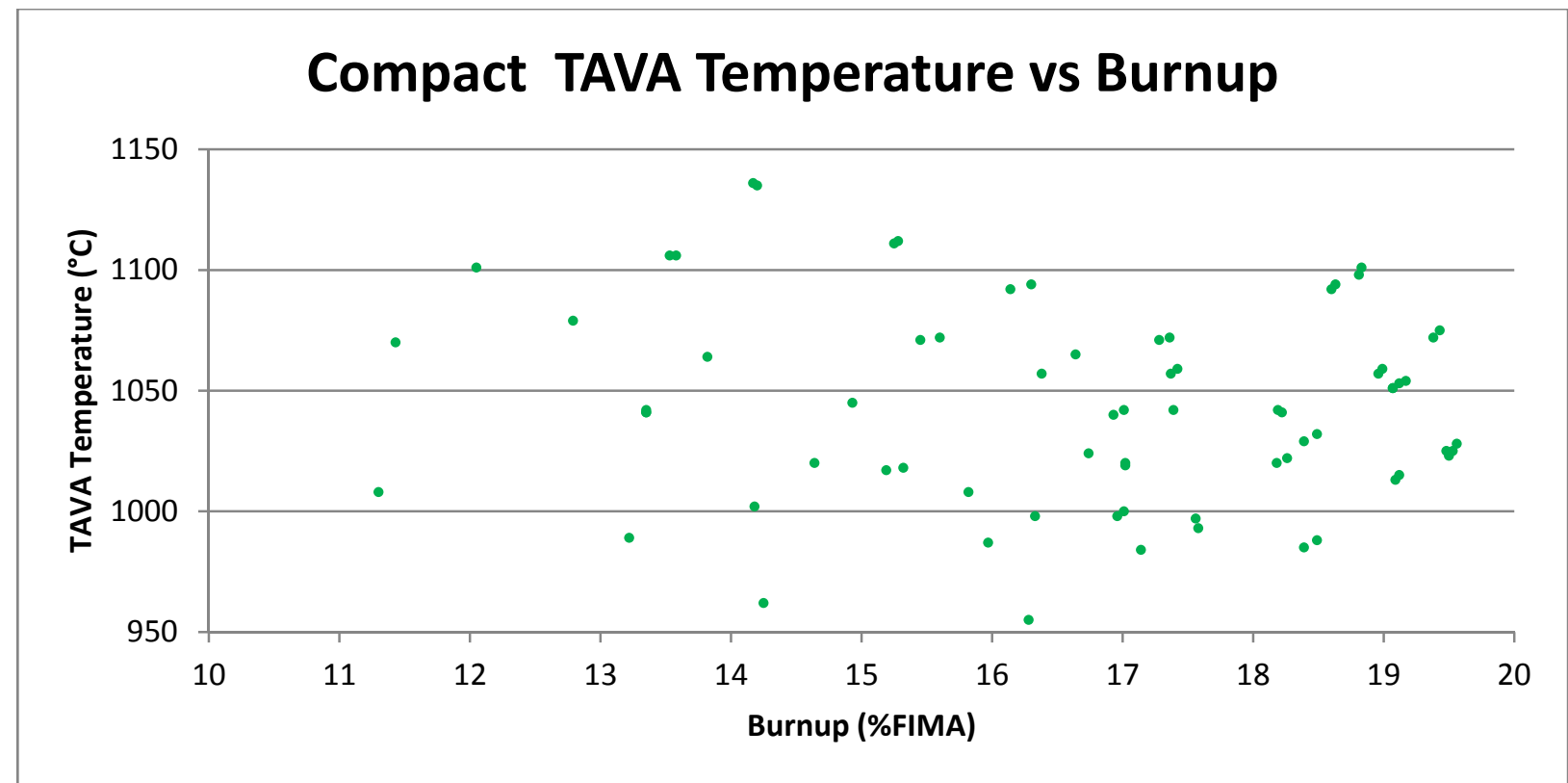

Figure 22. Time-average volume-average temperature $\left({ }^{\circ} \mathrm{C}\right)$ vs. Burnup (\%FIMA) for AGR-1 compacts.

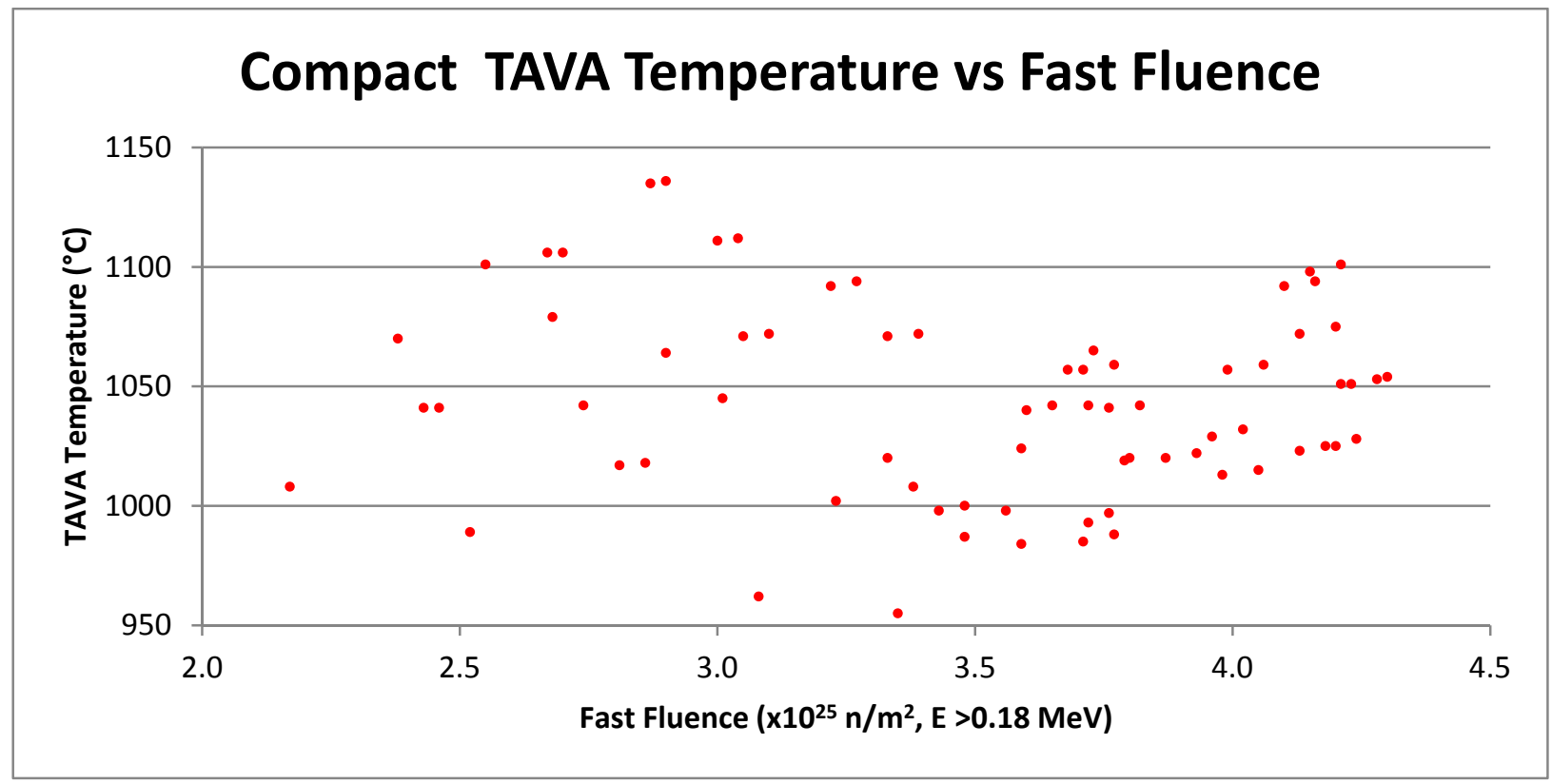

Figure 23. Time-average volume-average temperature $\left({ }^{\circ} \mathrm{C}\right)$ vs. Fast neutron fluence $(\mathrm{E}>0.18 \mathrm{MeV})$ for AGR-1 compacts. 


\subsection{Thermocouple Performance}

AGR-1 temperature measurements were performed by TCs terminating within the graphite sample holders of each capsule. These measurements support temperature control of the experiment where designated control TCs provide feedback to the automated sweep gas control system, which adjusts gas blends to maintain reference temperatures. TC measurements are also used to support thermal analyses of the test train, which ultimately determines fuel temperatures.

When a control TC failed during the irradiation, a previously-selected back-up TC within the same capsule was used as the control TC and the reference control temperature reset based on thermal analysis calculations. When all TCs failed within a capsule, results from physics and thermal analyses, and operating history of adjacent capsules were used to manually set the gas blends of the affected capsule.

Figure 24 gives a diagram of the locations and types of the various TCs in each capsule. Of the 19 planned TCs, three failed during fabrication and seven more failed during operation. The two failure mechanisms for the TCs were the formation of virtual junctions and open circuit failures where the signal ceases altogether. Because the capsules are numbered from 6 to 1 starting from the top of the test train, the TCs in the lower-numbered capsules tend to form virtual junctions with the higher numbered capsules. This is why the failed TCs are grouped at the bottom of the test train in Capsules 1-4. Virtual junctions are detected by perturbing the temperature in a single capsule using gas flow, then observing the TC readings from capsules below this one to see if they respond. If a capsule $\mathrm{TC}$ responds to temperature changes in a capsule above it, it is likely that a virtual junction has formed and the TC can be considered failed.

Table 8 shows the various TC types, locations, insertion depths, and their failure status (failure date and cycle). TC-2 in Capsule 5 was damaged during fabrication of the test train and never was operational. As a result of the neon injection tests, it was concluded that TC-1 in Capsule 1 had formed a virtual junction near the location of Capsule 6, and was thus considered failed. TC-1 in Capsule 2 was also declared failed during fabrication. By the end of the second cycle, two more had failed: TC-2 in Capsule 2 and TC-2 in Capsule 3. By the end of the third cycle, another two TCs were declared failed: TC-2 in Capsule 1 and TC-3 in Capsule 2. After the fourth cycle, TC-3 in Capsule 3 was declared failed. TC-1 in Capsule 3 was declared failed after the end of the sixth cycle and TC-3 in Capsule 4 was the last to fail after the ninth irradiation cycle. By the end of irradiation, all TCs in Capsules 1, 2, and 3, plus TC-3 in Capsule 4 had been declared failed. 

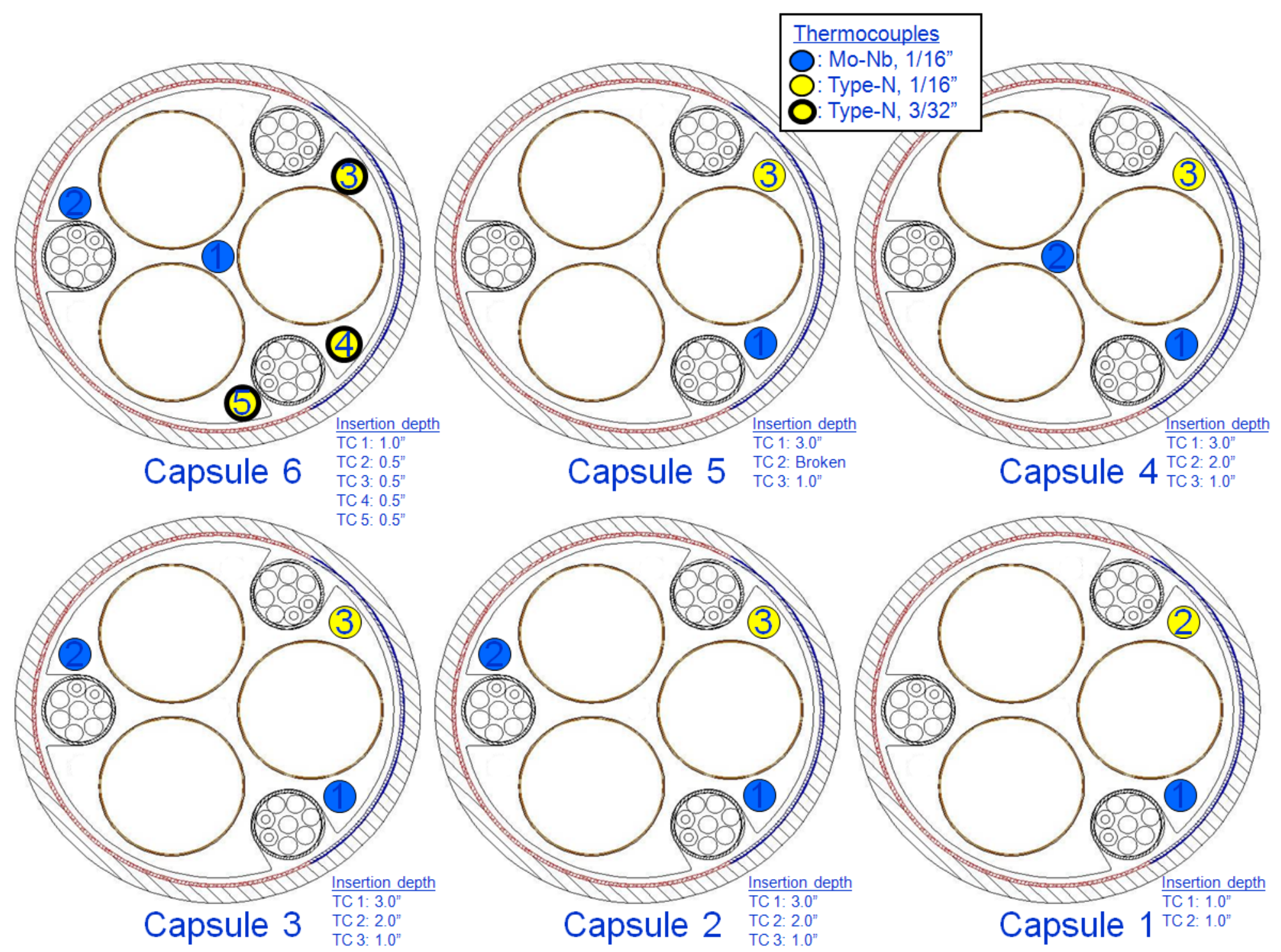

Figure 24. Cutaway view of each capsule showing type and position of TCs. 
Table 8. TC types, locations, and conditions in AGR-1 test train.

\begin{tabular}{|c|c|c|c|c|c|c|c|c|}
\hline Capsule & TC & Final Function & Azimuthal Orientation $^{\mathrm{a}}$ & Depth $^{b}$ & TC type ${ }^{\mathrm{c}}$ & Sheath/Insulation & Sleeve & Condition $^{\mathrm{d}}$ \\
\hline \multirow[t]{5}{*}{6} & 1 & & $\mathrm{CL}$ & 2.54 & $\mathrm{Mo}-\mathrm{Nb}$ & $\mathrm{Nb}+0.1 \% \mathrm{Zr} / \mathrm{HfO}_{2}$ & none & \\
\hline & 2 & & $293^{\circ}$ & 1.27 & $\mathrm{Mo}-\mathrm{Nb}$ & $\mathrm{Nb}+0.1 \% \mathrm{Zr} / \mathrm{HfO}_{2}$ & none & \\
\hline & 3 & control & $53^{\circ}$ & 1.27 & Type N (2.38) & $\mathrm{Mo} / \mathrm{Al}_{2} \mathrm{O}_{3}$ & none & \\
\hline & 4 & & $127^{\circ}$ & 1.27 & Type N (2.38) & $\mathrm{Mo} / \mathrm{Al}_{2} \mathrm{O}_{3}$ & none & \\
\hline & 5 & & $173^{\circ}$ & 1.27 & Type N (2.38) & $\mathrm{Mo} / \mathrm{Al}_{2} \mathrm{O}_{3}$ & none & \\
\hline \multirow[t]{3}{*}{5} & 1 & & $127^{\circ}$ & 7.62 & $\mathrm{Mo}-\mathrm{Nb}$ & $\mathrm{Nb}+0.1 \% \mathrm{Zr} / \mathrm{HfO}_{2}$ & none & \\
\hline & 2 & - & - & - & - & - & - & Failed $11 / 30 / 06$ during fabrication \\
\hline & 3 & control & $53^{\circ}$ & 2.54 & Type N & Inconel $/ \mathrm{MgO}$ & $\mathrm{Nb}$ & \\
\hline \multirow[t]{3}{*}{4} & 1 & control & $127^{\circ}$ & 7.62 & $\mathrm{Mo}-\mathrm{Nb}$ & $\mathrm{Nb}+0.1 \% \mathrm{Zr} / \mathrm{HfO}_{2}$ & none & \\
\hline & 2 & & $\mathrm{CL}$ & 5.08 & $\mathrm{Mo}-\mathrm{Nb}$ & $\mathrm{Nb}+0.1 \% \mathrm{Zr} / \mathrm{HfO}_{2}$ & none & \\
\hline & 3 & & $53^{\circ}$ & 2.54 & Type N & Inconel/MgO & $\mathrm{Nb}$ & $\begin{array}{l}\text { Failed 10/16/08 after end of } \\
\text { 9th cycle }\end{array}$ \\
\hline \multirow[t]{3}{*}{3} & 1 & & $127^{\circ}$ & 7.62 & $\mathrm{Mo}-\mathrm{Nb}$ & $\mathrm{Nb}+0.1 \% \mathrm{Zr} / \mathrm{HfO}_{2}$ & none & Failed 3/9/08 after end of 6th cycle \\
\hline & 2 & & $293^{\circ}$ & 5.08 & $\mathrm{Mo}-\mathrm{Nb}$ & $\mathrm{Nb}+0.1 \% \mathrm{Zr} / \mathrm{HfO}_{2}$ & none & Failed mid-2nd cycle \\
\hline & 3 & & $53^{\circ}$ & 2.54 & Type N & Inconel/MgO & $\mathrm{Nb}$ & Failed $12 / 2 / 07$ after end of 4 th cycle \\
\hline \multirow[t]{3}{*}{2} & 1 & & $127^{\circ}$ & 7.62 & $\mathrm{Mo}-\mathrm{Nb}$ & $\mathrm{Nb}+0.1 \% \mathrm{Zr} / \mathrm{HfO}_{2}$ & none & Failed 11/30/06 during fabrication \\
\hline & 2 & & $293^{\circ}$ & 5.08 & $\mathrm{Mo}-\mathrm{Nb}$ & $\mathrm{Nb}+0.1 \% \mathrm{Zr} / \mathrm{HfO}_{2}$ & none & $\begin{array}{l}\text { Failed } 4 / 22 / 07 \text { after end of } \\
\text { 2nd cycle }\end{array}$ \\
\hline & 3 & & $53^{\circ}$ & 2.54 & Type $\mathrm{N}$ & Inconel $/ \mathrm{MgO}$ & $\mathrm{Nb}$ & Failed 9/30/07 after end of 3rd cycle \\
\hline \multirow[t]{2}{*}{1} & 1 & & $127^{\circ}$ & 2.54 & $\mathrm{Mo}-\mathrm{Nb}$ & $\mathrm{Nb}+0.1 \% \mathrm{Zr} / \mathrm{HfO}_{2}$ & none & Failed $11 / 30 / 06$ during fabrication \\
\hline & 2 & & $53^{\circ}$ & 2.54 & Type N & Inconel/MgO & $\mathrm{Nb}$ & Failed mid-3rd cycle \\
\hline
\end{tabular}

a. Azimuthal orientation given in degrees rotated clockwise as viewed from above (as in Figure 3) with North being $0^{\circ}$. Approximate cardinal directions given as well. CL indicates that the thermocouple was installed in the central location of the capsule.

b. Depth (in $\mathrm{cm}$ ) of insertion into graphite sleeve.

c. All TCs are $1.59 \mathrm{~mm}(1 / 16 \mathrm{in}$.) in diameter unless noted as $2.38 \mathrm{~mm}(3 / 32 \mathrm{in}$.) in diameter.

d. No entry here implies that the TC was considered functional at the end of the irradiation. 
TC drift was monitored by analysis (which uses as-run sweep gas mixes and heat generation rates from physics analyses) where thermal model results are compared to TC readings. Figure 25 shows the measured temperatures versus EFPD for the TCs while they were considered operational. Data are not shown for failed TCs after they were declared failed. Figure 26 shows differences between measured and calculated TC temperatures. A downward drift of measured TC temperatures relative to calculated TC temperatures over irradiation time can be observed inTC-2 (red dots in Figure 26) in Capsules 2, 3, and 4. Readings from other TCs are consistent with their simulation results.

TC measurements provide feedback to the automated sweep gas control system and they also support thermal analyses. As such, they require adequate qualification. Conversely, results of the thermal simulations can be used in combination with the statistical analysis methods to further improve qualification of measured TC data (Pham and Einerson 2012). The combined analysis of measured and simulation data can also generate insights about simulation model uncertainty that can be useful for model improvement. Uncertainty quantification of both experimental measurements on one side, and model and numerical solutions on the other side, requires a systematic approach as described in Pham and Einerson's report (Pham and Einerson 2012). 


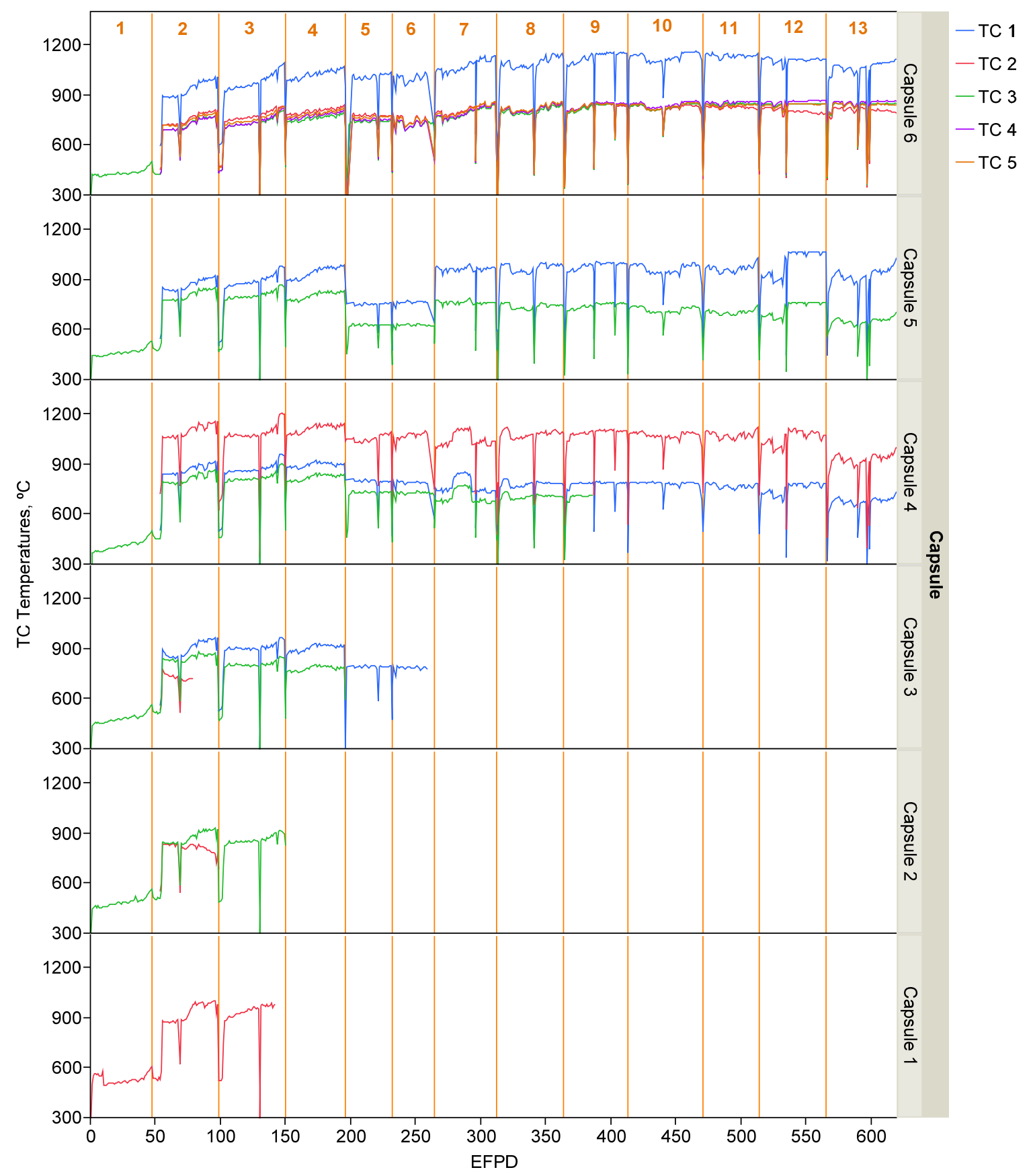

Figure 25. Measured TC temperatures versus EFPD. 


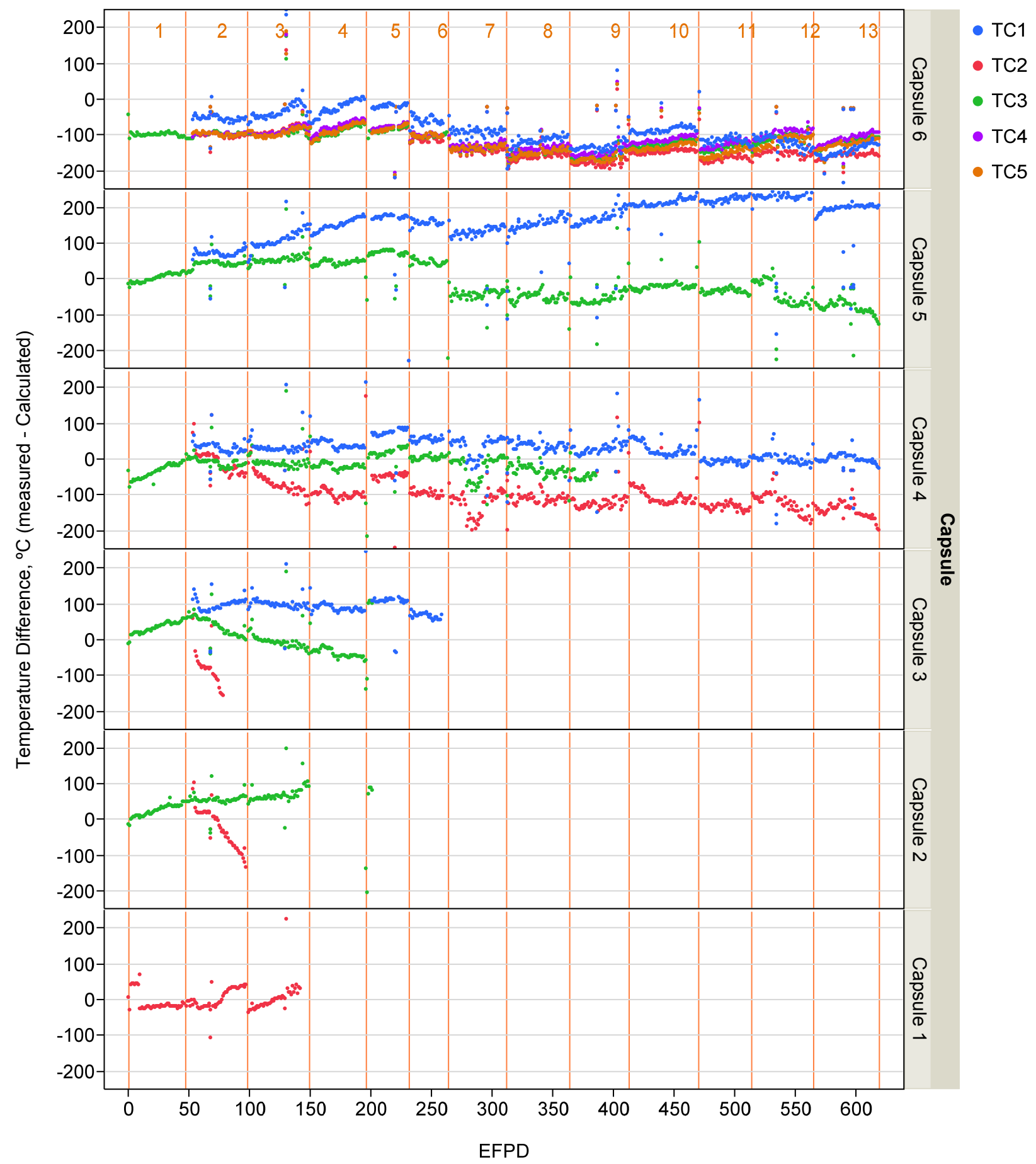

Figure 26. Difference between measured and calculated TC temperatures versus EFPD. 


\subsection{Uncertainty Quantification of Calculated Temperatures}

Calculated fuel temperatures serve crucial roles in achieving AGR experimental program objectives, such as the validation of the fission product transport and fuel performance simulation models. They consequently require accurate determination of the model temperature uncertainties (Pham et al. 2012).

Early analysis of thermocouple data indicated that they performed reliably during the beginning cycles of irradiation. Therefore, the thermal models were calibrated to match the TC readings during this portion of the irradiation. Continued monitoring and analysis of the difference between measured and calculated temperatures for operational TCs show a random pattern around and near zero for at least one TC in every capsule (except Capsule 6) as shown on Figure 26. This suggests negligible model bias; therefore, the uncertainty quantification completed for AGR-1 relies solely on model input parameters.

To quantify the uncertainty of AGR-1 calculated temperatures, the uncertainty assessment identified and analyzed ABAQUS model parameters of potential importance to the AGR-1 predicted fuel temperatures. Expert judgments were used as a basis to specify the uncertainty range for a set of select parameters (see Table 9) including those with high sensitivity and those with large uncertainty since the effect of a parameter uncertainty on the model prediction variation is a product of input uncertainty and sensitivity coefficient. Propagation of model parameter uncertainty was then used to quantify the overall uncertainty of AGR-1 calculated temperatures. For Capsule 6, a bias is present but is largely compensated for by the $10 \%$ bias identified as a portion of the fuel heat rate uncertainty.

Table 9. Uncertainty information of the most significant parameters of the AGR-1 thermal model.

\begin{tabular}{|l|c|c|l|}
\hline \multicolumn{1}{|c|}{ Input Parameter } & Random (\%) & Bias (\%) & \multicolumn{1}{c|}{ Comments } \\
\hline Control gas gap width & $3.5-10.7$ & 0 & $\begin{array}{l}\text { Random: } \sim \text { 1 mil fabricated tolerance for initial gas } \\
\text { gap width. The gas gap uncertainty is time } \\
\text { dependent because of shrinking and swelling. The } \\
\text { graphite shrinkage and swelling are proportional to } \\
\text { the reaction rate in the graphite leading to the } \\
\text { physics-based linear gas gap model. The model is } \\
\text { justified by significant correlation between R/B and } \\
\text { fuel temperature profiles. }\end{array}$ \\
\hline Neon fraction & 3.0 & 0 & \begin{tabular}{l} 
Random: $\sim$ sccm flow rate tolerance. \\
\hline Fuel heat rate
\end{tabular} \\
\hline 2.5 & +10 for & $\begin{array}{l}\text { Random: good fit between predicted and PIE fuel } \\
\text { burnup (less than 10\%) lead to small heat } \\
\text { uncertainty. } \\
\text { Bias: ATR axial depletion effects not accounted for } \\
\text { in structure (absorbing) above the core. These affect } \\
\text { mostly Capsule } 6 .\end{array}$ \\
\hline Graphite conductivity & 15 & 0 & $\begin{array}{l}\text { Additional conductivity data for the test graphite } \\
\text { allows a lower uncertainty estimate for graphite } \\
\text { than for fuel. }\end{array}$ \\
\hline Fuel conductivity & 20 & 0 & $\begin{array}{l}\text { Fuel conductivity values used in the model are } \\
\text { based on historic German data corrected for packing } \\
\text { fraction and matrix density. }\end{array}$ \\
\hline
\end{tabular}


The overall uncertainty in the calculated temperatures for AGR-1 ranged from 2.0 to $6.5 \%$ ( 40 to $60^{\circ} \mathrm{C}$ at $1 \sigma ; 100$ to $120^{\circ} \mathrm{C}$ at $2 \sigma$ ), depending on irradiation time (thermal conditions), capsule, and the temperature parameter being predicted (peak fuel temperature, volume-average fuel temperature, or TC). Table 10 presents temperatures and their relative and absolute standard deviations for time-average volume-average and time-average peak fuel temperatures at the end of AGR-1 for six capsules.

- In some cases the uncertainty is dominated by uncertainty in fuel heat rate (Capsule 6).

- For peripheral TCs, the uncertainty is driven by the increasing uncertainty of the control gas gap distance, especially for the middle capsules at the end of irradiation. The increase of gap uncertainty has more effect on the temperature uncertainty of peripheral TCs than on the uncertainty of the center TC.

- The fuel temperature uncertainty is dominated by uncertainties in fuel and graphite thermal conductivity. The center TC uncertainty is dominated by uncertainties in graphite thermal conductivity.

Table 10. Temperatures and uncertainty for time-average fuel temperatures at the end of AGR-1.

\begin{tabular}{|l|c|c|c|c|c|c|}
\hline \multirow{2}{*}{ Capsule } & \multicolumn{3}{|c|}{ Time-Average Volume-Average Fuel } & \multicolumn{3}{c|}{ Time-Average Peak Fuel } \\
\cline { 2 - 7 } & $\mathrm{T},{ }^{\circ} \mathrm{C}$ & $\sigma_{\mathrm{T}}, \%$ & $\sigma_{\mathrm{T}},{ }^{\circ} \mathrm{C}$ & $\mathrm{T},{ }^{\circ} \mathrm{C}$ & $\sigma_{\mathrm{T}}, \%$ & $\sigma_{\mathrm{T}},{ }^{\circ} \mathrm{C}$ \\
\hline Capsule 6 & 1088 & 5.014 & 55 & 1204 & 5.012 & 60 \\
\hline Capsule 5 & 1023 & 3.700 & 38 & 1157 & 4.301 & 50 \\
\hline Capsule 4 & 1070 & 3.743 & 40 & 1202 & 4.327 & 52 \\
\hline Capsule 3 & 1029 & 3.777 & 39 & 1162 & 4.330 & 50 \\
\hline Capsule 2 & 1003 & 3.830 & 38 & 1141 & 4.379 & 50 \\
\hline Capsule 1 & 1055 & 3.165 & 33 & 1178 & 3.776 & 45 \\
\hline
\end{tabular}

The daily temperature and one standard deviation of fuel compact temperatures in Capsule 4 are presented in Figure 27 (instantaneous), and Figure 28 (time-average) as illustrations.

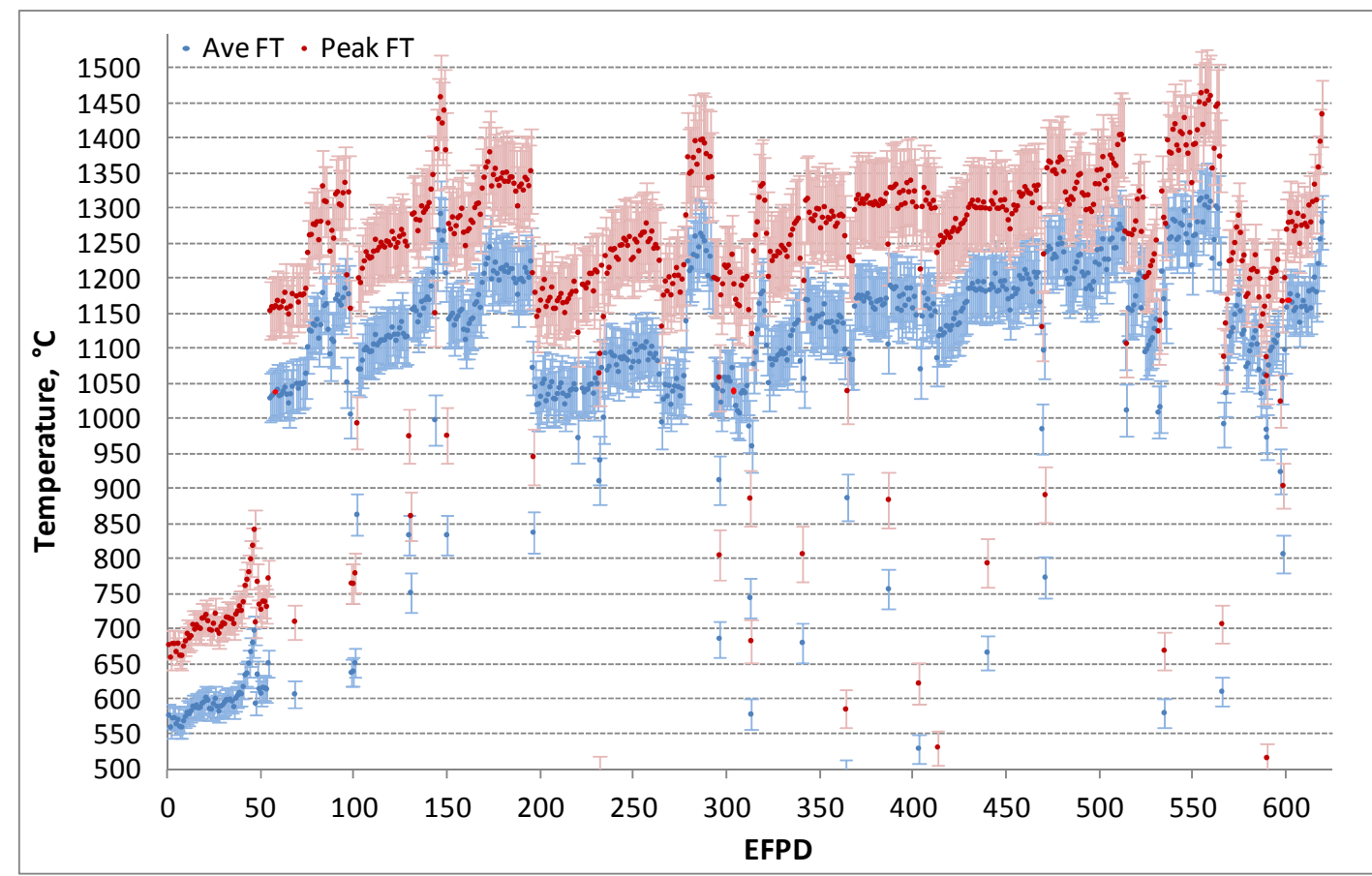

Figure 27. Instantaneous peak and average fuel temperature and associated uncertainty for Capsule 4. 


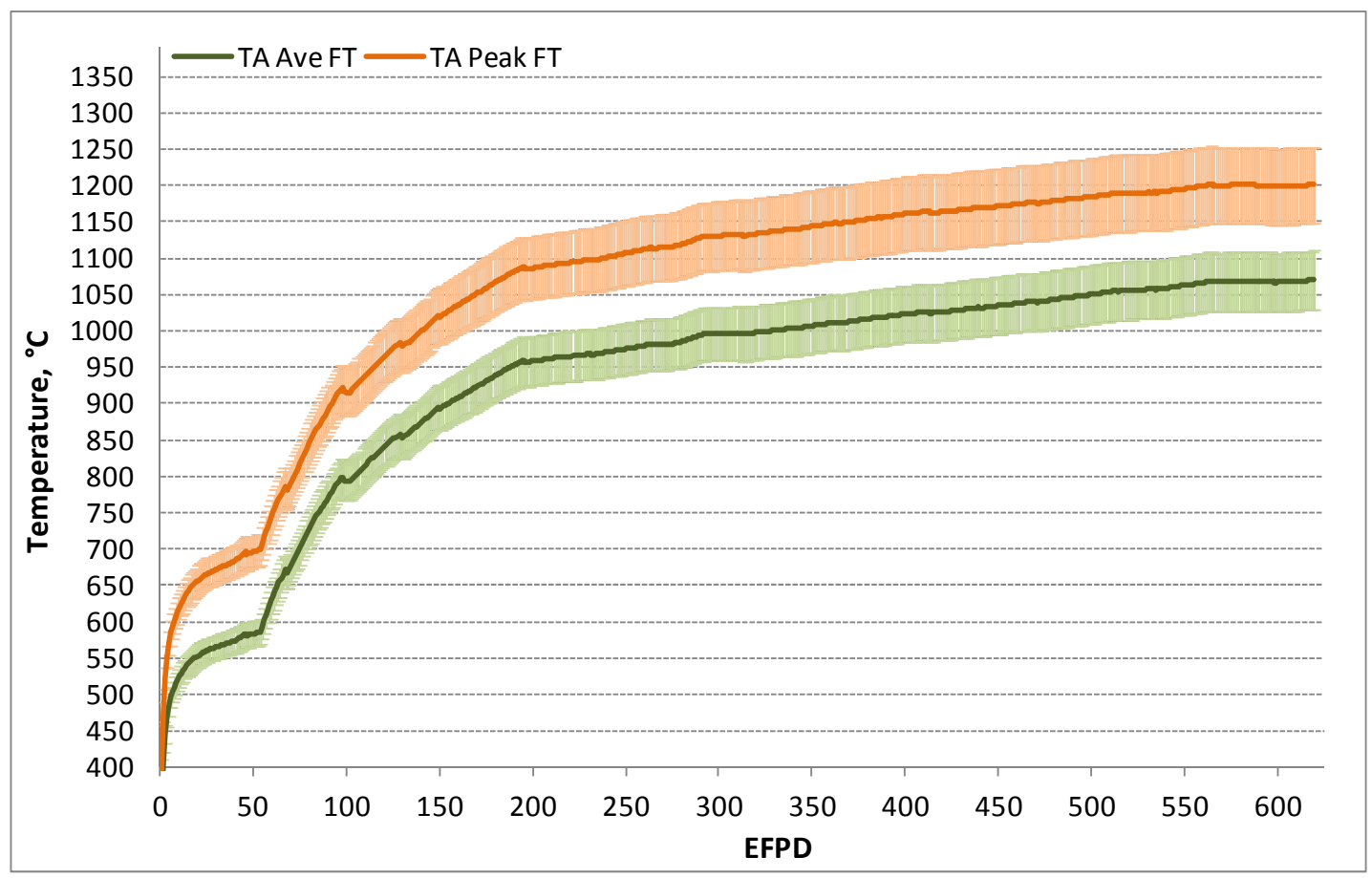

Figure 28. Time-average peak and time-average volume-average temperatures for Capsule 4.

\subsection{Palladium Penetration}

As a fission product created during irradiation, palladium $(\mathrm{Pd})$ is known to attack silicon carbide ( $\mathrm{SiC})$ at localized reaction sites, resulting in a thinning of the $\mathrm{SiC}$ layer and a subsequent possible failure of the TRISO particle. This $\mathrm{Pd}-\mathrm{SiC}$ interaction has been the subject of extensive studies and all the available in-reactor data for $\mathrm{Pd}$ penetration in $\mathrm{SiC}$ were mathematically fitted according to an Arrhenius temperature dependency (Petti et al. 2004). The resulting penetration rate correlation is given by:

$\mathrm{P}=38.232 \mathrm{e}^{-11342.3 / \mathrm{T}}(\mu \mathrm{m} /$ day $)$

This correlation can be used in combination with thermal calculations results (Hawkes 2012) to calculate the expected penetration depth of palladium in the AGR-1 compacts. For each of the 72 compacts, the minimum, average, and maximum temperatures are calculated with a daily time-step. The correlation above allows calculating daily Pd penetration, and the overall penetration is obtained by integration over time (summing all the daily contributions). Table 11 shows the total palladium penetration depth for each of the six capsules using the minimum, average, and maximum calculated compact temperatures. Penetration depths for the 72 compacts are provided in Appendix E. These values do not reflect the Pd penetration at the particle level, but the maximum depths in Table 11 give an upper limit of Pd penetration in each capsule. 
In a given compact, the particle experiencing the maximum total penetration depth is not necessarily the particle carrying the peak temperature. Since the daily peak temperature can move spatially in the compact over the course of irradiation, the particle bearing the maximum peak temperature can experience lower temperatures during the rest of the irradiation and it may end up being colder on average than a particle with a steadier temperature profile. Consequently, the particle with the maximum peak temperature can experience a smaller penetration depth than, for instance, the particle having the maximum time-average temperature. Furthermore, since the relation between the penetration rate and the temperature is not linear, it is not straightforward to correlate the total penetration depth and the time-average temperature: the distribution of the daily temperatures around the time-average temperature would be needed to do so.

As an illustration, comparison of Compact 5-3-2 (irradiation peak temperature of $1501^{\circ} \mathrm{C}$ ) and Compact 6-2-3 (time-average temperature of $1137^{\circ} \mathrm{C}$, maximum among all 72 compacts) shows that:

- The total Pd penetration depth in the hot particle of Compact 5-3-2 is $9.56 \mu \mathrm{m}$, slightly lower than the $9.74 \mu \mathrm{m}$ in the particle that has the maximum time-average temperature $\left(1080^{\circ} \mathrm{C}\right)$ in that compact.

- In Compact 6-2-3 the particle bearing the maximum temperature $\left(1427^{\circ} \mathrm{C}\right)$ experiences a penetration of $14.11 \mu \mathrm{m}$, about equal to the $14.06 \mu \mathrm{m}$ of the particle that has the maximum time-average temperature $\left(1192^{\circ} \mathrm{C}\right.$ ) in that compact (note that the time-average temperature of the compact $1137^{\circ} \mathrm{C}$ - is lower than the maximum time-average temperature of the constituent particles).

At the compact level, calculating the penetration depth at each time step using the peak temperature (possibly carried by different particles throughout irradiation) assures that a daily upper limit is obtained, and it provides an upper limit for the time-integrated total penetration depth.

At the capsule level, the "Maximum" values shown in Table 11 are the maximum compact values (see Appendix E) for each capsule. They provide upper limits of the penetration depths that can be expected in all the particles contained in that capsule at the end of irradiation.

Table 12 shows the measured $\mathrm{SiC}$ thickness for each of the six capsules (see Appendix A) and the lower 2-sigma value. Comparison of the respective $\mathrm{SiC}$ thicknesses and maximum $\mathrm{Pd}$ penetration depths shows that no $\mathrm{SiC}$ layer is expected to fail through Pd attack.

Table 11. Total Pd penetration depth $(\mu \mathrm{m})$.

\begin{tabular}{|l|c|c|c|c|c|c|}
\hline & Capsule 6 & Capsule 5 & Capsule 4 & Capsule 3 & Capsule 2 & Capsule 1 \\
\hline Minimum & 2.0 & 1.4 & 1.9 & 1.3 & 1.0 & 1.5 \\
\hline Average & 8.3 & 6.4 & 7.6 & 5.9 & 5.0 & 6.6 \\
\hline Maximum & 14.4 & 11.5 & 13.7 & 10.8 & 9.6 & 12.0 \\
\hline
\end{tabular}

Table 12. SiC thickness $(\mu \mathrm{m})$.

\begin{tabular}{|l|c|c|c|c|c|c|}
\hline & Capsule 6 & Capsule 5 & Capsule 4 & Capsule 3 & Capsule 2 & Capsule 1 \\
\hline Mean (M) & 35.3 & 35.7 & 35.9 & 35.3 & 35.0 & 35.9 \\
\hline Sigma ( $\sigma)$ & 1.3 & 1.2 & 2.1 & 1.3 & 1.0 & 2.1 \\
\hline M-2 $\sigma$ & 32.7 & 33.3 & 31.7 & 32.7 & 33.0 & 31.7 \\
\hline
\end{tabular}


Table 13 shows the sensitivity to temperature of the total Pd penetration depth. An increase of $75^{\circ} \mathrm{C}$ in the compact temperatures would increase the maximum Pd penetration by $\sim 40-45 \%$, reaching depths still significantly less than the $\mathrm{SiC}$ thicknesses $(\sim 14-20 \mu \mathrm{m}$ of penetration versus $\sim 35 \mu \mathrm{m}$ of $\mathrm{SiC}$ thickness).

Table 13. Temperature sensitivity of the total Pd penetration depth $(\mu \mathrm{m})$. and relative increase over base calculation (\%).

\begin{tabular}{|c|c|c|c|c|c|c|}
\hline$+\mathbf{5 0}^{\circ} \mathbf{C}$ & Capsule 6 & Capsule 5 & Capsule 4 & Capsule 3 & Capsule 2 & Capsule 1 \\
\hline & 2.8 & 2.0 & 2.7 & 1.9 & 1.5 & 2.2 \\
Minimum & $43 \%$ & $45 \%$ & $43 \%$ & $47 \%$ & $50 \%$ & $46 \%$ \\
\hline & 10.7 & 8.2 & 9.9 & 7.7 & 6.6 & 8.7 \\
Average & $28 \%$ & $30 \%$ & $29 \%$ & $31 \%$ & $32 \%$ & $30 \%$ \\
\hline & 18.0 & 14.6 & 17.1 & 13.8 & 12.3 & 15.2 \\
Maximum & $25 \%$ & $26 \%$ & $26 \%$ & $27 \%$ & $28 \%$ & $27 \%$ \\
\hline $\mathbf{7 5}^{\circ} \mathbf{C}$ & Capsule 6 & Capsule 5 & Capsule 4 & Capsule 3 & Capsule 2 & Capsule 1 \\
\hline & 3.4 & 2.4 & 3.2 & 2.3 & 1.8 & 2.7 \\
Minimum & $69 \%$ & $73 \%$ & $69 \%$ & $77 \%$ & $82 \%$ & $74 \%$ \\
\hline & 12.0 & 9.3 & 11.1 & 8.8 & 7.6 & 9.8 \\
Average & $45 \%$ & $47 \%$ & $46 \%$ & $49 \%$ & $51 \%$ & $48 \%$ \\
\hline & 20.0 & 16.3 & 19.1 & 15.5 & 13.9 & 17.0 \\
Maximum & $39 \%$ & $41 \%$ & $40 \%$ & $43 \%$ & $45 \%$ & $42 \%$ \\
\hline
\end{tabular}




\section{FISSION PRODUCT GAS RELEASE ANALYSIS}

As previously mentioned, no fuel particle failures occurred during the AGR-1 irradiation. The rate of release of fission product gases by intact TRISO fuel particles is also important in assessing fuel performance. Fission product gas R/B ratio values provide indicators of initial fuel quality and fuel performance during irradiation. AGR-1 reactor physics personnel provided as-run fission product birthrates for Kr-85m, Kr-87, Kr-88, Kr-89, Kr-90, Xe-131m, Xe-133, Xe-135, Xe-135m, Xe-137, $\mathrm{Xe}-138$, and $\mathrm{Xe}-139$. These nuclides were selected because they are chemically inert fission product gases with relatively short half-lives, allowing each isotope to reach equilibrium concentration in the fuel during each cycle. The FPMS system described in Section 1.2 was used to quantify release rates during irradiation giving the $\mathrm{R} / \mathrm{B}$ ratios for the radionuclides of interest.

\subsection{Birth Rate Calculations Methodology}

The birth rates of noble gas fission products of interest were calculated using ORIGEN2 Version 2.2 (Croff 1983). These calculations used compact flux and reactions rates from MCNP (LANL 2004). The ORIGEN2 libraries used in the calculation were modified to remove the isotope depletion methods for the isotopes of interest for birthrates. The increase in the concentration of the isotope during the irradiation time interval divided by the irradiation time interval was determined to be the isotope birthrate of the isotope during the time interval. This was performed at four points in time per ATR cycle-once at the beginning of each cycle, once at the end, and two times during each cycle. Documentation of birth rate calculations can be found in interoffice memoranda (Mitchell 2009, all). In the calculation of R/B values, interpolation is performed between the four sets of birthrate calculations per cycle to get birthrate at any point in time during the irradiation.

\subsection{Release Rate Calculations Methodology}

As was mentioned in Section 1.2, spectrometer detector systems measure the concentrations of various krypton and xenon isotopes in the sweep gas from each capsule. Eight-hour counting intervals are used to measure the concentrations of Kr-85m, Kr-87, Kr-88, Kr-89, Kr-90, Xe-131m, Xe-133, Xe-135, $\mathrm{Xe}-135 \mathrm{~m}, \mathrm{Xe}-137, \mathrm{Xe}-138$, and Xe-139.

The radionuclides of interest decay in transit from the capsule to the counters. Given a certain measured activity, $A$, radionuclide release rate, $R$, of a particular nuclide can be calculated as:

$$
R=3.7 \times 10^{4} \frac{A e^{\frac{\lambda V_{T}}{f}}}{\left(1-e^{-\lambda V_{S} / f}\right)}
$$

where $V_{S}$ is the sample volume, $\lambda$ is the nuclide decay constant, $f$ is the capsule volumetric flow rate, and $V_{T}$ is the transport volume from the capsule to the sample volume (Scates 2012). The transport volumes were determined from a lead-out flow test performed during the AGR-1 irradiation (Hartwell et al. 2007). The ratio of the experimentally determined release rates to the calculated birth rates is then computed. To obtain birth rates on a daily basis, interpolation is performed between the calculated values described in Section 4.1. The report by Scates (2012) contains information about the software and hardware used to take and process these release rate measurements along with detailed $\mathrm{R} / \mathrm{B}$ results, which are summarized in the following section. 


\subsection{R/B Results}

Figure 29 shows R/B versus time for $\mathrm{Kr}-85 \mathrm{~m}, \mathrm{Kr}-88$ and $\mathrm{Xe}-135$ plotted using NDMAS.

AGR-1 irradiation cycle numbers are shown across the top of the figure. See Table 2 for a mapping of AGR-1 cycle numbers to the ATR cycle names. These nuclides were selected for plotting because they have relatively short half-lives allowing them to come into equilibrium in each cycle. These are daily-average values filtered such that data coinciding with low reactor power are removed. Also, because large helium flow rates lower the capsule temperatures, which artificially lowers the release rate, helium flows greater than $20 \mathrm{sccm}$ (standard cubic centimeters per minute) have been removed from this plot as well. R/B data in Capsule 5 during AGR-1 irradiation Cycles 5 and 6 (ATR Cycles 140B and 141A) have been filtered out as a result of high helium flow rates. Appendix $\mathrm{C}$ contains a figure equivalent to Figure 29 only without any filtering. Figure 29 shows the low values of R/B that would be expected in Capsule 5 during these cycles.

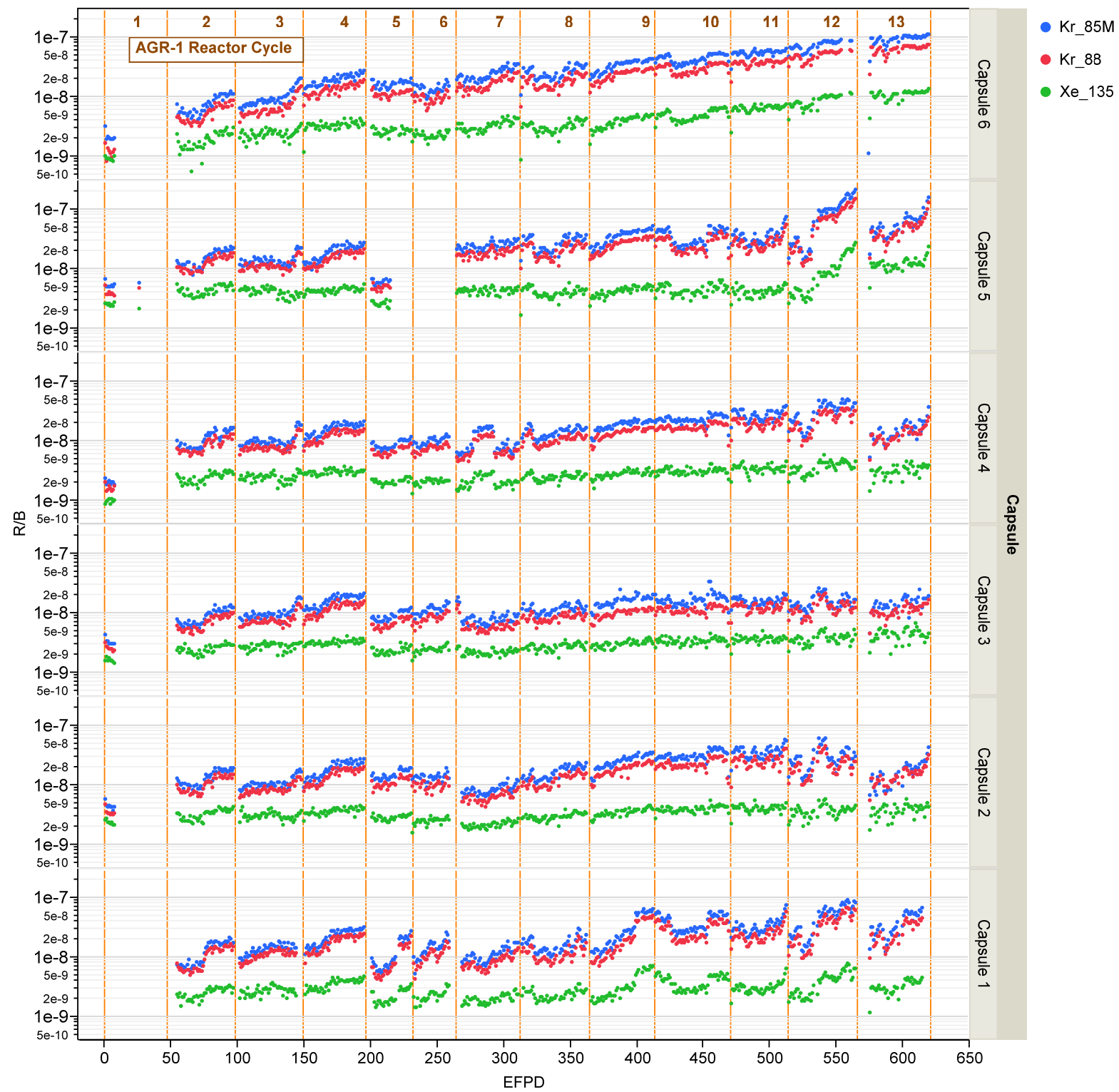

Figure 29. R/B ratios for $\mathrm{Kr}-85 \mathrm{~m}, \mathrm{Kr}-88$, and $\mathrm{Xe}-135$ versus time in EFPD. 
The $\mathrm{R} / \mathrm{B}$ rates for these nuclides are below approximately $10^{-7}$ for the duration of the test with the exception of Capsule 5, which reaches higher temperatures during these cycles than other capsules and ends the irradiation with an $\mathrm{R} / \mathrm{B}$ of approximately $2 \times 10^{-7}$. The data from Cycle $138 \mathrm{~B}$ is filtered out because of the full helium flow mentioned in Section 2.1. The lack of data for Capsule 5 in Cycles 5 and 6 (ATR Cycles 140B and 141A) is also caused by high helium flow during these cycles. A similar figure is included in Appendix $\mathrm{C}$ without these filters in place. The somewhat erratic behavior of $\mathrm{R} / \mathrm{B}$ in the final cycle of irradiation is a result of neon flow controller problems summarized in Section 5.6. 


\section{AGR-1 SHAKEDOWN ISSUES}

The prime objective of the AGR-1 irradiation experiment is to gain experience with the multi-capsule test train design, fabrication, and operation to reduce the probability of failure in subsequent irradiation tests. Several issues pertaining to the conduct of AGR-1 have arisen. These include matters dealing with data management, moisture monitor operation, activated Ar-41, sweep gas flow, detector spectral gain shifts, neon flow controllers, and TC behavior. Each is discussed below.

\subsection{Data Management}

The electronic files containing all online AGR-1 control data (TC readings, moisture monitor readings, sweep gas compositions, flow rates and pressures) for the entire first AGR-1 irradiation cycle (ATR cycle 138B) and the first week of the second cycle were irretrievably lost before they were placed on the server from which they are transferred to the NDMAS. However, hardcopy log sheets containing control TC and sweep gas data recorded at 2-hour intervals were maintained and were manually entered into the NDMAS for this period. Corrective actions were subsequently put in place such that all online control data are properly stored and backed-up, as initially intended. For the remainder of the second cycle (March 4 through April 21, 2007) online control data recorded at 10-minute intervals, with the exception of moisture monitor readings, were available electronically. Beginning with the third cycle, all online control data were recorded at 5-minute intervals, and are available electronically in the NDMAS.

\subsection{Moisture Monitors}

Indicators of moisture ingress (sweep gas outlet moisture content higher than inlet content) were closely monitored during the AGR-1 experiment. However, from the start of irradiation, the moisture monitors were indicating high levels of moisture, and by the end of the first cycle, the monitors had failed. Several tests were conducted to determine the possible source of the moisture and the proper functioning of the monitors (Cole 2007). During the reactor outage between the first and second cycles, several small gas line leaks were discovered and repaired and the monitors were replaced. However, by the end of the third cycle, it was concluded that the moisture monitors had degraded and failed because of radiation damage to the sensor electronics. This implied that all moisture readings through the first three cycles were erroneous. During the reactor outage between the third and fourth cycles, the moisture monitors were replaced with fresh sensors and relocated to an area with significantly reduced radiation fields. These monitors indicated extremely low moisture levels, typically $0.02 \mathrm{ppm}$-volume or less, from the fourth cycle to the end of the irradiation.

\subsection{Activated Ar-41}

The FPMS detected activated Ar-41 during the initial startup of the AGR-1 experiment. It is believed that the argon was from the small amount of air trapped in the system during the connection of the experiment to the control gas system. The FPMS also continued to detect small amounts of Ar-41, which is believed to come from trace impurities in the Ultra High Purity grade helium supply gas used in the control system (Scates 2012).

\subsection{Sweep Gas Flow}

During portions of the first three AGR-1 irradiation cycles, normal sweep gas flow conditions were both unintentionally and intentionally not maintained. These conditions resulted from as-installed equipment failures, safety precautions, and testing to determine possible sources of leaks, moisture, cross lines, and TC failures. Several of these incidences (Cole 2007) are briefly described as follows:

- During the entire first AGR-1 irradiation cycle (ATR cycle 138B), the automatic gas control system was under manual control, and with the exception of the periods of capsule isolation and neon injection tests noted below, the AGR-1 test train was swept with $100 \%$ helium because of the high moisture monitor readings. 
- Near the beginning of the first cycle, gas flow was increased from a nominal $30 \mathrm{sccm}$ to $50 \mathrm{sccm}$ in an attempt to dry the capsules from the moisture problem.

- Near the middle of the first cycle, inlet and outlet gas flow valves were closed for 12 hours, thus isolating the capsules, in order to observe moisture levels. This test helped to identify the presence of small leaks in the gas system.

- Near the end of the first cycle, the capsules were again isolated from January 29, 2007, through February 7, 2007, because of ATR safety requirements stemming from the failure of the moisture monitors.

- During the first cycle, neon injection tests (where neon is routed to a specific capsule) began. These tests measured activated neon in the FPMS, which helped to ascertain gas flow paths.

- $\quad$ During the outage between the first and second cycles (ATR cycles 138B and 139A), it was determined that a three way valve to the spare FPMS, which was intended to monitor the gas from Capsule 1, had been indicating an opposite flow direction than intended. Also, a solenoid isolation valve on the outlet of Capsule 1 had failed shut, even though its indicator was showing it was opening and closing as desired. These conditions resulted in Capsule 1 effluent gas entering the leadout cavity and being forced into the other capsules around their respective thru tubes. Therefore, the FPMS for Capsules 2 through 6 were measuring effluent from the intended capsule and some unknown quantity from Capsule 1.

- Also during the outage between the first and second cycles, all accessible gas lines and connections were inspected with no crossed lines or incorrect connections found. After replacing the faulty valves noted above, and minor leaks repaired, all gases were flowing as originally designed.

- The automatic gas control system remained under manual operation for the second cycle. From startup through the first 8 days of the cycle, the test train was swept with $100 \%$ helium. Afterwards, the control gas was changed to $100 \%$ neon with the leadout flow remaining on helium until the end of the cycle.

- During the third cycle (ATR cycle 139B), the gas control system was operated in automatic mode. However, the control gas consisted mostly of neon, and leadout flow still consisted of helium. TC drift may have contributed to the inability of the automatic gas control system to maintain fuel temperatures below desired maximum levels and is currently being investigated further.

- Near the end of the third cycle, the control TC in Capsule 1 failed. Sweep gas to Capsule 1 was then manually changed to $100 \%$ helium.

- Moisture monitors were replaced during the reactor outage between the first and second cycles. The monitors were replaced again, and relocated during the reactor outage between the third and fourth cycles (as discussed in Section 5.2 above).

\subsection{Detector Spectral Gain Shifts}

The activity of the nuclides was closely monitored over the course of the AGR-1 experiment. Anomalies were noted, and it became evident during the $12^{\text {th }}$ irradiation cycle (ATR Cycle 144B) that repeated spectral gain shifts had occurred in Detector G2, which monitors the effluent from AGR-1 Capsule 2. These spectral gain shifts occurred over the duration of the experiment, resulting in misidentification of some gamma peaks and hence inaccurate estimates of some isotopic activity, $\mathrm{Kr}-88$ in particular. Prior to the start of the last irradiation cycle (ATR cycle 145A), fission product monitoring personnel swapped Detector G2 with the online spare G7 detector to maintain data integrity. 
Detector gain shift software tools were developed to correct past spectrum data from Detector G2. These tools were intended to process a batch of spectra, summarize gain shifts in the spectra, and correct for it in a copy of the spectra. The corrected files were then reanalyzed to get reliable results for the noble gas isotopes (Scates 2012).

\subsection{Neon Flow Controller}

Toward the end of the irradiation of AGR-1, 100\% neon was needed to achieve high temperatures compensating for the lower heat production in the burned fuel compacts. The required neon flow rates to accomplish this were around $30 \mathrm{sccm}$, close to the maximum flow obtainable with the flow controllers used. When this maximum value was approached, the controller was not able to maintain a steady flow rate and the neon flow became unstable. This is the cause of the erratic values of R/B shown in Figure 29 for the last irradiation cycle (ATR cycle 145A). For AGR-2, 0-100 sccm controllers have been specified. With these controllers, the required neon flow rates will not be close to the maximum value of the controller and controlling to $\pm 1 \%$ should not be an issue.

\subsection{Thermocouple Behavior}

As can be seen in Figure 24 and Table 8, two types of TCs were used in the AGR-1 test train: commercially available Type $\mathrm{N}$ and molybdenum-niobium (Mo-Nb) TCs developed at INL. The Mo-Nb TCs were used under the premise that they may perform longer under irradiation than the Type N TCs. During the AGR-1 irradiation, however, no apparent difference in survivability was observed between the two types of TCs. Therefore, only the commercially available, less-expensive Type N TCs were specified for the AGR-2 test train.

The general performance of TCs was better than expected. Of the 19 planned TCs, three failed during fabrication and another seven failed during operation, leaving nine functional TCs at the end of the 13 cycles of irradiation in the ATR. The failed TCs were thus declared based on either the detection of virtual junctions with other capsules or open circuit failures resulting in loss of signal. These failed TCs were located in the bottom four capsules of the test train. The expected downward drift of TC temperature readings did occur with some exceptions. Inspection of the TCs during PIE may give more useful information about the performance of TCs during this irradiation. 


\section{CONCLUSIONS}

The AGR-1 fuel test was successful in irradiating the fuel compacts to a substantial burnup (peak burnup of $19.6 \%$ FIMA) and fast neutron fluence (peak fast fluence of $4.30 \times 10^{25} \mathrm{n} / \mathrm{cm}^{2}$ ) with no TRISO fuel particle failures. Time-averaged volume-averaged temperatures on a capsule basis at the end of irradiation ranged from $1002^{\circ} \mathrm{C}$ in Capsule 2 to $1087^{\circ} \mathrm{C}$ in Capsule 6. TCs performed well, failing at a lower rate than expected. At the end of the irradiation, nine of the originally planned 19 TCs were still considered functional. Fission product R/B ratios were quite low. In most capsules, R/B values at the end of the irradiation were well below $10^{-7}$, with the exception of two capsules, one that reached $10^{-7}$ and the other that reached $2 \times 10^{-7}$ near the end of the irradiation.

Several shakedown issues were encountered and resolved during the first three cycles. These included repairing minor gas line leaks, repairing faulty gas line valves, positioning moisture monitors in regions of low radiation fields for proper functioning, enforcing proper online data storage and backup, monitoring TC performance, correcting for detector spectral gain shift, and changing the mass flow rate range of the neon flow controllers.

The results of this test will provide irradiation performance data for baseline fuel and for variants of this fuel fabricated with predetermined, yet slight changes in selected fabrication processes. PIE is on-going for the AGR-1 fuel compacts (Demkowicz 2006 and 2011). The PIE for this experiment focuses on (1) assessing the performance of the multi-capsule instrumented test train and components; (2) evaluating the fission product retention of the fuel during irradiation and during post-irradiation accident testing; and (3) characterizing the compacts and individual particles to observe the condition of the matrix material, kernels, and coatings and document any concerns. Once the PIE is completed, this test will provide the first in a series of data that will form a link between fabrication processes, fuel product properties, and irradiation performance. 


\section{REFERENCES}

Abbott, M. L., L. Hull, B. Pham, and M. A. Plummer, "AGR-1 Data Qualification Report," INL/EXT-10-17943, March 2010.

Barnes, C. M., “AGR-1 Fuel Product Specification and Characterization Guidance,” EDF-4380, Rev. 8, April 25, 2006.

Chang, G. S., "Preliminary Physics Analysis of the German UO2 and GA UCO Fuel Test Assembly in North and South Large B Hole Positions," Memorandum GSC-PBMR-04-2002, August 2, 2002.

Chang, G. S. and M.A. Lillo, "Confirmatory Neutronics Analysis of the AGR-1 Experiment Irradiated in ATR B-10 Position,” EDF-7120, Rev. 1, February 13, 2007.

Cole, L. T., "Discussions of Early AGR-1 Problems," E-mail communication to J. T. Maki, November 30, 2007.

Croff, A. G., "ORIGEN2: A Versatile Computer Code for Calculating the Nuclide Compositions and Characteristics of Nuclear Materials, Nuclear Technology," Vol. 62, pp. 335-352, 1983.

Demkowicz, P. A., “AGR-1 Post-Irradiation Examination Test Requirements," INL/EXT-06-12051, December 19, 2006.

Demkowicz, P. A., "AGR-1 Irradiated Test Train Preliminary Inspection and Disassembly First Look," INL/EXT-10-20722, January 6, 2011.

Fluent Inc., "Fluent 6.3 User's Guide,” Lebanon, NH, September 2006.

General Atomics, "Conceptual Design Report - Steam Cycle Modular Helium Reactor (SC-MHR) Demonstation Plant", NGNP-RP00016, December 23, 2010.

Gontard, R. and H. Nabielek, "Performance Evaluation of Modern HTR TRISO Fuels," Forschungszentrum Jülich GmbH, HTA-IB-05/90, July 31, 1990.

Hartwell, J. K., D.M. Scates, and M.W. Drigert, "Design and Expected Performance of the AGR-1 Fission Product Monitoring System,” INL/EXT-05-00073, September 2005.

Hartwell, J. K., J.B. Walter, D.M. Scates, and M.W. Drigert, "Determination of the AGR-1 capsule to FPMS Spectrometer Transport Volumes from Leadout Flow Test Data," INL/EXT-07-12494, April 2007.

Hawkes, G. L., “AGR-1 Daily As-run Thermal Analyses,” ECAR-968, Rev. 3, May 16, 2012.

Hunn, J. D. and R. A. Lowden, "Data Compilation for AGR-1 Baseline Coated Particle Composite LEU01-46T," ORNL/TM-2006/019, April 2006a.

Hunn, J. D. and R. A. Lowden, "Data Compilation for AGR-1 Variant 1 Coated Particle Composite LEU01-47T," ORNL/TM-2006/020, April 2006b.

Hunn, J. D. and R. A. Lowden, "Data Compilation for AGR-1 Variant 2 Coated Particle Composite LEU01-48T,” ORNL/TM-2006/021, May 2006c.

Hunn, J. D. and R. A. Lowden, "Data Compilation for AGR-1 Variant 3 Coated Particle Composite LEU01-49T," ORNL/TM-2006/022, May 2006d.

Hunn, J. D., F. C. Montgomery and P. J. Pappano, "Data Compilation for AGR-1 Baseline Compact Lot LEU01-46T-Z," ORNL/TM-2006/507, August 2006a.

Hunn, J. D., F. C. Montgomery and P. J. Pappano, "Data Compilation for AGR-1 Variant 1 Compact Lot LEU01-47T-Z," ORNL/TM-2006/508, August 2006b. 
Hunn, J. D., F. C. Montgomery and P. J. Pappano, "Data Compilation for AGR-1 Variant 2 Compact Lot LEU01-48T-Z," ORNL/TM-2006/509, August 2006c.

Hunn, J. D., F.C. Montgomery and P.J. Pappano, "Data Compilation for AGR-1 Variant 3 Compact Lot LEU01-49T-Z," ORNL/TM-2006/510, August 2006d.

INL, 2009a, "Very High Temperature Reactor Program Data Management and Analysis Plan," PLN-2709 Rev 1, Idaho National Laboratory, Idaho Falls, Idaho, p. 23.

INL, 2009b, "Very High Temperature Gas Reactor Technology Development Office Quality Assurance Program Plan,” PLN-2690, Rev 3, July 22, 2009.

LANL, X-5 Monte Carlo Team, "MCNP-A General Monte Carlo N-Particle Transport Code, Version 5," Volume I, LA-UR-03-1987, Los Alamos National Laboratory, April 24, 2003

(Revised 6/30/2004) and Volume II, LA-CP-0245, Los Alamos National Laboratory, April 24, 2003 (Revised 6/30/2004).

Maki, J. T., “AGR-1 Irradiation Test Specification,” EDF-4731, Rev. 1, July 15, 2004.

Maki, J. T., “AGR-1 Irradiation Experiment Test Plan,” INL/EXT-05-00593 Rev. 3, October 20, 2009.

Mitchell, J. R., “AGR-1 Experiment As-Run Birth Rates for ATR Cycle 138B (AGR-1 irradiation interval \#1)," Interoffice Memorandum to J. T. Maki, February 20, 2009.

Mitchell, J. R., “AGR-1 Experiment As-Run Birth Rates for ATR Cycle 139A (AGR-1 irradiation interval \#2)," Interoffice Memorandum to J. T. Maki, February 20, 2009.

Mitchell, J. R., “AGR-1 Experiment As-Run Birth Rates for ATR Cycle 139B (AGR-1 irradiation interval \#3)," Interoffice Memorandum to J. T. Maki, February 20, 2009.

Mitchell, J. R., “AGR-1 Experiment As-Run Birth Rates for ATR Cycle 140A (AGR-1 irradiation interval \#4)," Interoffice Memorandum to J. T. Maki, February 20, 2009.

Mitchell, J. R., "AGR-1 Experiment As-Run Birth Rates for ATR Cycle 140B (AGR-1 irradiation interval \#5)," Interoffice Memorandum to J. T. Maki, February 20, 2009.

Mitchell, J. R., "AGR-1 Experiment As-Run Birth Rates for ATR Cycle 141A (AGR-1 irradiation interval \#6)," Interoffice Memorandum to J. T. Maki, February 20, 2009.

Mitchell, J. R., "AGR-1 Experiment As-Run Birth Rates for ATR Cycle 142A (AGR-1 irradiation interval \#7)," Interoffice Memorandum to J. T. Maki, February 20, 2009.

Mitchell, J. R., "AGR-1 Experiment As-Run Birth Rates for ATR Cycle 142B (AGR-1 irradiation interval \#8)," Interoffice Memorandum to J. T. Maki, February 20, 2009.

Mitchell, J. R., "AGR-1 Experiment As-Run Birth Rates for ATR Cycle 143A (AGR-1 irradiation interval \#9)," Interoffice Memorandum to J. T. Maki, February 20, 2009.

Mitchell, J. R., "AGR-1 Experiment As-Run Birth Rates for ATR Cycle 143B (AGR-1 irradiation interval \#10)," Interoffice Memorandum to J. T. Maki, March 12, 2009.

Mitchell, J. R., "AGR-1 Experiment As-Run Birth Rates for ATR Cycle 144A (AGR-1 irradiation interval \#11)," Interoffice Memorandum to J. T. Maki, March 27, 2009.

Mitchell, J. R., “AGR-1 Experiment As-Run Birth Rates for ATR Cycle 144B (AGR-1 irradiation interval \#12)," Interoffice Memorandum to J. T. Maki, August 3, 2009.

Mitchell, J. R., “AGR-1 Experiment As-Run Birth Rates for ATR Cycle 145A (AGR-1 irradiation interval \#13)," Interoffice Memorandum to J. T. Maki, November 23, 2009. 
Petti, D. A., P. Martin, M. Phelip and R. Balinger, "Development of Improved Models and Designs for Coated-Particle Gas Reactor Fuels,” INEEL/EXT-05-02615, December 2004.

Pham, B. T., and J. J. Einerson, “AGR-1 Thermocouple Data Analysis,” INL/EXT-12-24761, April 2012.

Pham, B. T., J. J. Einerson, and G. L. Hawkes, "Uncertainty Quantification of Calculated Temperatures for the AGR-1 Experiment”, INL/EXT-12-25169, April 2012.

Scates, D. M., "Release-to-Birth Ratios for AGR-1 Operating Cycles 138B through 145A," ECAR-907, Rev. 1, June 2012.

Simonds, J., "Technical Program Plan for the Next Generation Nuclear Plant/ Advanced Gas Reactor Fuel Development and Qualification Program," PLN-3636, September 30, 2010.

Snead, L. L. and T. D. Burchell, "Reduction in Thermal Conductivity Due to Neutron Irradiation," 22nd Biennial Conference on Carbon, Extended Abstracts, 774-775, 1995.

Sterbentz, J. W., "Fast Flux to DPA Multiplier,” E-mail communication to G.L. Hawkes, August 5, 2009.

Sterbentz, J. W., "JMOCUP As-Run Daily Depletion Calculation for the AGR-1 Experiment in ATR B-10 position,” ECAR-958, Rev. 1, August 18, 2011.

Sterbentz, J. W., "JMOCUP As-Run Daily Depletion Calculation for the AGR-1 Experiment in ATR B-10 position,” ECAR-958, Rev. 2, September 3, 2013.

Thompson, T. L. Letter from GrafTech to the Idaho National Laboratory, July 13, 2006. 
Appendix A

\section{As-Manufactured Fuel Data}




\section{Appendix A As-Manufactured Fuel Data}

Kernels for AGR-1 consist of LEU fuel in the form of UCO. The kernels were fabricated by BWXT in accordance with the AGR-1 Fuel Product Specification (Barnes 2006). Several production batches were combined into a single composite, Lot G73D-20-69302. This composite was used in all of the AGR-1 fuel, including the baseline and each of the three fuel variants. Selected properties for these kernels are given in Table A-1.

Table A-1. Selected properties for kernel Lot G73D-20-69302.

\begin{tabular}{|l|c|c|}
\hline \multicolumn{1}{|c|}{ Kernel Property } & $\begin{array}{c}\text { Specified Range for } \\
\text { Mean Value }\end{array}$ & $\begin{array}{c}\text { Actual Mean Value } \pm \\
\text { Population Standard Deviation }\end{array}$ \\
\hline Diameter $(\mu \mathrm{m})$ & $350 \pm 10$ & $349.7 \pm 9.0$ \\
\hline Density $\left(\mathrm{Mg} / \mathrm{m}^{3}\right)$ & $\geq 10.4$ & $10.924 \pm 0.015$ \\
\hline U-235 enrichment (wt \%) & $19.80 \pm 0.10$ & $19.736 \pm 0.047$ \\
\hline Carbon/uranium (atomic ratio) & $0.50 \pm 0.20$ & $0.3253 \pm 0.0028$ \\
\hline Oxygen/uranium (atomic ratio) & $1.50 \pm 0.20$ & $1.3613 \pm 0.0064$ \\
\hline$[$ Carbon + oxygen]/uranium (atomic ratio) & $\leq 2.0$ & $1.6850 \pm 0.0093$ \\
\hline Total uranium (wt \%) & $\geq 87.0$ & $90.059 \pm 0.086$ \\
\hline Sulfur impurity(ppm - wt) & $\leq 1500$ & 608 \\
\hline All other impurities & various & Below minimum detection limits \\
\hline
\end{tabular}

The UCO kernels were coated by Oak Ridge National Laboratory (ORNL) who also provided characterization data (Hunn and Lowden 2006a through 2006d). Coating was performed in accordance with the AGR-1 Fuel Product Specification (Barnes 2006). A summary of selected properties, based on actual characterization data, for each of the four coated particle composites is listed in Table A-2.

After coating, AGR-1 fuel was formed into right cylindrical compacts. The compact matrix material is composed of a thermosetting carbonaceous material. Prior to compacting, the fuel particles were overcoated with approximately $165 \mu \mathrm{m}$ thick layers of the compact matrix material. This overcoat is intended to prevent particle to particle contact and help achieve the desired packing fraction of fuel particles. A summary of selected properties, based on actual characterization data (Hunn et al. 2006a through 2006d) and derived from these data, for each fuel type is listed in Table A-3. 
Table A-2. Selected properties for AGR-1 coated particle composites.

\begin{tabular}{|c|c|c|c|c|c|}
\hline \multirow{2}{*}{ Property } & \multirow{2}{*}{$\begin{array}{c}\text { Specified Range for } \\
\text { Mean Value }\end{array}$} & \multicolumn{4}{|c|}{ Actual Mean Value \pm Population Standard Deviation } \\
\hline & & Baseline & Variant 1 & Variant 2 & Variant 3 \\
\hline Buffer thickness $(\mu \mathrm{m})$ & $100 \pm 15$ & $103.5 \pm 8.2$ & $102.5 \pm 7.1$ & $102.9 \pm 7.3$ & $104.2 \pm 7.8$ \\
\hline IPyC thickness $(\mu \mathrm{m})$ & $40 \pm 4$ & $39.4 \pm 2.3$ & $40.5 \pm 2.4$ & $40.1 \pm 2.8$ & $38.8 \pm 2.1$ \\
\hline SiC thickness $(\mu \mathrm{m})$ & $35 \pm 3$ & $35.3 \pm 1.3$ & $35.7 \pm 1.2$ & $35.0 \pm 1.0$ & $35.9 \pm 2.1$ \\
\hline OPyC thickness $(\mu \mathrm{m})$ & $40 \pm 4$ & $41.0 \pm 2.1$ & $41.1 \pm 2.4$ & $39.8 \pm 2.1$ & $39.3 \pm 2.1$ \\
\hline Buffer density $\left(\mathrm{Mg} / \mathrm{m}^{3}\right)$ & $0.95 \pm 0.15$ & $1.10 \pm 0.04$ & $1.10 \pm 0.04$ & $1.10 \pm 0.04$ & $1.10 \pm 0.04$ \\
\hline IPyC density $\left(\mathrm{Mg} / \mathrm{m}^{3}\right)$ & $1.90 \pm 0.05$ & $1.904 \pm 0.014$ & $1.853 \pm 0.012$ & $1.912 \pm 0.015$ & $1.904 \pm 0.013$ \\
\hline SiC density $\left(\mathrm{Mg} / \mathrm{m}^{3}\right)$ & $\geq 3.19$ & $3.208 \pm 0.003$ & $3.206 \pm 0.002$ & $3.207 \pm 0.002$ & $3.205 \pm 0.001$ \\
\hline OPyC density $\left(\mathrm{Mg} / \mathrm{m}^{3}\right)$ & $1.90 \pm 0.05$ & $1.907 \pm 0.008$ & $1.898 \pm 0.009$ & $1.901 \pm 0.008$ & $1.911 \pm 0.008$ \\
\hline${\text { IPyC } \text { anisotropy }^{(a)}(B A F)}$ & $\leq 1.035$ & $1.022 \pm 0.002$ & $1.014 \pm 0.001$ & $1.023 \pm 0.002$ & $1.029 \pm 0.002$ \\
\hline OPyC anisotropy (BAF) & $\leq 1.035$ & $1.019 \pm 0.003$ & $1.013 \pm 0.002$ & $1.018 \pm 0.001$ & $1.021 \pm 0.003$ \\
\hline $\begin{array}{l}\text { IPyC anisotropy post } \\
\text { compact anneal (BAF) }\end{array}$ & Not specified & $1.033 \pm 0.004$ & $1.021 \pm 0.002$ & $1.036 \pm 0.001$ & $1.034 \pm 0.003$ \\
\hline $\begin{array}{l}\text { OPyC anisotropy post } \\
\text { compact anneal (BAF) }\end{array}$ & Not specified & $1.033 \pm 0.003$ & $1.030 \pm 0.003$ & $1.029 \pm 0.004$ & $1.036 \pm 0.002$ \\
\hline $\begin{array}{l}\text { Sphericity } \\
\text { (aspect ratio) }\end{array}$ & Mean not specified ${ }^{(b)}$ & $1.054 \pm 0.019$ & $1.056 \pm 0.019$ & $1.053 \pm 0.019$ & $1.055 \pm 0.018$ \\
\hline Particle diameter $^{(\mathrm{c})}(\mu \mathrm{m})$ & Mean not specified & 799.7 & 804.0 & 798.3 & 795.1 \\
\hline Particle mass (g) & Mean not specified & $7.27 \times 10^{-4}$ & $7.33 \times 10^{-4}$ & $7.24 \times 10^{-4}$ & $7.26 \times 10^{-4}$ \\
\hline
\end{tabular}

\footnotetext{
a. Specification does not apply to Variants 1 and 2 .

b. Critical region is specified such that $\leq 1 \%$ of the particles shall have an aspect ratio $\geq 1.14$.

c. Based upon mean average particle measurements, not sums of mean layer thicknesses.
} 
Table A-3. Selected properties for AGR-1 compacts.

\begin{tabular}{|c|c|c|c|c|c|}
\hline \multirow[b]{2}{*}{ Property } & \multirow{2}{*}{$\begin{array}{c}\text { Specified } \\
\text { Range for } \\
\text { Mean Value }\end{array}$} & \multicolumn{4}{|c|}{ Actual Mean Value \pm Population Standard Deviation } \\
\hline & & Baseline & Variant 1 & Variant 2 & Variant 3 \\
\hline Compact mass $(\mathrm{g})$ & Not specified & 5.4789 & 5.3371 & 5.3736 & 5.5930 \\
\hline $\begin{array}{l}\text { Mean uranium loading } \\
\text { (g U/compact) }\end{array}$ & $0.905 \pm 0.04$ & 0.917 & 0.915 & 0.904 & 0.912 \\
\hline Diameter $^{(\mathrm{b})}(\mathrm{mm})$ & $12.22-12.46$ & $12.36 \pm 0.01$ & $12.36 \pm 0.01$ & $12.36 \pm 0.01$ & $12.34 \pm 0.01$ \\
\hline Length $^{(\mathrm{b})}(\mathrm{mm})$ & $25.02-25.40$ & $25.066 \pm 0.080$ & $25.123 \pm 0.030$ & $25.077 \pm 0.065$ & $25.227 \pm 0.037$ \\
\hline $\begin{array}{l}\text { Number of particles per } \\
\text { compact }^{(a)}\end{array}$ & Not specified & 4154 & 4145 & 4095 & 4132 \\
\hline $\begin{array}{l}\text { Particle volume packing } \\
\text { fraction }^{(a)}(\%)\end{array}$ & Not specified & 36.99 & 37.42 & 36.26 & 36.04 \\
\hline $\begin{array}{l}\text { Effective overall compact } \\
\text { density }^{(a)}\left(\mathrm{Mg} / \mathrm{m}^{3}\right)\end{array}$ & Not specified & 1.822 & 1.771 & 1.786 & 1.854 \\
\hline $\begin{array}{l}\text { Compact matrix density } \\
\left(\mathrm{Mg} / \mathrm{m}^{3}\right)\end{array}$ & Not specified & 1.297 & 1.219 & 1.256 & 1.344 \\
\hline Compact weight $\% \mathrm{U}^{(\mathrm{a})}$ & Not specified & 16.737 & 17.144 & 16.823 & 16.306 \\
\hline Compact weight $\% \mathrm{O}^{(\mathrm{a})}$ & Not specified & 1.535 & 1.572 & 1.543 & 1.495 \\
\hline Compact weight $\% \mathrm{Si}^{(\mathrm{a})}$ & Not specified & 8.509 & 8.827 & 8.476 & 8.444 \\
\hline Compact weight $\% \mathrm{C}^{(\mathrm{a})}$ & Not specified & 73.219 & 72.457 & 73.158 & 73.754 \\
\hline $\begin{array}{l}\text { Iron content ( } \mu \mathrm{g} \text { Fe outside of } \\
\mathrm{SiC} / \text { compact) }\end{array}$ & $\leq 25$ & 1.57 & 0.97 & 1.88 & 1.81 \\
\hline $\begin{array}{l}\text { Chromium content ( } \mu \mathrm{g} \mathrm{Cr} \text { outside } \\
\text { of } \mathrm{SiC} / \text { compact) }\end{array}$ & $\leq 75$ & 1.58 & 1.62 & 0.50 & 0.18 \\
\hline $\begin{array}{l}\text { Manganese content ( } \mu \mathrm{g} \mathrm{Mn} \\
\text { outside of } \mathrm{SiC} / \text { compact) }\end{array}$ & $\leq 75$ & 0.12 & 0.25 & 0.08 & 0.05 \\
\hline $\begin{array}{l}\text { Cobalt content ( } \mu \mathrm{g} \text { Co outside of } \\
\text { SiC/compact) }\end{array}$ & $\leq 75$ & 0.63 & 0.65 & 0.19 & 0.06 \\
\hline $\begin{array}{l}\text { Nickel content ( } \mu \mathrm{g} \mathrm{Ni} \text { outside of } \\
\text { SiC/compact) }\end{array}$ & $\leq 75$ & 1.20 & 1.03 & 1.64 & 0.61 \\
\hline $\begin{array}{l}\text { Calcium content ( } \mu \mathrm{g} \mathrm{Ca} \text { outside } \\
\text { of } \mathrm{SiC} / \text { compact) }\end{array}$ & $\leq 90$ & 7.95 & 5.86 & 15.13 & 10.10 \\
\hline $\begin{array}{l}\text { Aluminum content ( } \mu \mathrm{g} \mathrm{Al} \text { outside } \\
\text { of } \mathrm{SiC} / \text { compact) }\end{array}$ & $\leq 45$ & 8.54 & 8.21 & 11.21 & 7.46 \\
\hline $\begin{array}{l}\text { Titanium content ( } \mu \mathrm{g} \text { Ti outside } \\
\text { of } \mathrm{SiC} / \text { compact) }\end{array}$ & Note $^{(c)}$ & 6.96 & 11.16 & 11.57 & 16.52 \\
\hline $\begin{array}{l}\text { Vanadium content ( } \mu \mathrm{g} \mathrm{V} \text { outside } \\
\text { of } \mathrm{SiC} / \text { compact) }\end{array}$ & Note $^{(c)}$ & 18.20 & 19.72 & 20.90 & 22.38 \\
\hline 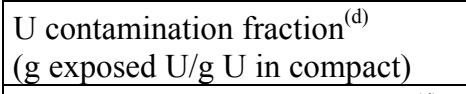 & $\leq 1.0 \times 10^{-4}$ & 0 & 0 & 0 & 0 \\
\hline Defective SiC coating fraction $^{(\mathrm{d})}$ & $\leq 2.0 \times 10^{-4}$ & $4.0 \times 10^{-5}$ & 0 & $2.0 \times 10^{-5}$ & 0 \\
\hline Defective IPyC coating fraction $^{(\mathrm{d})}$ & $\leq 2.0 \times 10^{-4}$ & 0 & 0 & 0 & 0 \\
\hline $\begin{array}{l}\text { Defective OPyC coating } \\
\text { fraction }^{(\mathrm{d})}\end{array}$ & $\leq 1.0 \times 10^{-2}$ & 0 & $9.6 \times 10^{-4}$ & 0 & 0 \\
\hline
\end{tabular}

\footnotetext{
a. Value derived from other characterized properties.

b. Allowable range corresponding to upper and lower critical limits specified with no compacts exceeding the limits which require $100 \%$ inspection of all compacts.

c. Mean value specification of $\leq 400 \mu \mathrm{g}$ Ti plus $\mathrm{V}$ outside of $\mathrm{SiC} /$ compact.

d. Value is an estimate of an attribute property, not the mean of a variable property.
} 
Appendix B

\section{Graphite Holder Data}




\section{Appendix B Graphite Holder Data}

Excerpt from letter from GrafTech International, Ltd. providing properties for graphite used in holders (Thompson 2006).

\section{GRAFTech}

UCAR CARBON COMPANY INC., a GrafTech International Ltd. company

Tracy L. Thompson, $\mathrm{Ph}$. D.

Staff Scientist
12900 Snow Road $\bullet$ Parma, Ohio 44130

(216) 676-2307 Facsimile (216) 676-2276 tracy.thompson@graftech.com

July 13,2006

To Whom it May Concern:

Please find the attached chemical and physical properties of the materials shipped per PO\#00050342.

Physical Properties of Boronated Graphite*:

\begin{tabular}{|c|c|c|c|c|c|c|c|c|c|}
\hline FO\# & Density & $\begin{array}{c}\text { WG } \\
\text { Flexural } \\
\text { Strength } \\
\end{array}$ & $\begin{array}{c}\text { AG } \\
\text { Flexural } \\
\text { Strength } \\
\end{array}$ & $\begin{array}{c}\text { WG } \\
\text { Youngs } \\
\text { Modulus } \\
\end{array}$ & $\begin{array}{c}\text { WG } \\
\text { Specific } \\
\text { Resistance } \\
\end{array}$ & $\begin{array}{c}\text { WG } \\
\text { CTE (1" } \\
\text { cube) } \\
\end{array}$ & $\begin{array}{c}\text { AG CTE } \\
(1 " \\
\text { cube }) \\
\end{array}$ & $\begin{array}{l}\text { WG Thermal } \\
\text { Conductivity }\end{array}$ & $\begin{array}{l}\text { AG Thermal } \\
\text { Conductivity }\end{array}$ \\
\hline & g/cc & psi & $\operatorname{psi}_{x} 10$ & 6 Psi & m ohm m & $\mathrm{ppm} / \mathrm{K}$ & $\mathrm{ppm} / \mathrm{K}$ & $\mathrm{w} / \mathrm{mK}$ & $\mathrm{w} / \mathrm{mK}$ \\
\hline $\begin{array}{c}P-61-6.2 \\
-2 \\
(5.5 \% \\
\text { boron) } \\
\text { (4 cores) }\end{array}$ & $\overline{1.7}$ & 4470 & 4935 & 2.42 & 8.04 & 1.22 & 2.01 & 81.8 & $\overline{72.7}$ \\
\hline $\begin{array}{c}P-61-7.9 \\
-1(7.0 \% \\
\text { boron) } \\
\text { (4 cores) }\end{array}$ & 1.71 & 2215 & 2235 & 2.62 & 9.41 & 0.555 & 0.536 & 67.2 & 65 \\
\hline
\end{tabular}

* All testing reported in this table was carried out a room temperature.

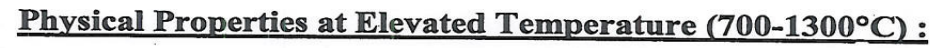

\begin{tabular}{|c|c|c|}
\hline & \begin{tabular}{|l|} 
Core ID\# \\
LP61-6.2-2 (5.5\% boron) \\
\end{tabular} & $\begin{array}{l}\text { Core ID\# } \\
\text { LP61-7.9-1 (7\% boron) }\end{array}$ \\
\hline $\begin{array}{l}\text { Unirradiated Thermal } \\
\text { Conductivity (wg/ag) }\end{array}$ & \multicolumn{2}{|c|}{ See Chart Below } \\
\hline $\begin{array}{l}\text { Average Coefficient of Thermal } \\
\text { Expansion (calculated) } \mathrm{x} \text { ppm } /{ }^{\circ} \mathrm{C}\end{array}$ & $\begin{array}{l}\text { WG: } 2.26-2.70 \\
\text { AG: } 3.05-3.49\end{array}$ & $\begin{array}{l}\text { WG: } 1.60-2.03 \\
\text { AG: } 1.58-2.02\end{array}$ \\
\hline $\begin{array}{l}\text { Average Specific Heat (700- } \\
1300 \mathrm{C})(\mathrm{J} / \mathrm{kg}-\mathrm{K})-\end{array}$ & $\begin{array}{c}1807 @ 700^{\circ} \mathrm{C} \\
2041 @ 1300^{\circ} \mathrm{C}\end{array}$ & $\begin{array}{l}1812 @ 700^{\circ} \mathrm{C} \\
2048 @ 1300^{\circ} \mathrm{C}\end{array}$ \\
\hline
\end{tabular}


Continuation of letter from GrafTech by (Thompson 2006).

- Unirradiated Thermal Comductivity (700-1300C)

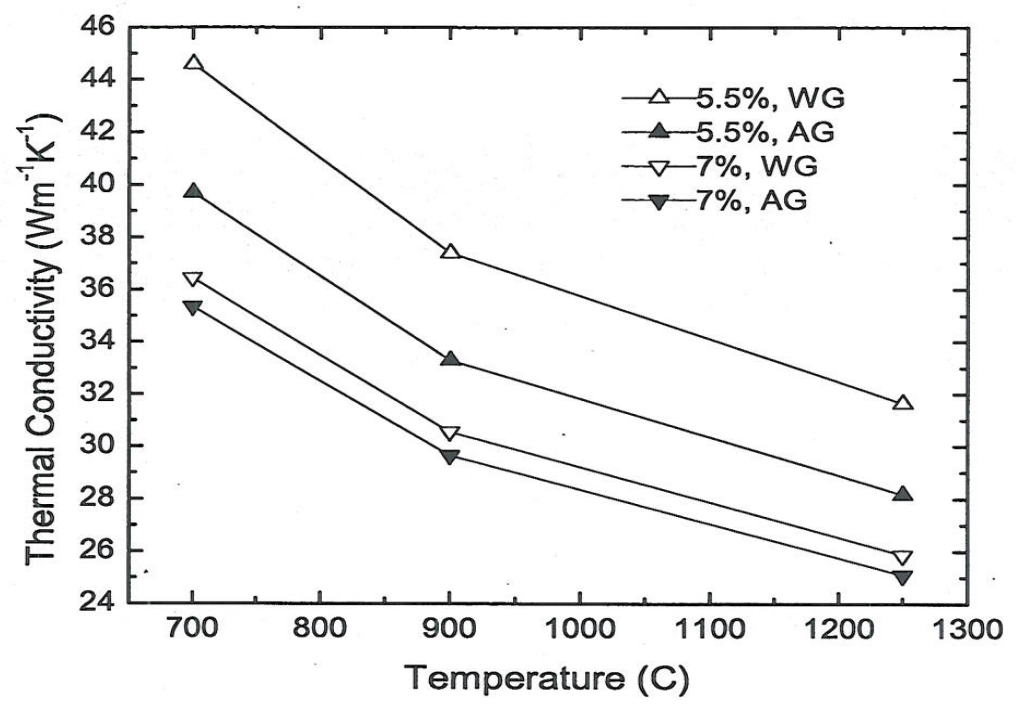

Elemental Analysis of Boronated Graphite ${ }^{\text {**: }}$

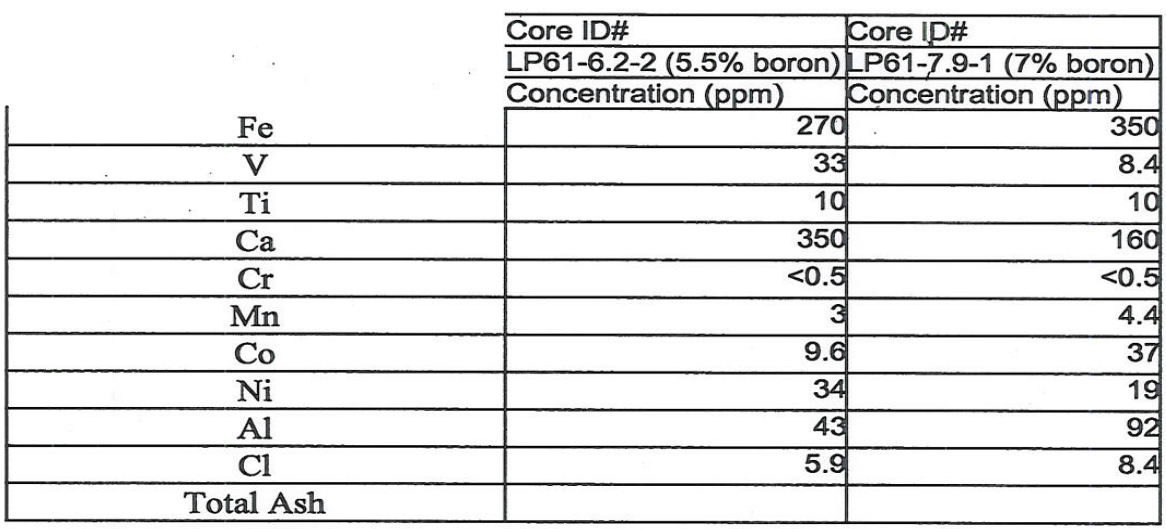

** Results obtained by GDMS analysis (Shiva Technologies). 
Appendix C

\section{Unfiltered Daily Average R/B Data}




\section{Appendix C Unfiltered Daily Average R/B Data}

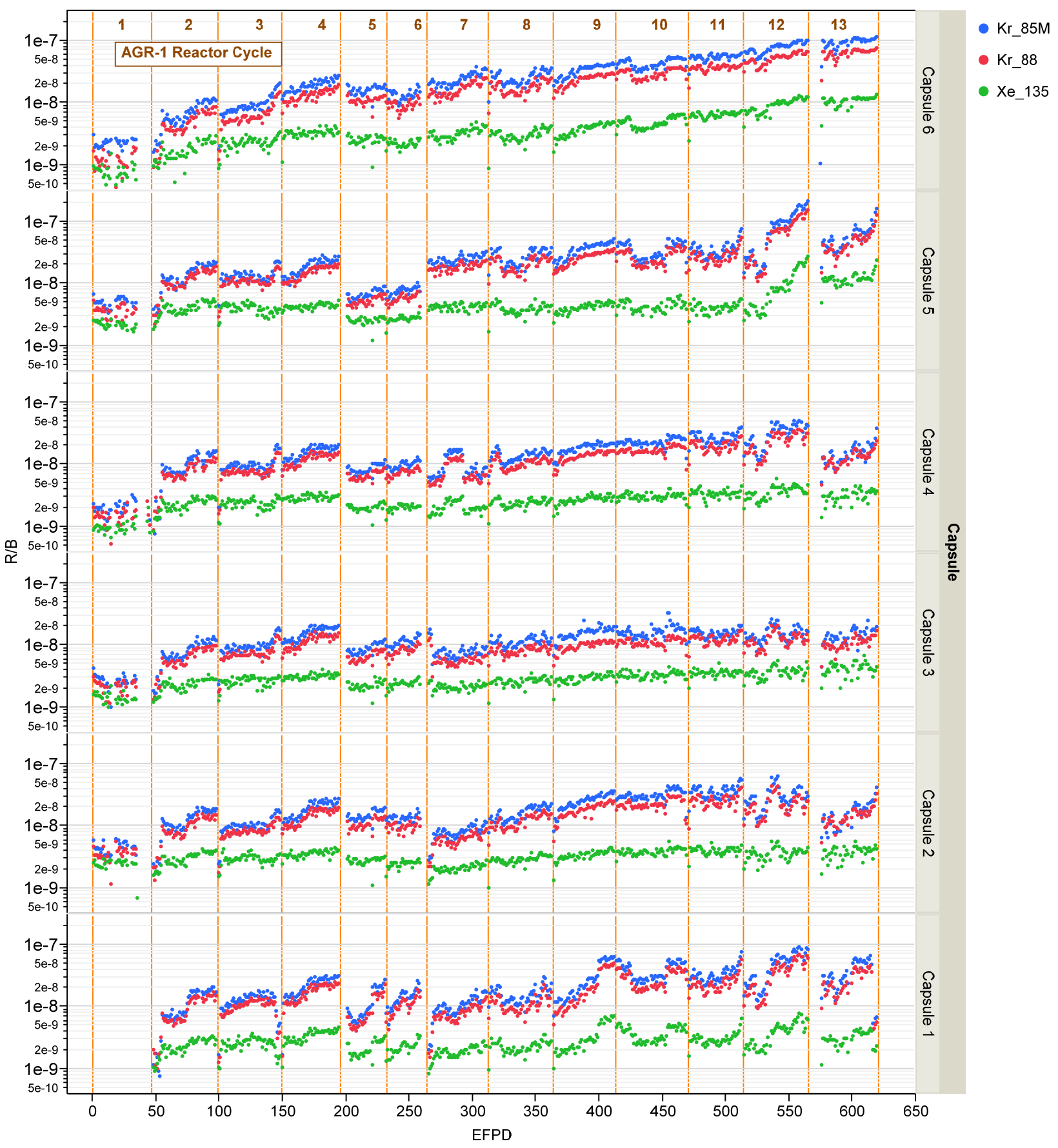

Figure C-1. Unfiltered daily-averaged R/B for $\mathrm{Kr}-85 \mathrm{~m}, \mathrm{Kr}-88$ and $\mathrm{Xe}-135$. 
Appendix D

Compact Burnup and Fast Fluence by Cycle 


\section{Appendix D \\ Compact Burnup and Fast Fluence by Cycle}

Table D-1. Compact burnup and fast fluence for capsules 6-4 after cycle 138B (AGR-1 cycle 1).

\begin{tabular}{|c|c|c|c|c|}
\hline Capsule & Stack & Compact & $\begin{array}{c}\text { Burnup } \\
\text { (\% FIMA) }\end{array}$ & $\begin{array}{l}\text { Fast Neutron Fluence } \\
\left(10^{25} \mathrm{n} / \mathrm{m}^{2} \mathrm{E}>0.18 \mathrm{MeV}\right)\end{array}$ \\
\hline \multirow{12}{*}{$\begin{array}{c}6 \\
\text { (top) }\end{array}$} & \multirow{4}{*}{1} & 4 & 0.72 & 0.17 \\
\hline & & 3 & 0.66 & 0.19 \\
\hline & & 2 & 0.69 & 0.20 \\
\hline & & 1 & 0.84 & 0.21 \\
\hline & \multirow{4}{*}{2} & 4 & 0.48 & 0.15 \\
\hline & & 3 & 0.40 & 0.16 \\
\hline & & 2 & 0.41 & 0.18 \\
\hline & & 1 & 0.53 & 0.19 \\
\hline & \multirow{4}{*}{3} & 4 & 0.73 & 0.17 \\
\hline & & 3 & 0.67 & 0.19 \\
\hline & & 2 & 0.71 & 0.20 \\
\hline & & 1 & 0.85 & 0.22 \\
\hline \multicolumn{3}{|c|}{ Capsule 6 Average } & 0.64 & 0.19 \\
\hline \multirow{12}{*}{5} & \multirow{4}{*}{1} & 4 & 0.83 & 0.24 \\
\hline & & 3 & 0.72 & 0.25 \\
\hline & & 2 & 0.74 & 0.26 \\
\hline & & 1 & 0.91 & 0.27 \\
\hline & \multirow{4}{*}{2} & 4 & 0.50 & 0.22 \\
\hline & & 3 & 0.40 & 0.22 \\
\hline & & 2 & 0.41 & 0.23 \\
\hline & & 1 & 0.55 & 0.24 \\
\hline & \multirow{4}{*}{3} & 4 & 0.84 & 0.25 \\
\hline & & 3 & 0.74 & 0.26 \\
\hline & & 2 & 0.76 & 0.27 \\
\hline & & 1 & 0.94 & 0.28 \\
\hline \multicolumn{3}{|c|}{ Capsule 5 Average } & 0.70 & 0.25 \\
\hline \multirow{12}{*}{4} & \multirow{4}{*}{1} & 4 & 0.98 & 0.29 \\
\hline & & 3 & 0.80 & 0.29 \\
\hline & & 2 & 0.81 & 0.30 \\
\hline & & 1 & 1.04 & 0.30 \\
\hline & \multirow{4}{*}{2} & 4 & 0.58 & 0.26 \\
\hline & & 3 & 0.44 & 0.26 \\
\hline & & 2 & 0.44 & 0.26 \\
\hline & & 1 & 0.59 & 0.27 \\
\hline & \multirow{4}{*}{3} & 4 & 1.00 & 0.29 \\
\hline & & 3 & 0.82 & 0.30 \\
\hline & & 2 & 0.83 & 0.30 \\
\hline & & 1 & 1.08 & 0.31 \\
\hline \multicolumn{3}{|c|}{ Capsule 4 Average } & 0.78 & 0.29 \\
\hline
\end{tabular}


Table D-2. Compact burnup and fast fluence for capsules 3-1 after cycle 138B (AGR-1 cycle 1).

\begin{tabular}{|c|c|c|c|c|}
\hline Capsule & Stack & Compact & $\begin{array}{c}\text { Burnup } \\
\text { (\% FIMA) }\end{array}$ & $\begin{array}{c}\text { Fast Neutron Fluence } \\
\left(10^{25} \mathrm{n} / \mathrm{m}^{2} \mathrm{E}>0.18 \mathrm{MeV}\right)\end{array}$ \\
\hline \multirow{12}{*}{3} & \multirow{4}{*}{1} & 4 & 1.07 & 0.30 \\
\hline & & 3 & 0.84 & 0.30 \\
\hline & & 2 & 0.83 & 0.30 \\
\hline & & 1 & 1.07 & 0.30 \\
\hline & \multirow{4}{*}{2} & 4 & 0.62 & 0.27 \\
\hline & & 3 & 0.45 & 0.27 \\
\hline & & 2 & 0.45 & 0.27 \\
\hline & & 1 & 0.61 & 0.27 \\
\hline & \multirow{4}{*}{3} & 4 & 1.10 & 0.31 \\
\hline & & 3 & 0.86 & 0.31 \\
\hline & & 2 & 0.86 & 0.31 \\
\hline & & 1 & 1.09 & 0.31 \\
\hline \multicolumn{3}{|c|}{ Capsule 3 Average } & 0.82 & 0.29 \\
\hline \multirow{12}{*}{2} & \multirow{4}{*}{1} & 4 & 1.01 & 0.29 \\
\hline & & 3 & 0.79 & 0.28 \\
\hline & & 2 & 0.78 & 0.28 \\
\hline & & 1 & 0.91 & 0.27 \\
\hline & \multirow{4}{*}{2} & 4 & 0.61 & 0.26 \\
\hline & & 3 & 0.45 & 0.25 \\
\hline & & 2 & 0.43 & 0.24 \\
\hline & & 1 & 0.55 & 0.24 \\
\hline & \multirow{4}{*}{3} & 4 & 1.05 & 0.29 \\
\hline & & 3 & 0.82 & 0.29 \\
\hline & & 2 & 0.80 & 0.28 \\
\hline & & 1 & 0.94 & 0.27 \\
\hline \multicolumn{3}{|c|}{ Capsule 2 Average } & 0.76 & 0.27 \\
\hline \multirow{12}{*}{$\begin{array}{c}1 \\
\text { (bottom) }\end{array}$} & \multirow{4}{*}{1} & 4 & 0.95 & 0.24 \\
\hline & & 3 & 0.78 & 0.23 \\
\hline & & 2 & 0.75 & 0.22 \\
\hline & & 1 & 0.83 & 0.20 \\
\hline & \multirow{4}{*}{2} & 4 & 0.62 & 0.21 \\
\hline & & 3 & 0.47 & 0.20 \\
\hline & & 2 & 0.46 & 0.19 \\
\hline & & 1 & 0.55 & 0.18 \\
\hline & \multirow{4}{*}{3} & 4 & 0.97 & 0.25 \\
\hline & & 3 & 0.80 & 0.23 \\
\hline & & 2 & 0.77 & 0.22 \\
\hline & & 1 & 0.85 & 0.20 \\
\hline \multicolumn{3}{|c|}{ Capsule 1 Average } & 0.73 & 0.21 \\
\hline
\end{tabular}


Table D-3. Compact burnup and fast fluence for capsules 6-4 after cycle 139A (AGR-1 cycle 2).

\begin{tabular}{|c|c|c|c|c|}
\hline Capsule & Stack & Compact & $\begin{array}{c}\text { Burnup } \\
\text { (\% FIMA) }\end{array}$ & $\begin{array}{c}\text { Fast Neutron Fluence } \\
\left(10^{25} \mathrm{n} / \mathrm{m}^{2} \mathrm{E}>0.18 \mathrm{MeV}\right)\end{array}$ \\
\hline \multirow{12}{*}{$\begin{array}{c}6 \\
\text { (top) }\end{array}$} & \multirow{4}{*}{1} & 4 & 1.60 & 0.37 \\
\hline & & 3 & 1.47 & 0.40 \\
\hline & & 2 & 1.57 & 0.43 \\
\hline & & 1 & 1.88 & 0.46 \\
\hline & \multirow{4}{*}{2} & 4 & 1.07 & 0.32 \\
\hline & & 3 & 0.90 & 0.35 \\
\hline & & 2 & 0.94 & 0.37 \\
\hline & & 1 & 1.20 & 0.40 \\
\hline & \multirow{4}{*}{3} & 4 & 1.60 & 0.37 \\
\hline & & 3 & 1.46 & 0.40 \\
\hline & & 2 & 1.56 & 0.43 \\
\hline & & 1 & 1.88 & 0.46 \\
\hline \multicolumn{3}{|c|}{ Capsule 6 Average } & 1.43 & 0.40 \\
\hline \multirow{12}{*}{5} & \multirow{4}{*}{1} & 4 & 1.89 & 0.52 \\
\hline & & 3 & 1.66 & 0.54 \\
\hline & & 2 & 1.72 & 0.56 \\
\hline & & 1 & 2.19 & 0.58 \\
\hline & \multirow{4}{*}{2} & 4 & 1.16 & 0.46 \\
\hline & & 3 & 0.94 & 0.48 \\
\hline & & 2 & 0.97 & 0.49 \\
\hline & & 1 & 1.31 & 0.51 \\
\hline & \multirow{4}{*}{3} & 4 & 1.89 & 0.53 \\
\hline & & 3 & 1.66 & 0.55 \\
\hline & & 2 & 1.71 & 0.57 \\
\hline & & 1 & 2.18 & 0.59 \\
\hline \multicolumn{3}{|c|}{ Capsule 5 Average } & 1.61 & 0.53 \\
\hline \multirow{12}{*}{4} & \multirow{4}{*}{1} & 4 & 2.40 & 0.62 \\
\hline & & 3 & 1.95 & 0.63 \\
\hline & & 2 & 2.00 & 0.64 \\
\hline & & 1 & 2.55 & 0.64 \\
\hline & \multirow{4}{*}{2} & 4 & 1.42 & 0.55 \\
\hline & & 3 & 1.05 & 0.55 \\
\hline & & 2 & 1.07 & 0.56 \\
\hline & & 1 & 1.51 & 0.57 \\
\hline & \multirow{4}{*}{3} & 4 & 2.38 & 0.63 \\
\hline & & 3 & 1.96 & 0.64 \\
\hline & & 2 & 1.98 & 0.64 \\
\hline & & 1 & 2.57 & 0.65 \\
\hline \multicolumn{3}{|c|}{ Capsule 4 Average } & 1.90 & 0.61 \\
\hline
\end{tabular}


Table D-4. Compact burnup and fast fluence for capsules 3-1 after cycle 139A (AGR-1 cycle 2).

\begin{tabular}{|c|c|c|c|c|}
\hline Capsule & Stack & Compact & $\begin{array}{c}\text { Burnup } \\
\text { (\% FIMA) }\end{array}$ & $\begin{array}{c}\text { Fast Neutron Fluence } \\
\left(10^{25} \mathrm{n} / \mathrm{m}^{2} \mathrm{E}>0.18 \mathrm{MeV}\right)\end{array}$ \\
\hline \multirow{12}{*}{3} & \multirow{4}{*}{1} & 4 & 2.63 & 0.65 \\
\hline & & 3 & 2.13 & 0.65 \\
\hline & & 2 & 2.08 & 0.64 \\
\hline & & 1 & 2.60 & 0.64 \\
\hline & \multirow{4}{*}{2} & 4 & 1.57 & 0.58 \\
\hline & & 3 & 1.11 & 0.57 \\
\hline & & 2 & 1.11 & 0.57 \\
\hline & & 1 & 1.54 & 0.57 \\
\hline & \multirow{4}{*}{3} & 4 & 2.63 & 0.66 \\
\hline & & 3 & 2.14 & 0.66 \\
\hline & & 2 & 2.12 & 0.66 \\
\hline & & 1 & 2.60 & 0.65 \\
\hline \multicolumn{3}{|c|}{ Capsule 3 Average } & 2.02 & 0.62 \\
\hline \multirow{12}{*}{2} & \multirow{4}{*}{1} & 4 & 2.45 & 0.62 \\
\hline & & 3 & 1.89 & 0.60 \\
\hline & & 2 & 1.83 & 0.59 \\
\hline & & 1 & 2.17 & 0.57 \\
\hline & \multirow{4}{*}{2} & 4 & 1.49 & 0.55 \\
\hline & & 3 & 1.06 & 0.53 \\
\hline & & 2 & 1.03 & 0.52 \\
\hline & & 1 & 1.31 & 0.51 \\
\hline & \multirow{4}{*}{3} & 4 & 2.47 & 0.63 \\
\hline & & 3 & 1.90 & 0.61 \\
\hline & & 2 & 1.83 & 0.60 \\
\hline & & 1 & 2.19 & 0.58 \\
\hline \multicolumn{3}{|c|}{ Capsule 2 Average } & 1.80 & 0.57 \\
\hline \multirow{12}{*}{$\begin{array}{c}1 \\
\text { (bottom) }\end{array}$} & \multirow{4}{*}{1} & 4 & 2.19 & 0.51 \\
\hline & & 3 & 1.78 & 0.49 \\
\hline & & 2 & 1.70 & 0.46 \\
\hline & & 1 & 1.87 & 0.43 \\
\hline & \multirow{4}{*}{2} & 4 & 1.43 & 0.45 \\
\hline & & 3 & 1.09 & 0.43 \\
\hline & & 2 & 1.05 & 0.40 \\
\hline & & 1 & 1.24 & 0.38 \\
\hline & \multirow{4}{*}{3} & 4 & 2.19 & 0.52 \\
\hline & & 3 & 1.78 & 0.49 \\
\hline & & 2 & 1.70 & 0.46 \\
\hline & & 1 & 1.88 & 0.43 \\
\hline \multicolumn{3}{|c|}{ Capsule 1 Average } & 1.66 & 0.45 \\
\hline
\end{tabular}


Table D-5. Compact burnup and fast fluence for capsules 6-4 after cycle 139B (AGR-1 cycle 3).

\begin{tabular}{|c|c|c|c|c|}
\hline Capsule & Stack & Compact & $\begin{array}{c}\text { Burnup } \\
(\% \text { FIMA) }\end{array}$ & $\begin{array}{c}\text { Fast Neutron Fluence } \\
\left(10^{25} \mathrm{n} / \mathrm{m}^{2} \mathrm{E}>0.18 \mathrm{MeV}\right)\end{array}$ \\
\hline \multirow{12}{*}{$\begin{array}{c}6 \\
\text { (top) }\end{array}$} & \multirow{4}{*}{1} & 4 & 2.57 & 0.55 \\
\hline & & 3 & 2.39 & 0.60 \\
\hline & & 2 & 2.57 & 0.65 \\
\hline & & 1 & 3.02 & 0.69 \\
\hline & \multirow{4}{*}{2} & 4 & 1.75 & 0.49 \\
\hline & & 3 & 1.50 & 0.53 \\
\hline & & 2 & 1.59 & 0.57 \\
\hline & & 1 & 1.98 & 0.61 \\
\hline & \multirow{4}{*}{3} & 4 & 2.54 & 0.56 \\
\hline & & 3 & 2.35 & 0.61 \\
\hline & & 2 & 2.52 & 0.66 \\
\hline & & 1 & 2.98 & 0.70 \\
\hline \multicolumn{3}{|c|}{ Capsule 6 Average } & 2.31 & 0.60 \\
\hline \multirow{12}{*}{5} & \multirow{4}{*}{1} & 4 & 3.10 & 0.79 \\
\hline & & 3 & 2.76 & 0.82 \\
\hline & & 2 & 2.88 & 0.85 \\
\hline & & 1 & 3.62 & 0.87 \\
\hline & \multirow{4}{*}{2} & 4 & 1.97 & 0.70 \\
\hline & & 3 & 1.63 & 0.72 \\
\hline & & 2 & 1.69 & 0.75 \\
\hline & & 1 & 2.25 & 0.77 \\
\hline & \multirow{4}{*}{3} & 4 & 3.05 & 0.80 \\
\hline & & 3 & 2.72 & 0.83 \\
\hline & & 2 & 2.82 & 0.86 \\
\hline & & 1 & 3.56 & 0.88 \\
\hline \multicolumn{3}{|c|}{ Capsule 5 Average } & 2.67 & 0.80 \\
\hline \multirow{12}{*}{4} & \multirow{4}{*}{1} & 4 & 4.00 & 0.93 \\
\hline & & 3 & 3.33 & 0.95 \\
\hline & & 2 & 3.42 & 0.96 \\
\hline & & 1 & 4.27 & 0.97 \\
\hline & \multirow{4}{*}{2} & 4 & 2.45 & 0.82 \\
\hline & & 3 & 1.89 & 0.83 \\
\hline & & 2 & 1.92 & 0.85 \\
\hline & & 1 & 2.66 & 0.86 \\
\hline & \multirow{4}{*}{3} & 4 & 3.92 & 0.94 \\
\hline & & 3 & 3.27 & 0.96 \\
\hline & & 2 & 3.36 & 0.97 \\
\hline & & 1 & 4.23 & 0.98 \\
\hline \multicolumn{3}{|c|}{ Capsule 4 Average } & 3.23 & 0.92 \\
\hline
\end{tabular}


Table D-6. Compact burnup and fast fluence for capsules 3-1 after cycle 139B (AGR-1 cycle 3).

\begin{tabular}{|c|c|c|c|c|}
\hline Capsule & Stack & Compact & $\begin{array}{c}\text { Burnup } \\
\text { (\% FIMA) }\end{array}$ & $\begin{array}{c}\text { Fast Neutron Fluence } \\
\left(10^{25} \mathrm{n} / \mathrm{m}^{2} \mathrm{E}>0.18 \mathrm{MeV}\right)\end{array}$ \\
\hline \multirow{12}{*}{3} & \multirow{4}{*}{1} & 4 & 4.40 & 0.98 \\
\hline & & 3 & 3.65 & 0.98 \\
\hline & & 2 & 3.58 & 0.98 \\
\hline & & 1 & 4.35 & 0.97 \\
\hline & \multirow{4}{*}{2} & 4 & 2.76 & 0.87 \\
\hline & & 3 & 2.02 & 0.86 \\
\hline & & 2 & 2.02 & 0.86 \\
\hline & & 1 & 2.70 & 0.86 \\
\hline & \multirow{4}{*}{3} & 4 & 4.33 & 0.99 \\
\hline & & 3 & 3.60 & 0.99 \\
\hline & & 2 & 3.56 & 0.99 \\
\hline & & 1 & 4.28 & 0.98 \\
\hline \multicolumn{3}{|c|}{ Capsule 3 Average } & 3.44 & 0.94 \\
\hline \multirow{12}{*}{2} & \multirow{4}{*}{1} & 4 & 4.09 & 0.93 \\
\hline & & 3 & 3.21 & 0.91 \\
\hline & & 2 & 3.10 & 0.89 \\
\hline & & 1 & 3.61 & 0.86 \\
\hline & \multirow{4}{*}{2} & 4 & 2.60 & 0.82 \\
\hline & & 3 & 1.90 & 0.80 \\
\hline & & 2 & 1.83 & 0.78 \\
\hline & & 1 & 2.28 & 0.76 \\
\hline & \multirow{4}{*}{3} & 4 & 4.05 & 0.94 \\
\hline & & 3 & 3.17 & 0.92 \\
\hline & & 2 & 3.04 & 0.90 \\
\hline & & 1 & 3.59 & 0.87 \\
\hline \multicolumn{3}{|c|}{ Capsule 2 Average } & 3.04 & 0.87 \\
\hline \multirow{12}{*}{$\begin{array}{c}1 \\
\text { (bottom) }\end{array}$} & \multirow{4}{*}{1} & 4 & 3.57 & 0.77 \\
\hline & & 3 & 2.94 & 0.74 \\
\hline & & 2 & 2.80 & 0.69 \\
\hline & & 1 & 3.03 & 0.64 \\
\hline & \multirow{4}{*}{2} & 4 & 2.42 & 0.69 \\
\hline & & 3 & 1.88 & 0.65 \\
\hline & & 2 & 1.79 & 0.61 \\
\hline & & 1 & 2.06 & 0.57 \\
\hline & \multirow{4}{*}{3} & 4 & 3.54 & 0.78 \\
\hline & & 3 & 2.91 & 0.75 \\
\hline & & 2 & 2.76 & 0.70 \\
\hline & & 1 & 3.00 & 0.65 \\
\hline \multicolumn{3}{|c|}{ Capsule 1 Average } & 2.73 & 0.69 \\
\hline
\end{tabular}


Table D-7. Compact burnup and fast fluence for capsules 6-4 after cycle 140A (AGR-1 cycle 4).

\begin{tabular}{|c|c|c|c|c|}
\hline Capsule & Stack & Compact & $\begin{array}{l}\text { Burnup } \\
\text { (\% FIMA) }\end{array}$ & $\begin{array}{c}\text { Fast Neutron Fluence } \\
\left(10^{25} \mathrm{n} / \mathrm{m}^{2} \mathrm{E}>0.18 \mathrm{MeV}\right)\end{array}$ \\
\hline \multirow{12}{*}{$\begin{array}{c}6 \\
\text { (top) }\end{array}$} & \multirow{4}{*}{1} & 4 & 3.46 & 0.72 \\
\hline & & 3 & 3.26 & 0.79 \\
\hline & & 2 & 3.53 & 0.85 \\
\hline & & 1 & 4.09 & 0.90 \\
\hline & \multirow{4}{*}{2} & 4 & 2.40 & 0.63 \\
\hline & & 3 & 2.10 & 0.69 \\
\hline & & 2 & 2.25 & 0.74 \\
\hline & & 1 & 2.76 & 0.79 \\
\hline & \multirow{4}{*}{3} & 4 & 3.43 & 0.73 \\
\hline & & 3 & 3.22 & 0.80 \\
\hline & & 2 & 3.47 & 0.86 \\
\hline & & 1 & 4.04 & 0.91 \\
\hline \multicolumn{3}{|c|}{ Capsule 6 Average } & 3.17 & 0.78 \\
\hline \multirow{12}{*}{5} & \multirow{4}{*}{1} & 4 & 4.26 & 1.03 \\
\hline & & 3 & 3.86 & 1.07 \\
\hline & & 2 & 4.03 & 1.11 \\
\hline & & 1 & 5.01 & 1.14 \\
\hline & \multirow{4}{*}{2} & 4 & 2.80 & 0.91 \\
\hline & & 3 & 2.37 & 0.94 \\
\hline & & 2 & 2.48 & 0.97 \\
\hline & & 1 & 3.23 & 1.01 \\
\hline & \multirow{4}{*}{3} & 4 & 4.22 & 1.04 \\
\hline & & 3 & 3.82 & 1.08 \\
\hline & & 2 & 3.97 & 1.12 \\
\hline & & 1 & 4.94 & 1.15 \\
\hline \multicolumn{3}{|c|}{ Capsule 5 Average } & 3.75 & 1.05 \\
\hline \multirow{12}{*}{4} & \multirow{4}{*}{1} & 4 & 5.58 & 1.22 \\
\hline & & 3 & 4.73 & 1.24 \\
\hline & & 2 & 4.88 & 1.25 \\
\hline & & 1 & 5.93 & 1.26 \\
\hline & \multirow{4}{*}{2} & 4 & 3.53 & 1.08 \\
\hline & & 3 & 2.83 & 1.09 \\
\hline & & 2 & 2.89 & 1.11 \\
\hline & & 1 & 3.87 & 1.12 \\
\hline & \multirow{4}{*}{3} & 4 & 5.48 & 1.23 \\
\hline & & 3 & 4.69 & 1.25 \\
\hline & & 2 & 4.82 & 1.27 \\
\hline & & 1 & 5.90 & 1.28 \\
\hline \multicolumn{3}{|c|}{ Capsule 4 Average } & 4.59 & 1.20 \\
\hline
\end{tabular}


Table D-8. Compact burnup and fast fluence for capsules 3-1 after cycle 140A (AGR-1 cycle 4).

\begin{tabular}{|c|c|c|c|c|}
\hline Capsule & Stack & Compact & $\begin{array}{l}\text { Burnup } \\
\text { (\% FIMA) }\end{array}$ & $\begin{array}{c}\text { Fast Neutron Fluence } \\
\left(10^{25} \mathrm{n} / \mathrm{m}^{2} \mathrm{E}>0.18 \mathrm{MeV}\right)\end{array}$ \\
\hline \multirow{12}{*}{3} & \multirow{4}{*}{1} & 4 & 6.11 & 1.28 \\
\hline & & 3 & 5.18 & 1.28 \\
\hline & & 2 & 5.14 & 1.28 \\
\hline & & 1 & 6.04 & 1.27 \\
\hline & \multirow{4}{*}{2} & 4 & 4.01 & 1.13 \\
\hline & & 3 & 3.05 & 1.13 \\
\hline & & 2 & 3.05 & 1.13 \\
\hline & & 1 & 3.95 & 1.12 \\
\hline & \multirow{4}{*}{3} & 4 & 6.05 & 1.30 \\
\hline & & 3 & 5.15 & 1.30 \\
\hline & & 2 & 5.11 & 1.29 \\
\hline & & 1 & 5.98 & 1.28 \\
\hline \multicolumn{3}{|c|}{ Capsule 3 Average } & 4.90 & 1.23 \\
\hline \multirow{12}{*}{2} & \multirow{4}{*}{1} & 4 & 5.69 & 1.21 \\
\hline & & 3 & 4.52 & 1.19 \\
\hline & & 2 & 4.36 & 1.16 \\
\hline & & 1 & 5.00 & 1.12 \\
\hline & \multirow{4}{*}{2} & 4 & 3.75 & 1.08 \\
\hline & & 3 & 2.83 & 1.05 \\
\hline & & 2 & 2.73 & 1.02 \\
\hline & & 1 & 3.28 & 1.00 \\
\hline & \multirow{4}{*}{3} & 4 & 5.63 & 1.23 \\
\hline & & 3 & 4.51 & 1.20 \\
\hline & & 2 & 4.32 & 1.17 \\
\hline & & 1 & 4.98 & 1.14 \\
\hline \multicolumn{3}{|c|}{ Capsule 2 Average } & 4.30 & 1.13 \\
\hline \multirow{12}{*}{$\begin{array}{c}1 \\
\text { (bottom) }\end{array}$} & \multirow{4}{*}{1} & 4 & 4.87 & 1.01 \\
\hline & & 3 & 4.07 & 0.96 \\
\hline & & 2 & 3.87 & 0.91 \\
\hline & & 1 & 4.12 & 0.84 \\
\hline & \multirow{4}{*}{2} & 4 & 3.41 & 0.90 \\
\hline & & 3 & 2.71 & 0.85 \\
\hline & & 2 & 2.56 & 0.80 \\
\hline & & 1 & 2.87 & 0.74 \\
\hline & \multirow{4}{*}{3} & 4 & 4.84 & 1.02 \\
\hline & & 3 & 4.04 & 0.97 \\
\hline & & 2 & 3.83 & 0.92 \\
\hline & & 1 & 4.09 & 0.85 \\
\hline \multicolumn{3}{|c|}{ Capsule 1 Average } & 3.77 & 0.90 \\
\hline
\end{tabular}


Table D-9. Compact burnup and fast fluence for capsules 6-4 after cycle 140B (AGR-1 cycle 5).

\begin{tabular}{|c|c|c|c|c|}
\hline Capsule & Stack & Compact & $\begin{array}{c}\text { Burnup } \\
(\% \text { FIMA) }\end{array}$ & $\begin{array}{c}\text { Fast Neutron Fluence } \\
\left(10^{25} \mathrm{n} / \mathrm{m}^{2} \mathrm{E}>0.18 \mathrm{MeV}\right)\end{array}$ \\
\hline \multirow{12}{*}{$\begin{array}{c}6 \\
\text { (top) }\end{array}$} & \multirow{4}{*}{1} & 4 & 4.12 & 0.84 \\
\hline & & 3 & 3.91 & 0.92 \\
\hline & & 2 & 4.25 & 0.99 \\
\hline & & 1 & 4.88 & 1.05 \\
\hline & \multirow{4}{*}{2} & 4 & 2.90 & 0.74 \\
\hline & & 3 & 2.57 & 0.80 \\
\hline & & 2 & 2.79 & 0.87 \\
\hline & & 1 & 3.37 & 0.92 \\
\hline & \multirow{4}{*}{3} & 4 & 4.11 & 0.85 \\
\hline & & 3 & 3.88 & 0.93 \\
\hline & & 2 & 4.21 & 1.00 \\
\hline & & 1 & 4.85 & 1.06 \\
\hline \multicolumn{3}{|c|}{ Capsule 6 Average } & 3.82 & 0.91 \\
\hline \multirow{12}{*}{5} & \multirow{4}{*}{1} & 4 & 5.14 & 1.20 \\
\hline & & 3 & 4.71 & 1.25 \\
\hline & & 2 & 4.93 & 1.29 \\
\hline & & 1 & 6.03 & 1.33 \\
\hline & \multirow{4}{*}{2} & 4 & 3.48 & 1.06 \\
\hline & & 3 & 3.01 & 1.10 \\
\hline & & 2 & 3.16 & 1.14 \\
\hline & & 1 & 4.01 & 1.17 \\
\hline & \multirow{4}{*}{3} & 4 & 5.11 & 1.21 \\
\hline & & 3 & 4.69 & 1.26 \\
\hline & & 2 & 4.89 & 1.31 \\
\hline & & 1 & 5.99 & 1.34 \\
\hline \multicolumn{3}{|c|}{ Capsule 5 Average } & 4.60 & 1.22 \\
\hline \multirow{12}{*}{4} & \multirow{4}{*}{1} & 4 & 6.72 & 1.42 \\
\hline & & 3 & 5.81 & 1.44 \\
\hline & & 2 & 5.99 & 1.46 \\
\hline & & 1 & 7.13 & 1.47 \\
\hline & \multirow{4}{*}{2} & 4 & 4.41 & 1.25 \\
\hline & & 3 & 3.64 & 1.27 \\
\hline & & 2 & 3.72 & 1.29 \\
\hline & & 1 & 4.83 & 1.31 \\
\hline & \multirow{4}{*}{3} & 4 & 6.66 & 1.44 \\
\hline & & 3 & 5.81 & 1.46 \\
\hline & & 2 & 5.97 & 1.48 \\
\hline & & 1 & 7.15 & 1.49 \\
\hline \multicolumn{3}{|c|}{ Capsule 4 Average } & 5.65 & 1.40 \\
\hline
\end{tabular}


Table D-10. Compact burnup and fast fluence for capsules 3-1 after cycle 140B (AGR-1 cycle 5).

\begin{tabular}{|c|c|c|c|c|}
\hline Capsule & Stack & Compact & $\begin{array}{c}\text { Burnup } \\
\text { (\% FIMA) } \\
\end{array}$ & $\begin{array}{c}\text { Fast Neutron Fluence } \\
\left(10^{25} \mathrm{n} / \mathrm{m}^{2} \mathrm{E}>0.18 \mathrm{MeV}\right) \\
\end{array}$ \\
\hline \multirow{12}{*}{3} & \multirow{4}{*}{1} & 4 & 7.35 & 1.49 \\
\hline & & 3 & 6.35 & 1.50 \\
\hline & & 2 & 6.30 & 1.49 \\
\hline & & 1 & 7.28 & 1.48 \\
\hline & \multirow{4}{*}{2} & 4 & 5.01 & 1.32 \\
\hline & & 3 & 3.94 & 1.32 \\
\hline & & 2 & 3.94 & 1.32 \\
\hline & & 1 & 4.93 & 1.31 \\
\hline & \multirow{4}{*}{3} & 4 & 7.33 & 1.51 \\
\hline & & 3 & 6.38 & 1.52 \\
\hline & & 2 & 6.33 & 1.51 \\
\hline & & 1 & 7.26 & 1.49 \\
\hline \multicolumn{3}{|c|}{ Capsule 3 Average } & 6.03 & 1.44 \\
\hline \multirow{12}{*}{2} & \multirow{4}{*}{1} & 4 & 6.86 & 1.42 \\
\hline & & 3 & 5.57 & 1.39 \\
\hline & & 2 & 5.37 & 1.36 \\
\hline & & 1 & 6.05 & 1.31 \\
\hline & \multirow{4}{*}{2} & 4 & 4.68 & 1.26 \\
\hline & & 3 & 3.64 & 1.23 \\
\hline & & 2 & 3.51 & 1.20 \\
\hline & & 1 & 4.11 & 1.16 \\
\hline & \multirow{4}{*}{3} & 4 & 6.84 & 1.44 \\
\hline & & 3 & 5.60 & 1.41 \\
\hline & & 2 & 5.36 & 1.37 \\
\hline & & 1 & 6.08 & 1.33 \\
\hline \multicolumn{3}{|c|}{ Capsule 2 Average } & 5.31 & 1.32 \\
\hline \multirow{12}{*}{$\begin{array}{c}1 \\
\text { (bottom) }\end{array}$} & \multirow{4}{*}{1} & 4 & 5.83 & 1.18 \\
\hline & & 3 & 4.94 & 1.12 \\
\hline & & 2 & 4.69 & 1.06 \\
\hline & & 1 & 4.94 & 0.98 \\
\hline & \multirow{4}{*}{2} & 4 & 4.20 & 1.05 \\
\hline & & 3 & 3.40 & 1.00 \\
\hline & & 2 & 3.20 & 0.93 \\
\hline & & 1 & 3.52 & 0.87 \\
\hline & \multirow{4}{*}{3} & 4 & 5.82 & 1.20 \\
\hline & & 3 & 4.93 & 1.14 \\
\hline & & 2 & 4.67 & 1.07 \\
\hline & & 1 & 4.92 & 1.00 \\
\hline \multicolumn{3}{|c|}{ Capsule 1 Average } & 4.59 & 1.05 \\
\hline
\end{tabular}


Table D-11. Compact burnup and fast fluence for capsules 6-4 after cycle 141A (AGR-1 cycle 6).

\begin{tabular}{|c|c|c|c|c|}
\hline Capsule & Stack & Compact & $\begin{array}{c}\text { Burnup } \\
\text { (\% FIMA) } \\
\end{array}$ & $\begin{array}{c}\text { Fast Neutron Fluence } \\
\left(10^{25} \mathrm{n} / \mathrm{m}^{2} \mathrm{E}>0.18 \mathrm{MeV}\right) \\
\end{array}$ \\
\hline \multirow{12}{*}{$\begin{array}{c}6 \\
\text { (top) }\end{array}$} & \multirow{4}{*}{1} & 4 & 4.88 & 0.97 \\
\hline & & 3 & 4.68 & 1.06 \\
\hline & & 2 & 5.09 & 1.14 \\
\hline & & 1 & 5.78 & 1.20 \\
\hline & \multirow{4}{*}{2} & 4 & 3.48 & 0.85 \\
\hline & & 3 & 3.14 & 0.93 \\
\hline & & 2 & 3.42 & 1.00 \\
\hline & & 1 & 4.07 & 1.06 \\
\hline & \multirow{4}{*}{3} & 4 & 4.85 & 0.98 \\
\hline & & 3 & 4.63 & 1.07 \\
\hline & & 2 & 5.03 & 1.15 \\
\hline & & 1 & 5.73 & 1.22 \\
\hline \multicolumn{3}{|c|}{ Capsule 6 Average } & 4.56 & 1.05 \\
\hline \multirow{12}{*}{5} & \multirow{4}{*}{1} & 4 & 6.20 & 1.38 \\
\hline & & 3 & 5.75 & 1.44 \\
\hline & & 2 & 6.03 & 1.49 \\
\hline & & 1 & 7.26 & 1.53 \\
\hline & \multirow{4}{*}{2} & 4 & 4.28 & 1.22 \\
\hline & & 3 & 3.79 & 1.27 \\
\hline & & 2 & 3.99 & 1.31 \\
\hline & & 1 & 4.97 & 1.35 \\
\hline & \multirow{4}{*}{3} & 4 & 6.14 & 1.40 \\
\hline & & 3 & 5.71 & 1.45 \\
\hline & & 2 & 5.97 & 1.50 \\
\hline & & 1 & 7.21 & 1.54 \\
\hline \multicolumn{3}{|c|}{ Capsule 5 Average } & 5.61 & 1.41 \\
\hline \multirow{12}{*}{4} & \multirow{4}{*}{1} & 4 & 8.07 & 1.63 \\
\hline & & 3 & 7.17 & 1.67 \\
\hline & & 2 & 7.36 & 1.69 \\
\hline & & 1 & 8.52 & 1.69 \\
\hline & \multirow{4}{*}{2} & 4 & 5.52 & 1.44 \\
\hline & & 3 & 4.68 & 1.47 \\
\hline & & 2 & 4.82 & 1.49 \\
\hline & & 1 & 6.00 & 1.50 \\
\hline & \multirow{4}{*}{3} & 4 & 7.99 & 1.65 \\
\hline & & 3 & 7.13 & 1.68 \\
\hline & & 2 & 7.31 & 1.70 \\
\hline & & 1 & 8.52 & 1.71 \\
\hline \multicolumn{3}{|c|}{ Capsule 4 Average } & 6.92 & 1.61 \\
\hline
\end{tabular}


Table D-12. Compact burnup and fast fluence for capsules 3-1 after cycle 141A (AGR-1 cycle 6).

\begin{tabular}{|c|c|c|c|c|}
\hline Capsule & Stack & Compact & $\begin{array}{c}\text { Burnup } \\
\text { (\% FIMA) }\end{array}$ & $\begin{array}{c}\text { Fast Neutron Fluence } \\
\left(10^{25} \mathrm{n} / \mathrm{m}^{2} \mathrm{E}>0.18 \mathrm{MeV}\right)\end{array}$ \\
\hline \multirow{12}{*}{3} & \multirow{4}{*}{1} & 4 & 8.76 & 1.72 \\
\hline & & 3 & 7.76 & 1.72 \\
\hline & & 2 & 7.72 & 1.72 \\
\hline & & 1 & 8.69 & 1.70 \\
\hline & \multirow{4}{*}{2} & 4 & 6.22 & 1.52 \\
\hline & & 3 & 5.11 & 1.53 \\
\hline & & 2 & 5.11 & 1.52 \\
\hline & & 1 & 6.16 & 1.51 \\
\hline & \multirow{4}{*}{3} & 4 & 8.71 & 1.74 \\
\hline & & 3 & 7.76 & 1.75 \\
\hline & & 2 & 7.72 & 1.74 \\
\hline & & 1 & 8.64 & 1.72 \\
\hline \multicolumn{3}{|c|}{ Capsule 3 Average } & 7.36 & 1.66 \\
\hline \multirow{12}{*}{2} & \multirow{4}{*}{1} & 4 & 8.22 & 1.63 \\
\hline & & 3 & 6.89 & 1.60 \\
\hline & & 2 & 6.64 & 1.56 \\
\hline & & 1 & 7.33 & 1.51 \\
\hline & \multirow{4}{*}{2} & 4 & 5.83 & 1.45 \\
\hline & & 3 & 4.68 & 1.42 \\
\hline & & 2 & 4.48 & 1.38 \\
\hline & & 1 & 5.12 & 1.34 \\
\hline & \multirow{4}{*}{3} & 4 & 8.18 & 1.65 \\
\hline & & 3 & 6.90 & 1.62 \\
\hline & & 2 & 6.61 & 1.58 \\
\hline & & 1 & 7.33 & 1.53 \\
\hline \multicolumn{3}{|c|}{ Capsule 2 Average } & 6.52 & 1.52 \\
\hline \multirow{12}{*}{$\begin{array}{c}1 \\
\text { (bottom) }\end{array}$} & \multirow{4}{*}{1} & 4 & 6.97 & 1.36 \\
\hline & & 3 & 5.94 & 1.30 \\
\hline & & 2 & 5.63 & 1.22 \\
\hline & & 1 & 5.86 & 1.13 \\
\hline & \multirow{4}{*}{2} & 4 & 5.11 & 1.21 \\
\hline & & 3 & 4.21 & 1.15 \\
\hline & & 2 & 3.96 & 1.08 \\
\hline & & 1 & 4.28 & 1.00 \\
\hline & \multirow{4}{*}{3} & 4 & 6.94 & 1.38 \\
\hline & & 3 & 5.91 & 1.31 \\
\hline & & 2 & 5.59 & 1.24 \\
\hline & & 1 & 5.83 & 1.15 \\
\hline \multicolumn{3}{|c|}{ Capsule 1 Average } & 5.52 & 1.21 \\
\hline
\end{tabular}


Table D-13. Compact burnup and fast fluence for capsules 6-4 after cycle 142A (AGR-1 cycle 7).

\begin{tabular}{|c|c|c|c|c|}
\hline Capsule & Stack & Compact & $\begin{array}{c}\text { Burnup } \\
\text { (\% FIMA) }\end{array}$ & $\begin{array}{c}\text { Fast Neutron Fluence } \\
\left(10^{25} \mathrm{n} / \mathrm{m}^{2} \mathrm{E}>0.18 \mathrm{MeV}\right)\end{array}$ \\
\hline \multirow{12}{*}{$\begin{array}{c}6 \\
\text { (top) }\end{array}$} & \multirow{4}{*}{1} & 4 & 5.97 & 1.16 \\
\hline & & 3 & 5.80 & 1.27 \\
\hline & & 2 & 6.30 & 1.36 \\
\hline & & 1 & 7.05 & 1.44 \\
\hline & \multirow{4}{*}{2} & 4 & 4.36 & 1.02 \\
\hline & & 3 & 4.03 & 1.11 \\
\hline & & 2 & 4.41 & 1.20 \\
\hline & & 1 & 5.13 & 1.27 \\
\hline & \multirow{4}{*}{3} & 4 & 5.95 & 1.17 \\
\hline & & 3 & 5.75 & 1.28 \\
\hline & & 2 & 6.25 & 1.38 \\
\hline & & 1 & 7.01 & 1.45 \\
\hline \multicolumn{3}{|c|}{ Capsule 6 Average } & 5.67 & 1.26 \\
\hline \multirow{12}{*}{5} & \multirow{4}{*}{1} & 4 & 7.70 & 1.65 \\
\hline & & 3 & 7.27 & 1.72 \\
\hline & & 2 & 7.64 & 1.78 \\
\hline & & 1 & 8.98 & 1.82 \\
\hline & \multirow{4}{*}{2} & 4 & 5.51 & 1.46 \\
\hline & & 3 & 5.04 & 1.52 \\
\hline & & 2 & 5.30 & 1.57 \\
\hline & & 1 & 6.39 & 1.62 \\
\hline & \multirow{4}{*}{3} & 4 & 7.67 & 1.67 \\
\hline & & 3 & 7.26 & 1.74 \\
\hline & & 2 & 7.58 & 1.80 \\
\hline & & 1 & 8.93 & 1.84 \\
\hline \multicolumn{3}{|c|}{ Capsule 5 Average } & 7.10 & 1.68 \\
\hline \multirow{12}{*}{4} & \multirow{4}{*}{1} & 4 & 9.89 & 1.94 \\
\hline & & 3 & 9.06 & 1.99 \\
\hline & & 2 & 9.26 & 2.01 \\
\hline & & 1 & 10.38 & 2.01 \\
\hline & \multirow{4}{*}{2} & 4 & 7.12 & 1.73 \\
\hline & & 3 & 6.25 & 1.76 \\
\hline & & 2 & 6.44 & 1.78 \\
\hline & & 1 & 7.69 & 1.79 \\
\hline & \multirow{4}{*}{3} & 4 & 9.82 & 1.97 \\
\hline & & 3 & 9.03 & 2.01 \\
\hline & & 2 & 9.22 & 2.03 \\
\hline & & 1 & 10.38 & 2.04 \\
\hline \multicolumn{3}{|c|}{ Capsule 4 Average } & 8.71 & 1.92 \\
\hline
\end{tabular}


Table D-14. Compact burnup and fast fluence for capsules 3-1 after cycle 142A (AGR-1 cycle 7).

\begin{tabular}{|c|c|c|c|c|}
\hline Capsule & Stack & Compact & $\begin{array}{c}\text { Burnup } \\
(\% \text { FIMA) }\end{array}$ & $\begin{array}{c}\text { Fast Neutron Fluence } \\
\left(10^{25} \mathrm{n} / \mathrm{m}^{2} \mathrm{E}>0.18 \mathrm{MeV}\right)\end{array}$ \\
\hline \multirow{12}{*}{3} & \multirow{4}{*}{1} & 4 & 10.61 & 2.04 \\
\hline & & 3 & 9.68 & 2.05 \\
\hline & & 2 & 9.66 & 2.05 \\
\hline & & 1 & 10.56 & 2.02 \\
\hline & \multirow{4}{*}{2} & 4 & 7.93 & 1.82 \\
\hline & & 3 & 6.84 & 1.82 \\
\hline & & 2 & 6.82 & 1.82 \\
\hline & & 1 & 7.88 & 1.80 \\
\hline & \multirow{4}{*}{3} & 4 & 10.57 & 2.06 \\
\hline & & 3 & 9.70 & 2.08 \\
\hline & & 2 & 9.67 & 2.07 \\
\hline & & 1 & 10.52 & 2.04 \\
\hline \multicolumn{3}{|c|}{ Capsule 3 Average } & 9.20 & 1.97 \\
\hline \multirow{12}{*}{2} & \multirow{4}{*}{1} & 4 & 10.06 & 1.94 \\
\hline & & 3 & 8.75 & 1.91 \\
\hline & & 2 & 8.44 & 1.87 \\
\hline & & 1 & 9.10 & 1.80 \\
\hline & \multirow{4}{*}{2} & 4 & 7.47 & 1.73 \\
\hline & & 3 & 6.22 & 1.70 \\
\hline & & 2 & 5.97 & 1.66 \\
\hline & & 1 & 6.62 & 1.60 \\
\hline & \multirow{4}{*}{3} & 4 & 10.03 & 1.96 \\
\hline & & 3 & 8.75 & 1.94 \\
\hline & & 2 & 8.45 & 1.89 \\
\hline & & 1 & 9.13 & 1.82 \\
\hline \multicolumn{3}{|c|}{ Capsule 2 Average } & 8.25 & 1.82 \\
\hline \multirow{12}{*}{$\begin{array}{c}1 \\
\text { (bottom) }\end{array}$} & \multirow{4}{*}{1} & 4 & 8.48 & 1.62 \\
\hline & & 3 & 7.36 & 1.55 \\
\hline & & 2 & 6.98 & 1.46 \\
\hline & & 1 & 7.17 & 1.35 \\
\hline & \multirow{4}{*}{2} & 4 & 6.43 & 1.44 \\
\hline & & 3 & 5.44 & 1.38 \\
\hline & & 2 & 5.13 & 1.29 \\
\hline & & 1 & 5.41 & 1.20 \\
\hline & \multirow{4}{*}{3} & 4 & 8.48 & 1.64 \\
\hline & & 3 & 7.34 & 1.57 \\
\hline & & 2 & 6.96 & 1.48 \\
\hline & & 1 & 7.15 & 1.37 \\
\hline \multicolumn{3}{|c|}{ Capsule 1 Average } & 6.86 & 1.44 \\
\hline
\end{tabular}


Table D-15. Compact burnup and fast fluence for capsules 6-4 after cycle 142B (AGR-1 cycle 8).

\begin{tabular}{|c|c|c|c|c|}
\hline Capsule & Stack & Compact & $\begin{array}{c}\text { Burnup } \\
\text { (\% FIMA) }\end{array}$ & $\begin{array}{c}\text { Fast Neutron Fluence } \\
\left(10^{25} \mathrm{n} / \mathrm{m}^{2} \mathrm{E}>0.18 \mathrm{MeV}\right)\end{array}$ \\
\hline \multirow{12}{*}{$\begin{array}{c}6 \\
\text { (top) }\end{array}$} & \multirow{4}{*}{1} & 4 & 7.17 & 1.37 \\
\hline & & 3 & 7.05 & 1.50 \\
\hline & & 2 & 7.64 & 1.61 \\
\hline & & 1 & 8.46 & 1.70 \\
\hline & \multirow{4}{*}{2} & 4 & 5.38 & 1.21 \\
\hline & & 3 & 5.09 & 1.32 \\
\hline & & 2 & 5.56 & 1.42 \\
\hline & & 1 & 6.34 & 1.51 \\
\hline & \multirow{4}{*}{3} & 4 & 7.16 & 1.38 \\
\hline & & 3 & 7.03 & 1.52 \\
\hline & & 2 & 7.61 & 1.63 \\
\hline & & 1 & 8.44 & 1.72 \\
\hline \multicolumn{3}{|c|}{ Capsule 6 Average } & 6.91 & 1.49 \\
\hline \multirow{12}{*}{5} & \multirow{4}{*}{1} & 4 & 9.39 & 1.95 \\
\hline & & 3 & 9.02 & 2.04 \\
\hline & & 2 & 9.48 & 2.11 \\
\hline & & 1 & 10.81 & 2.15 \\
\hline & \multirow{4}{*}{2} & 4 & 6.94 & 1.73 \\
\hline & & 3 & 6.52 & 1.81 \\
\hline & & 2 & 6.85 & 1.87 \\
\hline & & 1 & 8.03 & 1.92 \\
\hline & \multirow{4}{*}{3} & 4 & 9.40 & 1.98 \\
\hline & & 3 & 9.06 & 2.07 \\
\hline & & 2 & 9.49 & 2.14 \\
\hline & & 1 & 10.78 & 2.18 \\
\hline \multicolumn{3}{|c|}{ Capsule 5 Average } & 8.81 & 2.00 \\
\hline \multirow{12}{*}{4} & \multirow{4}{*}{1} & 4 & 11.76 & 2.30 \\
\hline & & 3 & 11.03 & 2.35 \\
\hline & & 2 & 11.24 & 2.38 \\
\hline & & 1 & 12.26 & 2.38 \\
\hline & \multirow{4}{*}{2} & 4 & 8.91 & 2.05 \\
\hline & & 3 & 8.10 & 2.09 \\
\hline & & 2 & 8.33 & 2.12 \\
\hline & & 1 & 9.53 & 2.12 \\
\hline & \multirow{4}{*}{3} & 4 & 11.72 & 2.33 \\
\hline & & 3 & 11.03 & 2.38 \\
\hline & & 2 & 11.23 & 2.41 \\
\hline & & 1 & 12.29 & 2.41 \\
\hline \multicolumn{3}{|c|}{ Capsule 4 Average } & 10.62 & 2.28 \\
\hline
\end{tabular}


Table D-16. Compact burnup and fast fluence for capsules 3-1 after cycle 142B (AGR-1 cycle 8).

\begin{tabular}{|c|c|c|c|c|}
\hline Capsule & Stack & Compact & $\begin{array}{c}\text { Burnup } \\
\text { (\% FIMA) }\end{array}$ & $\begin{array}{c}\text { Fast Neutron Fluence } \\
\left(10^{25} \mathrm{n} / \mathrm{m}^{2} \mathrm{E}>0.18 \mathrm{MeV}\right)\end{array}$ \\
\hline \multirow{12}{*}{3} & \multirow{4}{*}{1} & 4 & 12.48 & 2.41 \\
\hline & & 3 & 11.66 & 2.43 \\
\hline & & 2 & 11.65 & 2.42 \\
\hline & & 1 & 12.44 & 2.39 \\
\hline & \multirow{4}{*}{2} & 4 & 9.79 & 2.15 \\
\hline & & 3 & 8.78 & 2.17 \\
\hline & & 2 & 8.76 & 2.16 \\
\hline & & 1 & 9.74 & 2.13 \\
\hline & \multirow{4}{*}{3} & 4 & 12.48 & 2.44 \\
\hline & & 3 & 11.72 & 2.47 \\
\hline & & 2 & 11.69 & 2.46 \\
\hline & & 1 & 12.44 & 2.42 \\
\hline \multicolumn{3}{|c|}{ Capsule 3 Average } & 11.14 & 2.34 \\
\hline \multirow{12}{*}{2} & \multirow{4}{*}{1} & 4 & 11.93 & 2.29 \\
\hline & & 3 & 10.72 & 2.27 \\
\hline & & 2 & 10.40 & 2.21 \\
\hline & & 1 & 10.98 & 2.13 \\
\hline & \multirow{4}{*}{2} & 4 & 9.30 & 2.05 \\
\hline & & 3 & 8.04 & 2.02 \\
\hline & & 2 & 7.73 & 1.97 \\
\hline & & 1 & 8.37 & 1.91 \\
\hline & \multirow{4}{*}{3} & 4 & 11.94 & 2.33 \\
\hline & & 3 & 10.76 & 2.30 \\
\hline & & 2 & 10.45 & 2.24 \\
\hline & & 1 & 11.04 & 2.16 \\
\hline \multicolumn{3}{|c|}{ Capsule 2 Average } & 10.14 & 2.16 \\
\hline \multirow{12}{*}{$\begin{array}{c}1 \\
\text { (bottom) }\end{array}$} & \multirow{4}{*}{1} & 4 & 10.14 & 1.91 \\
\hline & & 3 & 8.92 & 1.84 \\
\hline & & 2 & 8.47 & 1.73 \\
\hline & & 1 & 8.59 & 1.60 \\
\hline & \multirow{4}{*}{2} & 4 & 7.91 & 1.71 \\
\hline & & 3 & 6.85 & 1.64 \\
\hline & & 2 & 6.47 & 1.54 \\
\hline & & 1 & 6.71 & 1.42 \\
\hline & \multirow{4}{*}{3} & 4 & 10.19 & 1.94 \\
\hline & & 3 & 8.96 & 1.86 \\
\hline & & 2 & 8.50 & 1.75 \\
\hline & & 1 & 8.61 & 1.62 \\
\hline \multicolumn{3}{|c|}{ Capsule 1 Average } & 8.36 & 1.71 \\
\hline
\end{tabular}


Table D-17. Compact burnup and fast fluence for capsules 6-4 after cycle 143A (AGR-1 cycle 9).

\begin{tabular}{|c|c|c|c|c|}
\hline Capsule & Stack & Compact & $\begin{array}{c}\text { Burnup } \\
(\% \text { FIMA) }\end{array}$ & $\begin{array}{c}\text { Fast Neutron Fluence } \\
\left(10^{25} \mathrm{n} / \mathrm{m}^{2} \mathrm{E}>0.18 \mathrm{MeV}\right)\end{array}$ \\
\hline \multirow{12}{*}{$\begin{array}{c}6 \\
\text { (top) }\end{array}$} & \multirow{4}{*}{1} & 4 & 8.44 & 1.57 \\
\hline & & 3 & 8.40 & 1.73 \\
\hline & & 2 & 9.05 & 1.86 \\
\hline & & 1 & 9.94 & 1.95 \\
\hline & \multirow{4}{*}{2} & 4 & 6.49 & 1.39 \\
\hline & & 3 & 6.27 & 1.52 \\
\hline & & 2 & 6.81 & 1.64 \\
\hline & & 1 & 7.63 & 1.74 \\
\hline & \multirow{4}{*}{3} & 4 & 8.38 & 1.59 \\
\hline & & 3 & 8.34 & 1.74 \\
\hline & & 2 & 8.96 & 1.88 \\
\hline & & 1 & 9.85 & 1.97 \\
\hline \multicolumn{3}{|c|}{ Capsule 6 Average } & 8.21 & 1.72 \\
\hline \multirow{12}{*}{5} & \multirow{4}{*}{1} & 4 & 11.11 & 2.24 \\
\hline & & 3 & 10.84 & 2.35 \\
\hline & & 2 & 11.33 & 2.43 \\
\hline & & 1 & 12.56 & 2.47 \\
\hline & \multirow{4}{*}{2} & 4 & 8.45 & 2.00 \\
\hline & & 3 & 8.09 & 2.09 \\
\hline & & 2 & 8.50 & 2.16 \\
\hline & & 1 & 9.70 & 2.21 \\
\hline & \multirow{4}{*}{3} & 4 & 11.06 & 2.27 \\
\hline & & 3 & 10.82 & 2.38 \\
\hline & & 2 & 11.28 & 2.46 \\
\hline & & 1 & 12.48 & 2.50 \\
\hline \multicolumn{3}{|c|}{ Capsule 5 Average } & 10.52 & 2.30 \\
\hline \multirow{12}{*}{4} & \multirow{4}{*}{1} & 4 & 13.51 & 2.63 \\
\hline & & 3 & 12.88 & 2.70 \\
\hline & & 2 & 13.09 & 2.73 \\
\hline & & 1 & 14.00 & 2.73 \\
\hline & \multirow{4}{*}{2} & 4 & 10.65 & 2.35 \\
\hline & & 3 & 9.93 & 2.41 \\
\hline & & 2 & 10.19 & 2.44 \\
\hline & & 1 & 11.30 & 2.44 \\
\hline & \multirow{4}{*}{3} & 4 & 13.42 & 2.67 \\
\hline & & 3 & 12.82 & 2.73 \\
\hline & & 2 & 13.03 & 2.77 \\
\hline & & 1 & 13.99 & 2.76 \\
\hline \multicolumn{3}{|c|}{ Capsule 4 Average } & 12.40 & 2.61 \\
\hline
\end{tabular}


Table D-18. Compact burnup and fast fluence for capsules 3-1 after cycle 143A (AGR-1 cycle 9).

\begin{tabular}{|c|c|c|c|c|}
\hline Capsule & Stack & Compact & $\begin{array}{c}\text { Burnup } \\
\text { (\% FIMA) }\end{array}$ & $\begin{array}{c}\text { Fast Neutron Fluence } \\
\left(10^{25} \mathrm{n} / \mathrm{m}^{2} \mathrm{E}>0.18 \mathrm{MeV}\right)\end{array}$ \\
\hline \multirow{12}{*}{3} & \multirow{4}{*}{1} & 4 & 14.20 & 2.76 \\
\hline & & 3 & 13.49 & 2.79 \\
\hline & & 2 & 13.48 & 2.78 \\
\hline & & 1 & 14.17 & 2.73 \\
\hline & \multirow{4}{*}{2} & 4 & 11.54 & 2.47 \\
\hline & & 3 & 10.65 & 2.49 \\
\hline & & 2 & 10.63 & 2.48 \\
\hline & & 1 & 11.51 & 2.44 \\
\hline & \multirow{4}{*}{3} & 4 & 14.15 & 2.80 \\
\hline & & 3 & 13.50 & 2.83 \\
\hline & & 2 & 13.47 & 2.82 \\
\hline & & 1 & 14.12 & 2.77 \\
\hline \multicolumn{3}{|c|}{ Capsule 3 Average } & 12.91 & 2.68 \\
\hline \multirow{12}{*}{2} & \multirow{4}{*}{1} & 4 & 13.66 & 2.63 \\
\hline & & 3 & 12.57 & 2.60 \\
\hline & & 2 & 12.27 & 2.54 \\
\hline & & 1 & 12.74 & 2.44 \\
\hline & \multirow{4}{*}{2} & 4 & 11.06 & 2.35 \\
\hline & & 3 & 9.86 & 2.32 \\
\hline & & 2 & 9.52 & 2.27 \\
\hline & & 1 & 10.09 & 2.19 \\
\hline & \multirow{4}{*}{3} & 4 & 13.63 & 2.66 \\
\hline & & 3 & 12.57 & 2.64 \\
\hline & & 2 & 12.27 & 2.57 \\
\hline & & 1 & 12.75 & 2.47 \\
\hline \multicolumn{3}{|c|}{ Capsule 2 Average } & 11.92 & 2.47 \\
\hline \multirow{12}{*}{$\begin{array}{c}1 \\
\text { (bottom) }\end{array}$} & \multirow{4}{*}{1} & 4 & 11.77 & 2.19 \\
\hline & & 3 & 10.54 & 2.11 \\
\hline & & 2 & 10.01 & 1.99 \\
\hline & & 1 & 10.03 & 1.84 \\
\hline & \multirow{4}{*}{2} & 4 & 9.38 & 1.96 \\
\hline & & 3 & 8.30 & 1.88 \\
\hline & & 2 & 7.88 & 1.77 \\
\hline & & 1 & 8.03 & 1.64 \\
\hline & \multirow{4}{*}{3} & 4 & 11.77 & 2.22 \\
\hline & & 3 & 10.50 & 2.14 \\
\hline & & 2 & 9.97 & 2.01 \\
\hline & & 1 & 10.00 & 1.86 \\
\hline \multicolumn{3}{|c|}{ Capsule 1 Average } & 9.85 & 1.97 \\
\hline
\end{tabular}


Table D-19. Compact burnup and fast fluence for capsules 6-4 after cycle 143B (AGR-1 cycle 10).

\begin{tabular}{|c|c|c|c|c|}
\hline Capsule & Stack & Compact & $\begin{array}{c}\text { Burnup } \\
(\% \text { FIMA) }\end{array}$ & $\begin{array}{c}\text { Fast Neutron Fluence } \\
\left(10^{25} \mathrm{n} / \mathrm{m}^{2} \mathrm{E}>0.18 \mathrm{MeV}\right)\end{array}$ \\
\hline \multirow{12}{*}{$\begin{array}{c}6 \\
\text { (top) }\end{array}$} & \multirow{4}{*}{1} & 4 & 9.77 & 1.81 \\
\hline & & 3 & 9.81 & 1.99 \\
\hline & & 2 & 10.49 & 2.14 \\
\hline & & 1 & 11.40 & 2.25 \\
\hline & \multirow{4}{*}{2} & 4 & 7.72 & 1.61 \\
\hline & & 3 & 7.59 & 1.76 \\
\hline & & 2 & 8.18 & 1.89 \\
\hline & & 1 & 9.00 & 2.00 \\
\hline & \multirow{4}{*}{3} & 4 & 9.74 & 1.83 \\
\hline & & 3 & 9.78 & 2.01 \\
\hline & & 2 & 10.42 & 2.16 \\
\hline & & 1 & 11.36 & 2.27 \\
\hline \multicolumn{3}{|c|}{ Capsule 6 Average } & 9.60 & 1.98 \\
\hline \multirow{12}{*}{5} & \multirow{4}{*}{1} & 4 & 12.82 & 2.58 \\
\hline & & 3 & 12.63 & 2.70 \\
\hline & & 2 & 13.14 & 2.79 \\
\hline & & 1 & 14.27 & 2.84 \\
\hline & \multirow{4}{*}{2} & 4 & 10.01 & 2.30 \\
\hline & & 3 & 9.75 & 2.41 \\
\hline & & 2 & 10.17 & 2.49 \\
\hline & & 1 & 11.40 & 2.54 \\
\hline & \multirow{4}{*}{3} & 4 & 12.82 & 2.61 \\
\hline & & 3 & 12.66 & 2.74 \\
\hline & & 2 & 13.12 & 2.83 \\
\hline & & 1 & 14.21 & 2.88 \\
\hline \multicolumn{3}{|c|}{ Capsule 5 Average } & 12.25 & 2.64 \\
\hline \multirow{12}{*}{4} & \multirow{4}{*}{1} & 4 & 15.18 & 3.02 \\
\hline & & 3 & 14.64 & 3.10 \\
\hline & & 2 & 14.85 & 3.14 \\
\hline & & 1 & 15.64 & 3.13 \\
\hline & \multirow{4}{*}{2} & 4 & 12.39 & 2.70 \\
\hline & & 3 & 11.80 & 2.77 \\
\hline & & 2 & 12.06 & 2.80 \\
\hline & & 1 & 13.07 & 2.80 \\
\hline & \multirow{4}{*}{3} & 4 & 15.11 & 3.06 \\
\hline & & 3 & 14.61 & 3.14 \\
\hline & & 2 & 14.82 & 3.18 \\
\hline & & 1 & 15.66 & 3.17 \\
\hline \multicolumn{3}{|c|}{ Capsule 4 Average } & 14.15 & 3.00 \\
\hline
\end{tabular}


Table D-20. Compact burnup and fast fluence for capsules 3-1 after cycle 143B (AGR-1 cycle 10).

\begin{tabular}{|c|c|c|c|c|}
\hline Capsule & Stack & Compact & $\begin{array}{c}\text { Burnup } \\
\text { (\% FIMA) }\end{array}$ & $\begin{array}{c}\text { Fast Neutron Fluence } \\
\left(10^{25} \mathrm{n} / \mathrm{m}^{2} \mathrm{E}>0.18 \mathrm{MeV}\right)\end{array}$ \\
\hline \multirow{12}{*}{3} & \multirow{4}{*}{1} & 4 & 15.82 & 3.17 \\
\hline & & 3 & 15.21 & 3.20 \\
\hline & & 2 & 15.21 & 3.19 \\
\hline & & 1 & 15.80 & 3.13 \\
\hline & \multirow{4}{*}{2} & 4 & 13.30 & 2.84 \\
\hline & & 3 & 12.51 & 2.87 \\
\hline & & 2 & 12.50 & 2.85 \\
\hline & & 1 & 13.29 & 2.81 \\
\hline & \multirow{4}{*}{3} & 4 & 15.80 & 3.21 \\
\hline & & 3 & 15.26 & 3.25 \\
\hline & & 2 & 15.23 & 3.24 \\
\hline & & 1 & 15.79 & 3.18 \\
\hline \multicolumn{3}{|c|}{ Capsule 3 Average } & 14.64 & 3.08 \\
\hline \multirow{12}{*}{2} & \multirow{4}{*}{1} & 4 & 15.33 & 3.01 \\
\hline & & 3 & 14.36 & 2.99 \\
\hline & & 2 & 14.08 & 2.92 \\
\hline & & 1 & 14.46 & 2.80 \\
\hline & \multirow{4}{*}{2} & 4 & 12.84 & 2.70 \\
\hline & & 3 & 11.74 & 2.68 \\
\hline & & 2 & 11.37 & 2.62 \\
\hline & & 1 & 11.86 & 2.52 \\
\hline & \multirow{4}{*}{3} & 4 & 15.32 & 3.06 \\
\hline & & 3 & 14.39 & 3.03 \\
\hline & & 2 & 14.10 & 2.96 \\
\hline & & 1 & 14.50 & 2.84 \\
\hline \multicolumn{3}{|c|}{ Capsule 2 Average } & 13.70 & 2.84 \\
\hline \multirow{12}{*}{$\begin{array}{c}1 \\
\text { (bottom) }\end{array}$} & \multirow{4}{*}{1} & 4 & 13.38 & 2.52 \\
\hline & & 3 & 12.15 & 2.42 \\
\hline & & 2 & 11.55 & 2.29 \\
\hline & & 1 & 11.49 & 2.11 \\
\hline & \multirow{4}{*}{2} & 4 & 10.90 & 2.26 \\
\hline & & 3 & 9.81 & 2.17 \\
\hline & & 2 & 9.37 & 2.04 \\
\hline & & 1 & 9.44 & 1.89 \\
\hline & \multirow{4}{*}{3} & 4 & 13.41 & 2.55 \\
\hline & & 3 & 12.18 & 2.46 \\
\hline & & 2 & 11.57 & 2.32 \\
\hline & & 1 & 11.50 & 2.14 \\
\hline \multicolumn{3}{|c|}{ Capsule 1 Average } & 11.40 & 2.27 \\
\hline
\end{tabular}


Table D-21. Compact burnup and fast fluence for capsules 6-4 after cycle 144A (AGR-1 cycle 11).

\begin{tabular}{|c|c|c|c|c|}
\hline Capsule & Stack & Compact & $\begin{array}{c}\text { Burnup } \\
\text { (\% FIMA) }\end{array}$ & $\begin{array}{c}\text { Fast Neutron Fluence } \\
\left(10^{25} \mathrm{n} / \mathrm{m}^{2} \mathrm{E}>0.18 \mathrm{MeV}\right)\end{array}$ \\
\hline \multirow{12}{*}{$\begin{array}{c}6 \\
\text { (top) }\end{array}$} & \multirow{4}{*}{1} & 4 & 10.84 & 1.99 \\
\hline & & 3 & 10.94 & 2.19 \\
\hline & & 2 & 11.62 & 2.35 \\
\hline & & 1 & 12.56 & 2.47 \\
\hline & \multirow{4}{*}{2} & 4 & 8.76 & 1.77 \\
\hline & & 3 & 8.70 & 1.94 \\
\hline & & 2 & 9.31 & 2.09 \\
\hline & & 1 & 10.12 & 2.20 \\
\hline & \multirow{4}{*}{3} & 4 & 10.83 & 2.02 \\
\hline & & 3 & 10.93 & 2.21 \\
\hline & & 2 & 11.58 & 2.38 \\
\hline & & 1 & 12.56 & 2.50 \\
\hline \multicolumn{3}{|c|}{ Capsule 6 Average } & 10.73 & 2.18 \\
\hline \multirow{12}{*}{5} & \multirow{4}{*}{1} & 4 & 14.12 & 2.83 \\
\hline & & 3 & 14.01 & 2.97 \\
\hline & & 2 & 14.49 & 3.07 \\
\hline & & 1 & 15.55 & 3.11 \\
\hline & \multirow{4}{*}{2} & 4 & 11.28 & 2.53 \\
\hline & & 3 & 11.08 & 2.65 \\
\hline & & 2 & 11.54 & 2.74 \\
\hline & & 1 & 12.75 & 2.79 \\
\hline & \multirow{4}{*}{3} & 4 & 14.15 & 2.87 \\
\hline & & 3 & 14.06 & 3.01 \\
\hline & & 2 & 14.50 & 3.11 \\
\hline & & 1 & 15.51 & 3.16 \\
\hline \multicolumn{3}{|c|}{ Capsule 5 Average } & 13.59 & 2.90 \\
\hline \multirow{12}{*}{4} & \multirow{4}{*}{1} & 4 & 16.41 & 3.31 \\
\hline & & 3 & 15.94 & 3.40 \\
\hline & & 2 & 16.14 & 3.44 \\
\hline & & 1 & 16.85 & 3.43 \\
\hline & \multirow{4}{*}{2} & 4 & 13.75 & 2.97 \\
\hline & & 3 & 13.24 & 3.04 \\
\hline & & 2 & 13.51 & 3.08 \\
\hline & & 1 & 14.43 & 3.08 \\
\hline & \multirow{4}{*}{3} & 4 & 16.37 & 3.36 \\
\hline & & 3 & 15.93 & 3.45 \\
\hline & & 2 & 16.13 & 3.49 \\
\hline & & 1 & 16.89 & 3.48 \\
\hline \multicolumn{3}{|c|}{ Capsule 4 Average } & 15.47 & 3.29 \\
\hline
\end{tabular}


Table D-22. Compact burnup and fast fluence for capsules 3-1 after cycle 144A (AGR-1 cycle 11).

\begin{tabular}{|c|c|c|c|c|}
\hline Capsule & Stack & Compact & $\begin{array}{c}\text { Burnup } \\
\text { (\% FIMA) }\end{array}$ & $\begin{array}{c}\text { Fast Neutron Fluence } \\
\left(10^{25} \mathrm{n} / \mathrm{m}^{2} \mathrm{E}>0.18 \mathrm{MeV}\right)\end{array}$ \\
\hline \multirow{12}{*}{3} & \multirow{4}{*}{1} & 4 & 17.01 & 3.47 \\
\hline & & 3 & 16.48 & 3.51 \\
\hline & & 2 & 16.48 & 3.50 \\
\hline & & 1 & 17.00 & 3.43 \\
\hline & \multirow{4}{*}{2} & 4 & 14.65 & 3.12 \\
\hline & & 3 & 13.95 & 3.15 \\
\hline & & 2 & 13.94 & 3.14 \\
\hline & & 1 & 14.65 & 3.08 \\
\hline & \multirow{4}{*}{3} & 4 & 17.03 & 3.52 \\
\hline & & 3 & 16.55 & 3.57 \\
\hline & & 2 & 16.52 & 3.55 \\
\hline & & 1 & 17.02 & 3.49 \\
\hline \multicolumn{3}{|c|}{ Capsule 3 Average } & 15.94 & 3.38 \\
\hline \multirow{12}{*}{2} & \multirow{4}{*}{1} & 4 & 16.56 & 3.30 \\
\hline & & 3 & 15.68 & 3.28 \\
\hline & & 2 & 15.42 & 3.21 \\
\hline & & 1 & 15.74 & 3.08 \\
\hline & \multirow{4}{*}{2} & 4 & 14.21 & 2.97 \\
\hline & & 3 & 13.19 & 2.95 \\
\hline & & 2 & 12.82 & 2.88 \\
\hline & & 1 & 13.24 & 2.77 \\
\hline & \multirow{4}{*}{3} & 4 & 16.57 & 3.36 \\
\hline & & 3 & 15.73 & 3.33 \\
\hline & & 2 & 15.45 & 3.25 \\
\hline & & 1 & 15.79 & 3.12 \\
\hline \multicolumn{3}{|c|}{ Capsule 2 Average } & 15.03 & 3.13 \\
\hline \multirow{12}{*}{$\begin{array}{c}1 \\
\text { (bottom) }\end{array}$} & \multirow{4}{*}{1} & 4 & 14.62 & 2.76 \\
\hline & & 3 & 13.40 & 2.66 \\
\hline & & 2 & 12.76 & 2.52 \\
\hline & & 1 & 12.64 & 2.32 \\
\hline & \multirow{4}{*}{2} & 4 & 12.14 & 2.48 \\
\hline & & 3 & 11.03 & 2.39 \\
\hline & & 2 & 10.57 & 2.25 \\
\hline & & 1 & 10.57 & 2.08 \\
\hline & \multirow{4}{*}{3} & 4 & 14.68 & 2.80 \\
\hline & & 3 & 13.49 & 2.70 \\
\hline & & 2 & 12.83 & 2.55 \\
\hline & & 1 & 12.68 & 2.36 \\
\hline \multicolumn{3}{|c|}{ Capsule 1 Average } & 12.62 & 2.49 \\
\hline
\end{tabular}


Table D-23. Compact burnup and fast fluence for capsules 6-4 after cycle 144B (AGR-1 cycle 12).

\begin{tabular}{|c|c|c|c|c|}
\hline Capsule & Stack & Compact & $\begin{array}{c}\text { Burnup } \\
\text { (\% FIMA) }\end{array}$ & $\begin{array}{c}\text { Fast Neutron Fluence } \\
\left(10^{25} \mathrm{n} / \mathrm{m}^{2} \mathrm{E}>0.18 \mathrm{MeV}\right)\end{array}$ \\
\hline \multirow{12}{*}{$\begin{array}{c}6 \\
\text { (top) }\end{array}$} & \multirow{4}{*}{1} & 4 & 12.15 & 2.20 \\
\hline & & 3 & 12.33 & 2.42 \\
\hline & & 2 & 12.99 & 2.60 \\
\hline & & 1 & 13.95 & 2.72 \\
\hline & \multirow{4}{*}{2} & 4 & 10.11 & 1.96 \\
\hline & & 3 & 10.14 & 2.15 \\
\hline & & 2 & 10.76 & 2.31 \\
\hline & & 1 & 11.56 & 2.43 \\
\hline & \multirow{4}{*}{3} & 4 & 12.17 & 2.23 \\
\hline & & 3 & 12.34 & 2.45 \\
\hline & & 2 & 12.96 & 2.63 \\
\hline & & 1 & 14.00 & 2.75 \\
\hline \multicolumn{3}{|c|}{ Capsule 6 Average } & 12.12 & 2.40 \\
\hline \multirow{12}{*}{5} & \multirow{4}{*}{1} & 4 & 15.63 & 3.12 \\
\hline & & 3 & 15.58 & 3.27 \\
\hline & & 2 & 16.03 & 3.37 \\
\hline & & 1 & 16.99 & 3.42 \\
\hline & \multirow{4}{*}{2} & 4 & 12.86 & 2.79 \\
\hline & & 3 & 12.73 & 2.93 \\
\hline & & 2 & 13.21 & 3.02 \\
\hline & & 1 & 14.39 & 3.07 \\
\hline & \multirow{4}{*}{3} & 4 & 15.68 & 3.16 \\
\hline & & 3 & 15.66 & 3.32 \\
\hline & & 2 & 16.06 & 3.42 \\
\hline & & 1 & 16.96 & 3.47 \\
\hline \multicolumn{3}{|c|}{ Capsule 5 Average } & 15.15 & 3.20 \\
\hline \multirow{12}{*}{4} & \multirow{4}{*}{1} & 4 & 17.79 & 3.63 \\
\hline & & 3 & 17.38 & 3.73 \\
\hline & & 2 & 17.58 & 3.78 \\
\hline & & 1 & 18.20 & 3.76 \\
\hline & \multirow{4}{*}{2} & 4 & 15.36 & 3.26 \\
\hline & & 3 & 14.92 & 3.35 \\
\hline & & 2 & 15.19 & 3.39 \\
\hline & & 1 & 16.03 & 3.38 \\
\hline & \multirow{4}{*}{3} & 4 & 17.78 & 3.69 \\
\hline & & 3 & 17.40 & 3.78 \\
\hline & & 2 & 17.59 & 3.83 \\
\hline & & 1 & 18.26 & 3.82 \\
\hline \multicolumn{3}{|c|}{ Capsule 4 Average } & 16.96 & 3.62 \\
\hline
\end{tabular}


Table D-24. Compact burnup and fast fluence for capsules 3-1 after cycle 144B (AGR-1 cycle 12).

\begin{tabular}{|c|c|c|c|c|}
\hline Capsule & Stack & Compact & $\begin{array}{c}\text { Burnup } \\
(\% \text { FIMA) }\end{array}$ & $\begin{array}{c}\text { Fast Neutron Fluence } \\
\left(10^{25} \mathrm{n} / \mathrm{m}^{2} \mathrm{E}>0.18 \mathrm{MeV}\right)\end{array}$ \\
\hline \multirow{12}{*}{3} & \multirow{4}{*}{1} & 4 & 18.33 & 3.81 \\
\hline & & 3 & 17.88 & 3.85 \\
\hline & & 2 & 17.88 & 3.84 \\
\hline & & 1 & 18.33 & 3.76 \\
\hline & \multirow{4}{*}{2} & 4 & 16.23 & 3.42 \\
\hline & & 3 & 15.61 & 3.46 \\
\hline & & 2 & 15.60 & 3.45 \\
\hline & & 1 & 16.23 & 3.39 \\
\hline & \multirow{4}{*}{3} & 4 & 18.38 & 3.86 \\
\hline & & 3 & 17.97 & 3.91 \\
\hline & & 2 & 17.95 & 3.90 \\
\hline & & 1 & 18.37 & 3.82 \\
\hline & \multicolumn{2}{|c|}{ Capsule 3 Average } & 17.40 & 3.71 \\
\hline \multirow{12}{*}{2} & \multirow{4}{*}{1} & 4 & 17.92 & 3.62 \\
\hline & & 3 & 17.15 & 3.60 \\
\hline & & 2 & 16.92 & 3.52 \\
\hline & & 1 & 17.17 & 3.38 \\
\hline & \multirow{4}{*}{2} & 4 & 15.80 & 3.26 \\
\hline & & 3 & 14.88 & 3.24 \\
\hline & & 2 & 14.52 & 3.17 \\
\hline & & 1 & 14.88 & 3.04 \\
\hline & \multirow{4}{*}{3} & 4 & 17.96 & 3.68 \\
\hline & & 3 & 17.22 & 3.66 \\
\hline & & 2 & 16.96 & 3.57 \\
\hline & & 1 & 17.25 & 3.43 \\
\hline \multicolumn{3}{|c|}{ Capsule 2 Average } & 16.55 & 3.43 \\
\hline \multirow{12}{*}{$\begin{array}{c}1 \\
\text { (bottom) }\end{array}$} & \multirow{4}{*}{1} & 4 & 16.03 & 3.03 \\
\hline & & 3 & 14.84 & 2.93 \\
\hline & & 2 & 14.18 & 2.77 \\
\hline & & 1 & 13.98 & 2.56 \\
\hline & \multirow{4}{*}{2} & 4 & 13.64 & 2.73 \\
\hline & & 3 & 12.55 & 2.63 \\
\hline & & 2 & 12.07 & 2.49 \\
\hline & & 1 & 12.00 & 2.29 \\
\hline & \multirow{4}{*}{3} & 4 & 16.12 & 3.08 \\
\hline & & 3 & 14.98 & 2.98 \\
\hline & & 2 & 14.29 & 2.81 \\
\hline & & 1 & 14.06 & 2.60 \\
\hline \multicolumn{3}{|c|}{ Capsule 1 Average } & 14.06 & 2.74 \\
\hline
\end{tabular}


Table D-25. Compact burnup and fast fluence for capsules 6-4 after cycle 145A (AGR-1 cycle 13).

\begin{tabular}{|c|c|c|c|c|}
\hline Capsule & Stack & Compact & $\begin{array}{c}\text { Burnup } \\
(\% \text { FIMA) }\end{array}$ & $\begin{array}{c}\text { Fast Neutron Fluence } \\
\left(10^{25} \mathrm{n} / \mathrm{m}^{2} \mathrm{E}>0.18 \mathrm{MeV}\right)\end{array}$ \\
\hline \multirow{12}{*}{$\begin{array}{c}6 \\
\text { (top) }\end{array}$} & \multirow{4}{*}{1} & 4 & 13.34 & 2.43 \\
\hline & & 3 & 13.57 & 2.67 \\
\hline & & 2 & 14.22 & 2.87 \\
\hline & & 1 & 15.24 & 3.00 \\
\hline & \multirow{4}{*}{2} & 4 & 11.34 & 2.17 \\
\hline & & 3 & 11.44 & 2.38 \\
\hline & & 2 & 12.05 & 2.55 \\
\hline & & 1 & 12.83 & 2.68 \\
\hline & \multirow{4}{*}{3} & 4 & 13.36 & 2.46 \\
\hline & & 3 & 13.59 & 2.70 \\
\hline & & 2 & 14.21 & 2.90 \\
\hline & & 1 & 15.29 & 3.04 \\
\hline \multicolumn{3}{|c|}{ Capsule 6 Average } & 13.37 & 2.65 \\
\hline \multirow{12}{*}{5} & \multirow{4}{*}{1} & 4 & 16.98 & 3.43 \\
\hline & & 3 & 16.97 & 3.60 \\
\hline & & 2 & 17.39 & 3.71 \\
\hline & & 1 & 18.26 & 3.76 \\
\hline & \multirow{4}{*}{2} & 4 & 14.27 & 3.08 \\
\hline & & 3 & 14.20 & 3.23 \\
\hline & & 2 & 14.68 & 3.33 \\
\hline & & 1 & 15.83 & 3.38 \\
\hline & \multirow{4}{*}{3} & 4 & 17.03 & 3.48 \\
\hline & & 3 & 17.05 & 3.65 \\
\hline & & 2 & 17.42 & 3.77 \\
\hline & & 1 & 18.24 & 3.82 \\
\hline \multicolumn{3}{|c|}{ Capsule 5 Average } & 16.53 & 3.52 \\
\hline \multirow{12}{*}{4} & \multirow{4}{*}{1} & 4 & 19.01 & 3.99 \\
\hline & & 3 & 18.64 & 4.10 \\
\hline & & 2 & 18.83 & 4.15 \\
\hline & & 1 & 19.39 & 4.13 \\
\hline & \multirow{4}{*}{2} & 4 & 16.77 & 3.59 \\
\hline & & 3 & 16.40 & 3.68 \\
\hline & & 2 & 16.66 & 3.73 \\
\hline & & 1 & 17.41 & 3.72 \\
\hline & \multirow{4}{*}{3} & 4 & 19.00 & 4.06 \\
\hline & & 3 & 18.66 & 4.16 \\
\hline & & 2 & 18.85 & 4.21 \\
\hline & & 1 & 19.46 & 4.20 \\
\hline \multicolumn{3}{|c|}{ Capsule 4 Average } & 18.26 & 3.98 \\
\hline
\end{tabular}


Table D-26. Compact burnup and fast fluence for capsules 3-1 after cycle 145A (AGR-1 cycle 13).

\begin{tabular}{|c|c|c|c|c|}
\hline Capsule & Stack & Compact & $\begin{array}{c}\text { Burnup } \\
(\% \text { FIMA) }\end{array}$ & $\begin{array}{c}\text { Fast Neutron Fluence } \\
\left(10^{25} \mathrm{n} / \mathrm{m}^{2} \mathrm{E}>0.18 \mathrm{MeV}\right)\end{array}$ \\
\hline \multirow{12}{*}{3} & \multirow{4}{*}{1} & 4 & 19.50 & 4.18 \\
\hline & & 3 & 19.09 & 4.23 \\
\hline & & 2 & 19.10 & 4.21 \\
\hline & & 1 & 19.51 & 4.13 \\
\hline & \multirow{4}{*}{2} & 4 & 17.60 & 3.76 \\
\hline & & 3 & 17.05 & 3.80 \\
\hline & & 2 & 17.03 & 3.79 \\
\hline & & 1 & 17.59 & 3.72 \\
\hline & \multirow{4}{*}{3} & 4 & 19.57 & 4.24 \\
\hline & & 3 & 19.19 & 4.30 \\
\hline & & 2 & 19.17 & 4.28 \\
\hline & & 1 & 19.57 & 4.20 \\
\hline \multicolumn{3}{|c|}{ Capsule 3 Average } & 18.66 & 4.07 \\
\hline \multirow{12}{*}{2} & \multirow{4}{*}{1} & 4 & 19.12 & 3.98 \\
\hline & & 3 & 18.42 & 3.96 \\
\hline & & 2 & 18.22 & 3.87 \\
\hline & & 1 & 18.43 & 3.71 \\
\hline & \multirow{4}{*}{2} & 4 & 17.18 & 3.59 \\
\hline & & 3 & 16.35 & 3.56 \\
\hline & & 2 & 16.01 & 3.48 \\
\hline & & 1 & 16.31 & 3.35 \\
\hline & \multirow{4}{*}{3} & 4 & 19.15 & 4.05 \\
\hline & & 3 & 18.50 & 4.02 \\
\hline & & 2 & 18.27 & 3.93 \\
\hline & & 1 & 18.51 & 3.77 \\
\hline \multicolumn{3}{|c|}{ Capsule 2 Average } & 17.87 & 3.77 \\
\hline \multirow{12}{*}{$\begin{array}{c}1 \\
\text { (bottom) }\end{array}$} & \multirow{4}{*}{1} & 4 & 17.31 & 3.33 \\
\hline & & 3 & 16.17 & 3.22 \\
\hline & & 2 & 15.46 & 3.05 \\
\hline & & 1 & 15.20 & 2.81 \\
\hline & \multirow{4}{*}{2} & 4 & 14.97 & 3.01 \\
\hline & & 3 & 13.86 & 2.90 \\
\hline & & 2 & 13.36 & 2.74 \\
\hline & & 1 & 13.25 & 2.52 \\
\hline & \multirow{4}{*}{3} & 4 & 17.39 & 3.39 \\
\hline & & 3 & 16.33 & 3.27 \\
\hline & & 2 & 15.61 & 3.10 \\
\hline & & 1 & 15.33 & 2.86 \\
\hline \multicolumn{3}{|c|}{ Capsule 1 Average } & 15.35 & 3.02 \\
\hline
\end{tabular}




\section{Appendix E}

\section{Palladium Penetration}




\section{Appendix E Palladium Penetration}

This appendix presents the palladium penetration for all 72 compacts based on their daily average, minimum, and maximum temperatures.

The numbering of the compacts is: Capsule - Level - Stack

- Capsules: bottom (C1) to top (C6)

- Levels: bottom (L1) to top (L4)

- Stacks: clockwise, Northwest (S1) to Southwest (S3).

Table E-1. Total palladium penetration depth for all 72 compacts.

\begin{tabular}{|c|r|r|r|c|c|c|c|c|c|c|c|}
\hline Compact & Ave & Min & Max & Compact & Ave & Min & Max & Compact & Ave & Min & Max \\
\hline $6-1-1$ & 8.8 & 3.5 & 13.9 & $5-1-1$ & 6.2 & 2.0 & 11.1 & $4-1-1$ & 7.2 & 2.4 & 13.0 \\
\hline $6-2-1$ & 10.6 & 6.1 & 14.4 & $5-2-1$ & 7.5 & 3.4 & 11.4 & $4-2-1$ & 8.7 & 3.7 & 13.5 \\
\hline $6-3-1$ & 9.2 & 5.0 & 13.2 & $5-3-1$ & 6.9 & 3.0 & 10.8 & $4-3-1$ & 8.4 & 3.6 & 13.1 \\
\hline $6-4-1$ & 6.1 & 2.3 & 10.5 & $5-4-1$ & 5.0 & 1.6 & 9.4 & $4-4-1$ & 6.6 & 2.1 & 12.1 \\
\hline $6-1-2$ & 7.6 & 3.1 & 12.4 & $5-1-2$ & 5.5 & 1.8 & 10.1 & $4-1-2$ & 6.3 & 2.1 & 11.7 \\
\hline $6-2-2$ & 9.2 & 5.3 & 12.7 & $5-2-2$ & 6.7 & 3.1 & 10.4 & $4-2-2$ & 7.7 & 3.4 & 12.3 \\
\hline $6-3-2$ & 7.9 & 4.3 & 11.7 & $5-3-2$ & 6.2 & 2.7 & 9.9 & $4-3-2$ & 7.4 & 3.2 & 11.9 \\
\hline $6-4-2$ & 5.2 & 2.0 & 9.3 & $5-4-2$ & 4.3 & 1.4 & 8.5 & $4-4-2$ & 5.7 & 1.9 & 10.8 \\
\hline $6-1-3$ & 8.8 & 3.6 & 14.0 & $5-1-3$ & 6.3 & 2.1 & 11.2 & $4-1-3$ & 7.3 & 2.5 & 13.1 \\
\hline $6-2-3$ & 10.6 & 6.3 & 14.4 & $5-2-3$ & 7.6 & 3.6 & 11.5 & $4-2-3$ & 8.8 & 4.0 & 13.7 \\
\hline $6-3-3$ & 9.3 & 5.2 & 13.3 & $5-3-3$ & 7.1 & 3.2 & 10.9 & $4-3-3$ & 8.5 & 3.8 & 13.2 \\
\hline $6-4-3$ & 6.1 & 2.4 & 10.6 & $5-4-3$ & 5.1 & 1.7 & 9.5 & $4-4-3$ & 6.7 & 2.3 & 12.2 \\
\hline $6-4-3$ & 8.8 & 3.5 & 13.9 & $5-1-1$ & 6.2 & 2.0 & 11.1 & $4-1-1$ & 7.2 & 2.4 & 13.0 \\
\hline & & & & & & & & & & \\
\hline Compact & Ave & Min & Max & Compact & Ave & Min & Max & Compact & Ave & Min & Max \\
\hline $3-1-1$ & 5.2 & 1.5 & 10.1 & $2-1-1$ & 4.1 & 1.2 & 8.1 & $1-1-1$ & 5.0 & 1.7 & 9.2 \\
\hline $3-2-1$ & 6.4 & 2.3 & 10.7 & $2-2-1$ & 5.3 & 1.9 & 8.9 & $1-2-1$ & 7.2 & 3.5 & 11.0 \\
\hline $3-3-1$ & 6.4 & 2.3 & 10.7 & $2-3-1$ & 5.6 & 2.0 & 9.5 & $1-3-1$ & 8.1 & 4.0 & 11.9 \\
\hline $3-4-1$ & 5.3 & 1.6 & 10.2 & $2-4-1$ & 4.9 & 1.5 & 9.2 & $1-4-1$ & 6.9 & 2.5 & 11.6 \\
\hline $3-1-2$ & 4.4 & 1.3 & 9.0 & $2-1-2$ & 3.5 & 1.0 & 7.2 & $1-1-2$ & 4.4 & 1.5 & 8.2 \\
\hline $3-2-2$ & 5.6 & 2.1 & 9.6 & $2-2-2$ & 4.6 & 1.7 & 8.0 & $1-2-2$ & 6.3 & 3.0 & 9.9 \\
\hline $3-3-2$ & 5.6 & 2.1 & 9.7 & $2-3-2$ & 4.8 & 1.8 & 8.5 & $1-3-2$ & 7.1 & 3.5 & 10.7 \\
\hline $3-4-2$ & 4.5 & 1.4 & 9.1 & $2-4-2$ & 4.1 & 1.3 & 8.2 & $1-4-2$ & 6.0 & 2.3 & 10.4 \\
\hline $3-1-3$ & 5.3 & 1.6 & 10.2 & $2-1-3$ & 4.1 & 1.3 & 8.2 & $1-1-3$ & 5.1 & 1.8 & 9.2 \\
\hline $3-2-3$ & 6.5 & 2.5 & 10.7 & $2-2-3$ & 5.4 & 2.1 & 9.0 & $1-2-3$ & 7.3 & 3.6 & 11.0 \\
\hline $3-3-3$ & 6.5 & 2.5 & 10.8 & $2-3-3$ & 5.7 & 2.2 & 9.6 & $1-3-3$ & 8.1 & 4.1 & 12.0 \\
\hline $3-4-3$ & 5.4 & 1.7 & 10.3 & $2-4-3$ & 4.9 & 1.6 & 9.3 & $1-4-3$ & 6.9 & 2.7 & 11.6 \\
\hline $3-1-1$ & 5.2 & 1.5 & 10.1 & $2-1-1$ & 4.1 & 1.2 & 8.1 & $1-1-1$ & 5.0 & 1.7 & 9.2 \\
\hline
\end{tabular}

